Otimização do processo de corte integrado à produção de bobinas - modelo e métodos de solução 



\section{Otimização do processo de corte integrado à produção de bobinas - modelo e métodos de solução}

Sônia Cristina Poltroniere Silva

Orientador: Prof. Dr. Marcos Nereu Arenales

Tese apresentada ao Instituto de Ciências Matemáticas e de

Computação - ICMC-USP, como parte dos requisitos para obtenção do título de Doutor em Ciências - Ciências de

Computação e Matemática Computacional.

USP - São Carlos

Fevereiro de 2006 



\section{Agradecimentos}

A Deus, pelo Dom da Vida.

Ao Prof. Marcos Arenales, pela orientação, compreensão e amizade. Toda a minha admiração, pelo ser humano que é.

Ao Paulinho e a Ana Paula, pelo amor incondicional, carinho e aceitação que dedicaram a mim durante este período. E boas vindas ao nosso bebê que vem chegando...

Aos meus pais, Antonio e Maria Rosa, pelo amor e dedicação incondicional que dispensam por todos nós.

Ao meu irmão Sérgio e a Juliane, pela amizade, colaboração e os bons momentos vivenciados.

A família do Paulinho, também minha família, pela amizade, compreensão e colaboração.

A Cristiane, pela colaboração, atenção e pela menina maravilhosa que é.

A Profa. Franklina, pelo incentivo e pela colaboração neste trabalho. Seu otimismo e confiança me ajudaram muito.

A Profa. Maristela, pela amizade e pelos momentos vivenciados.

Aos professores da UNESP-SJRP, Socorro, Silvio e Geraldo, pela amizade, atenção e colaboração.

A amiga Kelly, pelo apoio e incentivo. Também, meus agradecimentos a todos os colegas do laboratório de otimização.

As amigas Ivone e Luciana, pelo carinho com que me recebem e pelas boas conversas.

A amiga Juliana, pelo incentivo e pelas bons momentos de conversa.

A todos os meus amigos, que de alguma forma estiveram presentes no período de desenvolvimento deste trabalho.

Aos colegas da cidade do Porto - Portugal, pela atenção e carinho com que me receberam.

As funcionárias da pós-graduação, Laura, Ana Paula e Beth, pela orientação e atenção dispensadas.

A FAPESP, pelo apoio financeiro. 

"Feliz do homem que encontrou a sabedoria, aquele que adquiriu a inteligência.

Porque mais vale esse lucro que o da prata, e o fruto que se obtém é melhor que o fino ouro." Provérbios 3, 13-14 



\section{Resumo}

Um importante problema de programação da produção surge em indústrias de papel integrando o problema de planejamento em múltiplas máquinas paralelas com o problema de corte. O problema de dimensionamento de lotes deve determinar a quantidade de jumbos (bobinas grandes de papel) de diferentes tipos de papel a serem produzidos em cada máquina. Estes jumbos são então cortados para atender a demanda de itens (bobinas menores de papel). O planejamento, que minimiza custos de produção e preparação, deve produzir jumbos (cada máquina produz jumbos de larguras diferentes) que diminuam a perda no processo de corte. Por outro lado, o melhor número de jumbos do ponto de vista de minimizar a perda no processo de corte pode acarretar em altos custos de preparação. Ambos são problemas de otimização combinatória não trivial, o que tem motivado extensas pesquisas nas últimas décadas, entretanto, essa combinação não é bem explorada na literatura. Neste trabalho, são propostos um modelo de otimização integrado e métodos heurísticos de solução. Foram realizados experimentos computacionais com o intuito de analisar o desempenho dos métodos propostos e os resultados apresentaramse bastante satisfatórios, significando que tais métodos são apropriados para tratar o problema integrado.

Palavras-chave: problema de corte de estoque, problema de dimensionamento de lotes, relaxação lagrangiana. 



\begin{abstract}
An important production programming problem arises in paper industries coupling multiple machine scheduling with cutting stock. From machine scheduling the problem of determining the quantity of jumbos (large rolls of paper) of different types of paper to be produced in each machine arises. These jumbos are then cut to meet the demand for items (smaller rolls of paper). Scheduling that minimizes setups and production costs may produce jumbos (each machine produces jumbos of a specific width) which may increase waste in the cutting process. On the other hand, the best number of jumbos in the point of view of minimizing waste in the cutting process may lead to high setup costs. Both problems are non-trivial combinatorial optimization problems, which have motivated extensive research in the last decades, however their combination is not well explored in the literature. In this work, a coupled optimization modelling and heuristic solution methods are proposed. Computational experiments are devised in order to analyze the performance of the methods and the results had been presented sufficiently satisfactory, meaning that such methods are appropriate to deal with the integrated problem.
\end{abstract}

Keywords: cutting stock problems, lot sizing and scheduling problems, Lagrangian relaxation. 



\section{Conteúdo}

Introdução 11

1 Modelos básicos para os problemas de corte de estoque e de dimension$\begin{array}{ll}\text { amento de lotes } & 7\end{array}$

1.1 Problema de corte de estoque . . . . . . . . . . . . . 7

1.1.1 O problema de corte de estoque unidimensional . . . . . . . . . 8

1.1.2 O método simplex com geração de colunas . . . . . . . . . . . . . . 14

1.1.3 Heurísticas para o problema de corte de estoque inteiro . . . . . . 15

1.1.4 Problema de corte de estoque multiestagiado . . . . . . . . . . 17

1.2 Problema de dimensionamento de lotes . . . . . . . . . . . . . . . . . . . . 19

1.2.1 Problema de dimensionamento de lotes monoestágio . . . . . . . . . 20

2 Modelos integrados $\quad 25$

2.1 Um problema de dimensionamento de lotes e programação de cortes . . . . 26

2.2 Um problema de corte de estoque integrado ao planejamento . . . . . . 33

2.2.1 Descrição do problema . . . . . . . . . . . . . . . 33

2.2.2 Formulação do problema . . . . . . . . . . . . . . . 34

2.3 O problema de corte de estoque acoplado à programação da produção em indústrias de cobre . . . . . . . . . . . . . . . . . 4 40

2.4 O problema de alocação de pedidos às máquinas em indústrias papeleiras . 45

2.5 Alocação, sequenciamento e corte integrados na indústria de papel . . . . . 50

3 O problema de corte de estoque integrado à produção de bobinas de $\begin{array}{ll}\text { papel } & 57\end{array}$

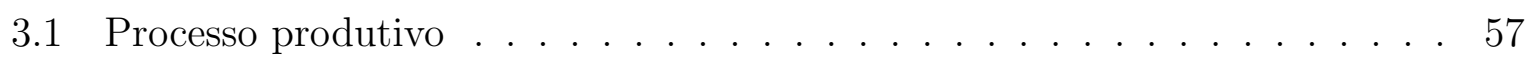


3.2 Modelagem matemática . . . . . . . . . . . . . . . . . 60

3.3 Problema de corte de estoque multiperíodo . . . . . . . . . . . . . . 66

4 Métodos de solução para o problema de corte de estoque multiperíodo 69

4.1 Solução lote por lote . . . . . . . . . . . . . . . . . . . . . . . 69

4.2 Solução usando heurística de antecipação de itens . . . . . . . . . . . . . . 70

4.3 Experimentos computacionais . . . . . . . . . . . . . . . 73

4.3 .1 Conjunto de dados . . . . . . . . . . . . . . . . . . . . . 73

4.3.2 Apresentação e análise dos resultados obtidos . . . . . . . . . . . . 74

5 Métodos de solução para o problema integrado $\quad 79$

5.1 Relaxação lagrangiana . . . . . . . . . . . . . . . . . . . . 80

5.2 A heurística lote-corte . . . . . . . . . . . . . . . . . 82

5.2.1 Um método de solução para o problema de dimensionamento de lotes 84

5.3 A heurística corte-lote . . . . . . . . . . . . . . . 85

5.4 Experimentos computacionais . . . . . . . . . . . . . . . . . 87

5.4.1 Conjunto de dados . . . . . . . . . . . . . . . . . 87

5.4.2 Apresentação e análise dos resultados obtidos . . . . . . . . . . . . 88

6 Conclusões e perspectivas $\quad 95$

$\begin{array}{ll}\text { Referências Bibliográficas } & 98\end{array}$ 


\section{Introdução}

Aspectos econômicos e a competitividade fazem com que as indústrias de manufatura sejam estimuladas a tornar seus processos produtivos cada vez mais eficientes. Isto provoca um crescimento considerável na complexidade dos modelos de planejamento e controle de sistemas produtivos, motivando intensas pesquisas acadêmicas.

O sistema de gerenciamento denominado planejamento e controle da produção (PCP) coordena todas as atividades, desde a aquisição de matérias-primas até a entrega dos produtos acabados. A estrutura hierárquica de um sistema PCP pode ser dividida em três níveis de planejamento distintos: estratégico, tático e operacional (Anthony, 1965).

O planejamento estratégico está relacionado ao mais alto nível de tomada de decisões, quando são definidas as metas globais da empresa e as políticas adequadas para atingí-las a longo prazo e envolve decisões como, entre outras, a expansão da produção, a instalação de uma nova planta industrial, o lançamento de um novo produto no mercado.

O planejamento tático é responsável pela utilização eficiente dos recursos disponíveis a fim de cumprir os objetivos determinados no planejamento estratégico. Seu objetivo principal é a efetiva alocação de recursos para satisfazer a demanda, levando em conta os custos envolvidos. Nesta etapa, devem ser tomadas as decisões de médio prazo que afetam a área de produção, tais como a contratação de pessoal e a aquisição de novas máquinas.

O planejamento operacional trata das decisões do dia-a-dia, tendo como função executar os planos definidos anteriormente, ou seja, a programação detalhada da produção e compras, que consiste em seqüenciar as ordens de produção nos centros de trabalho, a administração de estoques, o controle de qualidade, a alocação dos pedidos dos clientes às máquinas, a compra de componentes e matérias-primas e o programa de distribuição.

Este trabalho enfoca os problemas de tomada de decisão relacionados ao planejamento tático/operacional. Em muitas situações práticas que se observam em indústrias 
de manufatura como, por exemplo, indústrias moveleira, papeleira, metalúrgica, o problema de corte de estoque aparece como um subproblema fundamental de um problema de planejamento da produção mais amplo. Na literatura são encontrados vários trabalhos que tratam os problemas de planejamento da produção e de corte de estoque de forma desacoplada, tais como Johnson e Montgomery (1974), Bahl et al. (1987), Maes et al. (1991), Kuik et al. (1994), Drexl e Kimms (1997), Karimi et al. (2003), Gilmore e Gomory (1961, 1963, 1965), Wäscher e Gau (1996), Hinxman (1980), Dowsland et al. (1992), Dyckhoff et al. (1985), Lodi et al. (2002), entre outros.

O problema de planejamento da produção determina, para cada período do horizonte de planejamento, quantidades de produtos (problema de dimensionamento de lotes) que devem ser posteriormente cortados para o atendimento da demanda (problema de corte de estoque). Tratar estes dois problemas de forma separada pode elevar os custos globais, principalmente se o processo de corte for economicamente relevante no processo. Atualmente, existe uma tendência de tratar problemas de planejamento e programação da produção de forma acoplada (Thomas \& Griffin, 1996).

Drexl \& Kimms (1997) ressaltam que o problema de dimensionamento de lotes e programação da produção interagem com outras atividades de uma indústria, como o planejamento da distribuição, o problema de corte e empacotamento e a programação de projetos, e que a coordenação desses problemas pode diminuir os altos custos de transação, o que constitui um objetivo crucial de trabalhos futuros.

O problema-chave desta tese considera os problemas de dimensionamento de lotes e corte de estoque de forma integrada, motivada por uma aplicação prática em indústrias de papel. A indústria produz bobinas grandes, chamadas jumbos, de diferentes larguras que, posteriormente, são cortadas para atender a demanda de itens (bobinas menores ou retângulos) dentro de um horizonte de planejamento dividido em períodos. Os pedidos de itens finais são bem definidos por: largura, tipo de papel (gramatura), quantidade da demanda e data de entrega. Os jumbos são produzidos em diferentes máquinas, cada qual com velocidade de produção e preparações específicas (há perda com a mudança de um tipo de papel para outro). Além disso, as máquinas têm capacidades e produzem jumbos de diferentes larguras. Se, por um lado, procuramos uma solução com pequena perda por preparações das máquinas e estoques baixos, sem atrasos na entrega, etc., por outro 
lado, tentamos evitar perdas no processo de cortar os jumbos para a produção dos itens finais. Portanto, as decisões de planejamento dos jumbos e o estágio de corte dos itens são problemas interdependentes. A seguir, fazemos uma breve revisão de trabalhos que consideram problemas em indústrias de forma acoplada.

Chandra \& Fisher (1994) comparam a solução acoplada de um sistema de produçãodistribuição com a solução dos sistemas separados e relatam uma melhoria de $3 \%$ a $20 \%$ quando é aplicada versão acoplada.

Farley (1988) foi, talvez, o primeiro autor a publicar um estudo sobre o problema de corte de estoque em indústrias de roupa, acoplado ao problema de planejamento e programação da produção. Apesar desse problema ser, essencialmente, um problema de corte bidimensional irregular, esta dificuldade foi contornada por definir vários padrões de corte em retângulos de largura do rolo de tecido, de diferentes comprimentos, os quais foram usados para cortar os itens ao longo do comprimento do rolo, ou seja, um problema de corte unidimensional. O autor evitou trabalhar com o problema de corte embutido no processo produtivo e o problema foi formulado como um de programação da produção em um único período.

Nonas \& Thorstenson (2000) consideraram um problema de corte de estoque unidimensional com custos de preparações setup e atrasos associados aos padrões de corte.

Baseada num estudo de caso em indústria de móveis, Gramani (2001) propôs um modelo matemático para acoplar os problemas de dimensionamento de lotes e corte de estoque bidimensional. O modelo determina quais e como os vários produtos finais (mesas, prateleiras, guarda-roupas, etc.) devem ser produzidos num mesmo período. Desta decisão, segue um pedido de um determinado número de itens (retângulos menores), que devem ser cortados de placas disponíveis em estoque (retângulos maiores). Além disso, a demanda dos itens no problema de corte é desconhecida previamente. Ao contrário disso, no problema chave de planejamento da produção e corte de bobinas em indústrias de papel, a demanda de itens finais é conhecida, mas o estoque não, isto é, a disponibilidade de objetos (jumbos) para serem cortados é uma variável de decisão.

Em 2002, Respício e Captivo apresentaram um modelo de programação inteira, integrando o problema de corte de estoque unidimensional ao problema de planejamento, para um sistema de produção multi-item, com aplicações em indústrias papeleiras. As 
autoras consideraram uma máquina de papel simples, sem tempo ou custo de preparação, sendo que um modelo simplificado foi proposto e resolvido por um algoritmo do tipo branch \& price. Apesar da formulação detectar a influência do processo de corte na produção dos jumbos, não considera o compromisso (tradeoff) entre a produção dos jumbos e o processo de corte, já que as variáveis de estoque são consideradas implicitamente.

Hendry et al. (1996) estudaram o problema de corte acoplado ao problema de planejamento da produção em indústrias de cobre. A operação de fundição básica consiste em derreter pedaços de cobre numa fornalha, produzindo barras com diâmetros específicos, que são cortadas em itens menores de diâmetros e quantidades específicas. Os autores apresentam métodos de solução em dois estágios, baseados no desacoplamento dos problemas. No primeiro estágio, supõe-se conhecido o número máximo de barras de qualquer diâmetro que pode ser produzido por período, levando em conta a capacidade do forno (na nossa abordagem, esta é uma variável de decisão) e resolve-se um problema de corte unidimensional. Esta fornece o número de barras de cada diâmetro que deve ser produzida por período. Algumas restrições de planejamento são omitidas neste estágio. No segundo estágio, é feito um planejamento da produção diário, para cada período, determinando o número de barras do primeiro estágio.

Menon \& Schrage (2002) consideram o problema composto de alocação de pedidos às máquinas e corte de bobinas em indústrias de papel. Como é comum na área de corte e empacotamento, os autores analizaram um único período de planejamento (6 semanas) e a demanda de itens finais de mesma gramatura, tipo de papel e largura formam um pedido. Os pedidos não podem ser divididos (cada pedido precisa ser designado a apenas uma das máquinas), o que torna necessário o uso de variáveis binárias para alocar os pedidos às máquinas. Os autores propuseram uma abordagem de decomposição baseada na construção de bons limitantes inferiores para o problema de corte, com o objetivo de obter bons valores para as variáveis binárias, quando os limitantes são apertados.

Recentemente, Correia et al. (2004) estudaram um problema de planejamento da produção e otimização do corte de bobinas e resmas, com aplicações numa indústria papeleira portuguesa. Os autores propõem um método de solução heurístico baseado na enumeração lexicográfica dos padrões de corte, que são selecionados e usados como colunas num modelo de programação linear, o qual procura determinar a quantidade/peso de papel 
a ser produzido em cada padrão. Os resultados obtidos, segundo os autores, são bastante satisfatórios.

É importante ressaltar que a modelagem proposta neste trabalho se diferencia da modelagem proposta por Correia et al. (2004) em vários pontos, tais como: consideramos o horizonte de planejamento dividido em vários períodos e trabalhamos com antecipação de itens no processo de corte, desde que seja vantajoso; consideramos a produção em várias gramaturas; tratamos os problemas de dimensionamento de lotes e corte de estoque de forma integrada, o que dificulta a sua solução exata. Dessa forma, como método de solução, propomos heurísticas de decomposição, visando possibitar a transição de informações entre os problemas e obter melhores resultados globais. Diferentemente, Correia et al. (2004) resolvem primeiramente o problema de corte e, posteriormente, o problema de dimensionamento de lotes, não permitindo uma interação entre os problemas.

O texto está organizado como segue. O capítulo 1 define o problema de corte de estoque e apresenta os modelos básicos para o caso unidimensional, bem como os métodos de resolução. A seguir, comentamos uma abordagem utilizada por Zak (2002) para resolver o problema de corte multiestagiado, com aplicação em indústrias de papel. Finalmente, consideramos o problema de dimensionamento de lotes e destacamos alguns métodos de solução da literatura, bem como a heurística proposta por Toledo et al. (2005) que foi adaptada e incluída nas heurísticas Lote-Corte e Corte-Lote, as quais propomos neste trabalho para resolução do problema integrado.

O capítulo 2 faz uma revisão de trabalhos que contêm aspectos similares ao nosso problema-chave. Esses trabalhos procuram integrar o problema de corte à outras atividades relacionadas ao planejamento e produção da produção numa indústria.

O capítulo 3 traz a definição do nosso problema-chave, destacando o processo produtivo numa indústria de papel. Propomos um modelo matemático inteiro-misto que integra os problemas de corte e dimensionamento de lotes ao longo de um horizonte de planejamento. Definimos o problema de corte de estoque multiperíodo, que surge em muitas situações práticas e ainda é pouco discutido na literatura. No capítulo 4, apresentamos dois métodos de solução para o problema de corte multiperíodo: solução lote por lote, que geralmente é utilizada na prática e uma heurística de antecipação de itens. São realizados testes computacionais com as duas heurísticas e os resultados são comparados. 
No capítulo 5 apresentamos duas heurísticas de decomposição para o problema integrado modelado no capítulo 3, que abordam ambos os problemas separadamente e iterativamente: Heurística Lote-Corte e Heurística Corte-Lote. Realizamos testes computacionais com exemplos gerados aleatoriamente e os resultados obtidos são comparados.

O capítulo 6 traz as conclusões e perspectivas. 


\section{Capítulo 1}

\section{Modelos básicos para os problemas}

\section{de corte de estoque e de}

\section{dimensionamento de lotes}

\subsection{Problema de corte de estoque}

O problema de corte de estoque consiste na otimização do processo de corte de unidades maiores (objetos) que estejam disponíveis, para a produção de um conjunto de unidades menores (itens), com o objetivo de atender a demanda desses itens e satisfazer algum critério de otimização, por exemplo, minimizar a perda de material gerada pelo corte ou o custo total dos objetos cortados. As formas e medidas dos objetos e dos itens são bem especificadas. Tais problemas vêm sendo investigados nas últimas décadas, desde os trabalhos pioneiros de Gilmore e Gomory (1961, 1963, 1965), que propuseram a técnica de geração de colunas, viabilizando a resolução de problemas reais.

Uma característica importante deste problema é que muitos itens devem ser produzidos, porém, relativamente de poucos tipos, ou seja, é grande a repetição de itens. Além disso, os objetos em estoque podem ser de apenas um único tipo ou de vários tipos, podendo haver ou não limitação de estoque. Para a produção dos diferentes tipos de itens demandados, muitos objetos devem ser igualmente cortados, o que sugere o uso de padrões de corte que serão repetidos um certo número de vezes. Um padrão de corte corresponde a uma maneira de cortar um objeto em estoque em itens demandados. O número 
de padrões de corte pode ser muito grande, o que introduz a dificuldade de gerá-los e determinar sua repetição.

Dependendo do problema, algumas regras são necessárias para a definição dos padrões de corte. Quando apenas uma dimensão é relevante no processo de corte, o problema é dito unidimensional, como ocorre, por exemplo, no corte de bobinas de papel e barras de aço. No caso do corte de placas (por exemplo, placas de madeira na indústria de móveis, chapas de aço e placas de vidro), duas dimensões (comprimento e largura) são relevantes na obtenção da solução e o problema é dito bidimensional. Quando três dimensões (comprimento, largura e altura) são relevantes, tem-se um problema tridimensional. Também é possível encontrar problemas do tipo 1,5-dimensional, que são essencialmente bidimensionais, porém uma das duas dimensões é variável como ocorre, por exemplo, no corte de retângulos de uma bobina que é desenrolada, cuja largura é fixa mas o comprimento suficientemente longo. Neste tipo de problema objetiva-se minimizar o comprimento cortado. Quando mais de três dimensões são relevantes para a obtenção da solução, o problema é dito multidimensional, como ocorre no problema de alocação de tarefas (Morabito, 1992). Além disso, deve-se considerar os tipos de corte, como, por exemplo, cortes do tipo guilhotinados, quando cada corte feito sobre uma placa retangular sempre produz dois novos retângulos. Pode-se ainda levar em conta a limitação de cada item (cortes restritos), ou o número de estágios (um corte pode ser chamado 2-estágios quando apenas uma mudança no sentido dos cortes guilhotinados é permitida: vertical/horizontal, ou horizontal/vertical), etc.

Nas próximas seções revisamos uma modelagem matemática, com ênfase ao problema unidimensional, objeto principal desta tese, além das restrições adicionais que surgem em problemas práticos.

\subsubsection{O problema de corte de estoque unidimensional}

No caso unidimensional, o problema de corte de estoque pode ser apresentado inicialmente como segue:

Suponha um estoque suficientemente grande de objetos, por exemplo, barras de aço ou bobinas de papel, de uma largura $L$, e um conjunto de pedidos, com demanda conhecida $d_{i}, i=1, \cdots, N f$, de itens de larguras $l_{i}, i=1, \cdots, N f$ (as larguras dos itens 
são tais que $\left.l_{i} \leq L\right)$. Um custo é associado a cada um dos objetos em estoque e o problema consiste em atender a demanda ao menor custo. Outros critérios, tais como minimizar a perda de material ou o número necessário de peças em estoque, podem ser definidos, sem que dificuldades adicionais sejam introduzidas.

Como já observamos, neste tipo de problema, muitos objetos em estoque deverão ser igualmente cortados para a produção dos diferentes tipos de itens, o que sugere o uso de padrões de corte. A cada padrão de corte $j$ associa-se um vetor $N f$-dimensional (em que $N f$ é o número de tipos de itens demandados) que define quantos itens de cada tipo são produzidos pelo padrão:

$$
\mathbf{a}_{\mathbf{j}}=\left(\alpha_{1 j}, \alpha_{2 j}, \ldots, \alpha_{N f, j}\right)
$$

sendo $\alpha_{i j}$ a quantidade de itens do tipo $i$ no padrão de corte $j$.

Um vetor $\mathbf{a}=\left(\alpha_{1}, \alpha_{2}, \ldots, \alpha_{N f}\right)$ corresponde a um padrão de corte se, e somente se, satisfizer as restrições físicas do problema:

$$
\begin{aligned}
& l_{1} \alpha_{1}+l_{2} \alpha_{2}+\ldots+l_{N f} \alpha_{N f} \leq L \\
& \alpha_{1} \geq 0, \ldots, \alpha_{N f} \geq 0 \text { e inteiros. }
\end{aligned}
$$

Outras restrições do processo de corte, como por exemplo, limitação no número de facas, podem ser incluídas no sistema (1.1).

Um padrão de corte é chamado homogêneo se o vetor associado tem apenas uma coordenada não nula, ou seja, se produz apenas um tipo de item. Assim, sempre teremos Nf padrões homogêneos, cujos vetores associados definem uma matriz diagonal.

A modelagem matemática do problema de corte de estoque pode ser feita em duas etapas:

1. defina todas as possíveis maneiras de cortar os objetos em estoque, isto é, defina todos os possíveis padrões de corte;

2. decida quantas vezes cada padrão de corte é utilizado para atender a demanda.

A primeira etapa, que consiste em gerar os padrões de corte, pode ser realizada independentemente da demanda dos itens. A segunda etapa corresponde a resolver um sistema de equações lineares algébricas com $N f$ equações e $n$ variáveis, sendo $n$ o número de padrões de corte gerados na primeira etapa. 
Há dois fatores contribuindo para tornar esta formulação do problema de corte de estoque de difícil resolução. O primeiro fator é a restrição de integralidade sobre as variáveis (quantas vezes cada padrão de corte será utilizado) que, se relaxada, o problema pode ser resolvido pelo método simplex desenvolvido por Dantzig em 1947. O segundo fator é o tamanho de $n$, que em problemas práticos pode ser da ordem de centenas de milhares, o que inviabiliza a geração de todos os padrões de corte. Gilmore e Gomory (1961, 1963) mostram que esta última dificuldade pode ser superada fazendo-se uma modificação no método simplex: quando chegamos no passo de selecionar uma nova coluna que melhore a solução, em vez de examinar um número grande de colunas existentes para selecionar a de menor custo relativo, simplesmente geramos uma coluna resolvendo um problema auxiliar. No caso do problema de corte de estoque, o problema auxiliar será de programação inteira, que consiste no corte de um único objeto em estoque e pode ser resolvido por vários métodos, como por exemplo, enumeração implícita, programação dinâmica ou heurísticas (Arenales et al, 2004). A técnica proposta, embutida no algoritmo simplex, é denominada técnica de geração de colunas. A solução ótima obtida para o problema relaxado é, em geral, fracionária. Então, utilizam-se heurísticas desenvolvidas para determinar o arredondamento da solução (Wäscher \& Gau, 1996; Poldi \& Arenales, 2005).

A seguir apresentamos um dos modelos clássicos para o problema de corte de estoque unidimensional, que considera diferentes tipos de objetos em estoque, em quantidades limitadas, sendo essa a situação do problema de corte a ser estudado nesta tese.

\section{Diferentes tipos de barra em estoque, em quantidades limitadas}

Consideremos vários tipos de objetos em estoque de largura $L_{m}, m=1, \cdots, M$, em quantidades disponíveis limitadas. Por simplicidade, nos referimos objeto tipo $m$. Este problema ocorre em indústrias onde os objetos são adquiridos com antecedência e estocados, ou ainda podem ser produzidos, porém a capacidade de produção é limitada. O custo do objeto tipo $m$ é dado por $c_{m}$ e a demanda a ser atendida é $d_{i}, i=1, \cdots, N f$. Considere como objetivo atender a demanda a custo mínimo. Além disso, é necessário adicionar o parâmetro $w_{m}$, que é a disponibilidade em estoque do objeto $m, m=1, \cdots, M$.

Definindo os padrões de corte para cada tipo de objeto em estoque, temos que: 


$$
\begin{aligned}
& l_{1} \alpha_{1 m}+l_{2} \alpha_{2 m}+\ldots+l_{N f} \alpha_{N f, m} \leq L_{m}, \\
& \alpha_{1 m} \geq 0, \ldots, \alpha_{N f, m} \geq 0 \text { e inteiros, } m=1, \cdots, M .
\end{aligned}
$$

Suponha que o sistema (1.2) tenha $n_{m}$ soluções, $m=1, \cdots, M$ dadas por:

$$
\mathbf{a}_{1 m}=\left[\begin{array}{c}
\alpha_{11}^{m} \\
\alpha_{21}^{m} \\
\vdots \\
\alpha_{N f, 1}^{m}
\end{array}\right], \quad \mathbf{a}_{2 m}=\left[\begin{array}{c}
\alpha_{12}^{m} \\
\alpha_{22}^{m} \\
\vdots \\
\alpha_{N f, 2}^{m}
\end{array}\right], \quad \cdots, \quad \mathbf{a}_{n_{m} m}=\left[\begin{array}{c}
\alpha_{1 n_{m}}^{m} \\
\alpha_{2 n_{m}}^{m} \\
\vdots \\
\alpha_{N f, n_{m}}^{m}
\end{array}\right]
$$

Uma vez definidos os padrões de corte, resta determinar quantas vezes utilizá-los. Seja $x_{j m}$ a variável de decisão, que representa o número de vezes que o objeto do tipo $m$ (isto é, de comprimento $L_{m}$ ) é cortado usando o padrão $j, j=1, \ldots, n_{m}, \quad m=1, \ldots, M$.

O problema pode ser formulado como:

$$
\begin{aligned}
& \operatorname{minimizar} \sum_{j=1}^{n_{1}} c_{1} x_{j 1}+\sum_{j=1}^{n_{2}} c_{2} x_{j 2}+\ldots+\sum_{j=1}^{n_{M}} c_{M} x_{j M}
\end{aligned}
$$

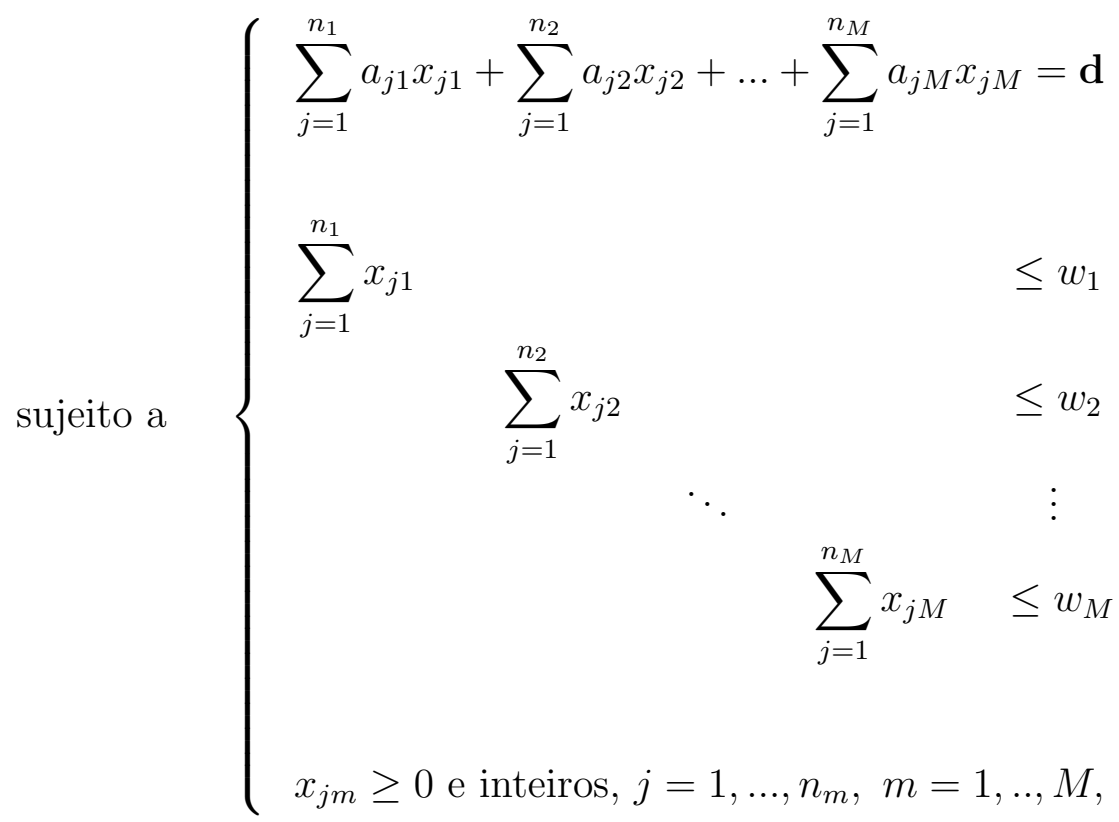

em que $\mathbf{d}$ é um vetor $N f$ - dimensional, cujas coordenadas são $d_{i}, i=1, \cdots, N f$.

Como observado anteriormente, os modelos matemáticos apresentados possuem um número grande de variáveis (uma variável para cada padrão), podendo, em problemas 
práticos, ser da ordem de centenas de milhares. Felizmente, tais modelos apresentam uma estrutura particular que permite trabalhar com estas variáveis implicitamente.

A função objetivo custo, proporcional ao número de objetos cortados, pode ser substituída pela função objetivo perda total, definindo-se:

$$
c_{j m}=L_{m}-\left(\alpha_{1 j}^{m} l_{1}+\alpha_{2 j}^{m} l_{2}+\cdots+\alpha_{N f, j}^{m} l_{N f}\right)
$$

como sendo a perda no padrão de corte $j$, cujo vetor associado é $\mathbf{a}_{j m}=\left(\alpha_{1 j}^{m}, \alpha_{2 j}^{m}, \cdots, \alpha_{N f, j}^{m}\right)$, $j=1, \cdots, n_{m} ; m=1, \cdots, M$.

Além da função objetivo, outras alterações no modelo básico podem ser convenientes.

- Uma característica do problema de corte de estoque, comum em aplicações práticas, consiste em que as demandas dos itens podem ser atendidas com uma certa tolerância, isto é, uma demanda de um item $i$, inicialmente especificada em $d_{i}$, pode ser qualquer valor no intervalo: $\left[d_{i}\left(1-\delta_{i}\right), d_{i}\left(1+\delta_{i}\right)\right]$ em que $\delta_{i}$ é um percentual previamente fornecido (por exemplo, na indústria de papel, esta tolerância varia de $5 \%$ a $15 \%$ ). Definindo os vetores de demanda mínima e máxima por $\mathbf{d}^{+}$e $\mathbf{d}^{-}$, cujas componentes são $d_{i}\left(1-\delta_{i}\right)$ e $d_{i}\left(1+\delta_{i}\right), i=1, \cdots, N f$, respectivamente, o problema de corte de estoque pode ser reformulado por:

$$
\begin{array}{ll}
\text { minimizar } & \mathbf{c}^{T} x \\
\text { sujeito a } & \left\{\begin{array}{l}
\mathbf{d}^{-} \leq \mathbf{A} \mathbf{x} \leq \mathbf{d}^{+} \\
\mathbf{x} \geq \mathbf{0} \text { e inteiro. }
\end{array}\right.
\end{array}
$$

- Em muitas aplicações (por exemplo, cortes de bobinas em indústrias papeleira, metalúrgica, etc.) a unidade de demanda usada é a tonelada. Portanto, o lado esquerdo das equações de demanda no modelo (1.3) precisa ser convertido. Suponha que todos os objetos tenham o mesmo peso, digamos $\mathrm{T}$ toneladas. Em outras palavras, consideramos bobinas de mesmo largura $L \mathrm{~cm}$ e mesmo diâmetro. O peso específico linear é $T / L$ ton $/ \mathrm{cm}$. Assim, um item de largura $l_{i} \mathrm{~cm}$ cortado do objeto pesa $l_{i}(T / L)$ ton e como num padrão $j$ o número de itens do tipo $i$ é $\alpha_{i j}$, segue que 
a tonelagem do item tipo $i$ produzida pelo padrão $j$ é $\alpha_{i j} l_{i}(T / L)$ ton, e as equações de demanda em (1.3) são alteradas para:

$$
\sum_{j=1}^{n}\left(\alpha_{i j} l_{i}(T / L)\right) x_{j}=d_{i}, \quad i=1, \cdots, N f .
$$

Podemos utilizar a variável $y_{j}=T x_{j}$ que representa a quantidade de papel (em toneladas) cortada pelo padrão $j$.

- 6. Uma outra particularidade da indústria de papel consiste em que muitas vezes parte da demanda é de retângulos $l_{i} \times w_{i}$, os quais são obtidos cortando-se inicialmente a bobina grande em sub-bobinas de largura $l_{i}$ que, em seguida, é desenrolada e cortada no tamanho $w_{i}$, conforme a figura 1.1.1:

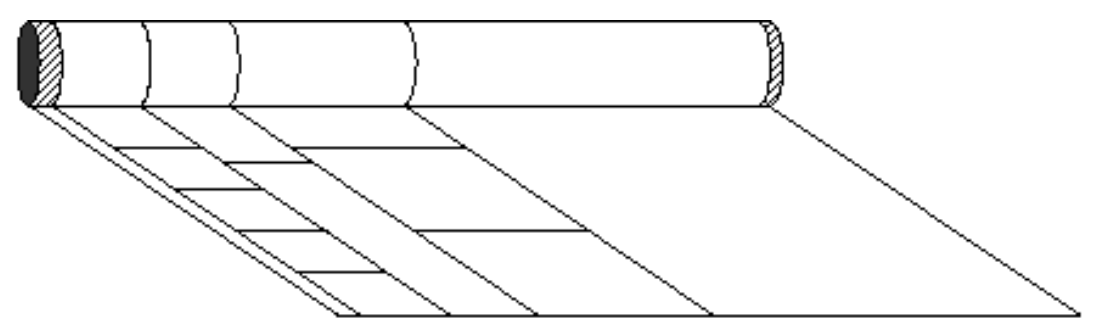

Figura 1.1: Produção de retângulos na indústria de papel.

Observe que o mesmo retângulo poderia ser obtido considerando-se $w_{i} \times l_{i}$. Em alguns casos, o sentido da fibra do papel dentro do retângulo é importante, de modo que este retângulo pode ser inaceitável, e os modelos anteriores são adequados.

Suponha que o sentido da fibra seja irrelevante, de modo que podemos cortar a bobina grande tanto em sub-bobinas de largura $l_{i}$, como de largura $w_{i}$. Isto significa que os padrões de corte podem combinar $2 m$ tamanhos: $l_{1}, \cdots l_{m}, w_{1}, \cdots, w_{m}$ ou de outra forma, definimos $l_{N f+i}=w_{i}, i=1, \cdots, N f$. Note, entretanto, que $\alpha_{i j}$ e $\alpha_{N f+i, j}$ dizem respeito à mesma demanda.

Considere a alteração do modelo básico em que a demanda é fornecida em toneladas. A largura da bobina grande que é utilizada para a produção do retângulo $l_{i} \times w_{i}$ (ou $w_{i} \times l_{i}$, indiferentemente) agora será dado por:

$$
\alpha_{i j} l_{i}+\alpha_{N f+i, j} w_{i}
$$


Deste modo, a restrição (1.5) torna-se:

$$
\sum_{j=1}^{n}\left(\left(\alpha_{i j} l_{i}+\alpha_{N f+i, j} w_{i}\right) T / L\right) x_{j}=d_{i}, \quad i=1, \cdots, N f
$$

\subsubsection{O método simplex com geração de colunas}

Relaxando-se as condições de integralidade, o método simplex pode ser usado na resolução de problemas de corte de estoque. Entretanto, a cada iteração do método, deve-se determinar uma nova coluna para entrar na base, dentre um grande número de colunas. Para contornar este problema, Gilmore e Gomory [21] propuseram uma técnica de geração de colunas bastante eficiente.

Este procedimento consiste em gerar uma coluna $j$, isto é, um novo padrão de corte, utilizando o critério de Dantizg, que procura a variável $x_{k m}$ com o menor custo relativo, o que sugere o seguinte sub-problema:

$$
\mathbf{c}_{k m}-\pi^{T} \mathbf{a}_{k m}=\min \left\{\mathbf{c}_{j m}-\pi^{T} \mathbf{a}_{j m}, \quad j=1,2, \cdots, n_{m}\right\}, m=1, \cdots, M
$$

em que $\pi$ é o vetor multiplicador simplex de uma determinada iteração (isto é, $\pi^{T}=$ $\mathbf{c}_{B}^{T} B^{-1}$, sendo $B$ a base da iteração).

É importante ressaltar que, no modelo (1.3), a matriz básica inicial do algoritmo primal-simplex com geração de colunas é construída com os padrões homogêneos da maior barra disponível em estoque, pois pode ocorrer de algum item ser maior que algum dos tipos de barras disponíveis. A solução homogênea pode ser infactível e a fase I do método simplex deve ser considerada [44].

Dependendo da função a ser minimizada, que pode ser o total de barras cortadas ou a perda total, devem ser realizadas algumas modificações no método simplex com geração de colunas.

Quando o objetivo é minimizar a perda total, como ocorre na indústria papeleira, onde a perda de papel durante o processo de corte dos intens finais deve ser minimizada, o custo associado ao padrão correspondente à coluna $\mathbf{a}_{\mathbf{j}}=\left(\alpha_{1}, \ldots, \alpha_{N f}\right)^{T}$ é $\mathbf{c}_{\mathbf{j}}=L-\sum_{i=1}^{N f} l_{i} \alpha_{i}$ 
(para um determinado tipo de objeto em estoque de largura $L$, ou seja, por simplicidade omitimos $m$ ). Portanto, a função objetivo do sub-problema (2.16) é dada por:

$$
\mathbf{c}_{j}-\pi^{T} \mathbf{a}_{j}=\left(L-\sum_{i=1}^{N f} l_{i} \alpha_{i}\right)-\sum_{i=1}^{N f} \pi_{i} \alpha_{i}=L-\sum_{i=1}^{N f}\left(l_{i}+\pi_{i}\right) \alpha_{i}
$$

O sub-problema (2.16) é equivalente ao seguinte problema da mochila:

$$
\begin{array}{ll}
\text { maximizar } & \sum_{i=1}^{N f}\left(l_{i}+\pi_{i}\right) \alpha_{i} \\
\text { sujeito a: } & \left\{\begin{array}{l}
\sum_{i=1}^{N f} l_{i} \alpha_{i} \leq L \\
\alpha_{i} \geq 0, i=1, \ldots, N f \quad \text { e inteiro. }
\end{array}\right.
\end{array}
$$

O algoritmo do método primal-simplex com geração de colunas utilizado na resolução dos problemas de corte de estoque encontra-se no apêndice.

\subsubsection{Heurísticas para o problema de corte de estoque inteiro}

O problema de corte de estoque unidimensional, formulado como um problema de programação inteira, é muito difícil de ser resolvido exatamente, também por causa das restrições de integralidade das variáveis. Os procedimentos heurísticos propostos para gerar uma solução inteira são basicamente de dois tipos: residuais e construtivos. Aqui, daremos ênfase aos procedimentos residuais, que segundo Wäscher e Gau (1996) e Poldi e Arenales (2005) são mais eficientes. Os métodos residuais propostos geram uma solução inteira para o problema de corte de estoque a partir de uma solução ótima fracionária, que pode ser obtida relaxando-se as restrições de integralidade do problema e utilizando-se o método de geração de colunas proposto por Gilmore e Gomory (1961, 1963). Alguns destes procedimentos heurísticos e vários outros estão em Wäscher e Gau (1996) e Poldi e Arenales (2005). 


\section{Métodos Residuais}

Considere o problema de corte de estoque formulado anteriormente, na forma matricial, com as restrições de integralidade relaxadas:

$$
\begin{array}{cl}
\operatorname{minimizar} & f(\mathbf{x})=\mathbf{c}^{T} \mathbf{x} \\
& \mathbf{A x}=\mathbf{d} \\
\text { sujeito a: } & \mathbf{W} \mathbf{x} \leq \mathbf{w} \\
& \mathbf{x} \geq \mathbf{0}
\end{array}
$$

sendo A a matriz dos padrões de corte e W a matriz de 0's e 1's das restrições de estoque.

Seja $\mathbf{x}^{*}$ uma solução ótima fracionária do problema relaxado (1.9):

$$
\mathbf{x}^{*}=\left(x_{11}^{*}, x_{21}^{*}, \cdots, x_{n_{M} M}^{*}\right)
$$

O problema residual parte da solução ótima $\mathbf{x}^{*}$ do problema (1.9). Uma técnica simples para obter uma solução inteira aproximada é arredondar todas as componentes do vetor solução para o número inteiro abaixo. Fazendo isto, teremos o vetor:

$$
\mathbf{y}^{*}=\left(\left\lfloor x_{11}^{*}\right\rfloor,\left\lfloor x_{21}^{*}\right\rfloor, \ldots,\left\lfloor x_{n_{M} M}^{*}\right\rfloor\right)
$$

de números inteiros. Outros procedimentos podem ser utilizados para determinar uma solução inteira aproximada, como propostos em Poldi e Arenales (2005). Esta solução não é uma solução viável pois, como foi arredondada para o inteiro inferior, não completa a demanda, ou seja, $\mathbf{A y}^{*} \leq \mathbf{d}$.

Considere $\mathbf{r}=\mathbf{d}-\mathbf{A y}^{*}$ a demanda residual e $\mathbf{s}=\mathbf{w}-\mathbf{W y}^{*}$ o estoque residual de objetos. Então o problema residual é dado por:

$$
\begin{array}{ll}
\operatorname{minimizar} & f(\mathbf{x})=\mathbf{c}^{T} \mathbf{x} \\
& \mathbf{A} \mathbf{x}=\mathbf{r} \\
\text { sujeito a: } & \mathbf{W} \mathbf{x} \leq \mathbf{s} \\
& \mathbf{x} \geq \mathbf{0} \text { e inteiro. }
\end{array}
$$


O problema (1.10) é resolvido (que consiste no problema (1.9) com a demanda e estoque redefinidos). Uma nova solução (possivelmente fracionária) é obtida e novamente uma solução inteira aproximada é gerada, obtendo-se uma nova demanda e um novo estoque residual. Repete-se o processo, até que o arredondamento gere frequências nulas. Se ainda restarem itens com demandas não atendidas, então teremos um último problema residual, que pode ser resolvido por alguma heurística que forneça uma solução inteira. Particularmente, pode-se utilizar as heurísticas FFD e Gulosa.

\subsubsection{Problema de corte de estoque multiestagiado}

Um problema de corte de estoque (PCE) unidimensional tem uma generalização prática importante quando o processo de corte ocorre em vários estágios sucessivos. Este PCE multiestagiado inclui, além dos itens finais, bobinas intermediárias e suas quantidades a serem produzidas em cada estágio do processo de corte. As bobinas intermediárias podem ser entrada ou saída durante o processo de corte. Nesta seção apresentaremos uma abordagem utilizada por Zak em ZAK (2002) para resolver este tipo de problema, que ocorre por exemplo nas indústrias de papel. Um problema parecido a este foi estudado por Hoto et al (2005) e Marques e Arenales (2005), chamado de Mochila Compartimentada, que surge no corte de bobinas de aço. Neste texto utiliza-se a terminologia da indústria de papel.

A Figura (1.1.4) ilustra um processo de corte em três estágios. Neste exemplo, três tipos de bobinas em estoque S1, S2 e S3 são usadas para produzir nove tipos de produtos finais (F1 - F9). É interessante notar que as bobinas em estoque podem entrar em qualquer estágio do processo. Aqui, S1 entra no primeiro estágio, S2 entra no segundo e S3 entra no terceiro. Reciprocamente, os produtos finais podem ser produzidos em qualquer estágio. Três tipos de bobinas intermediárias I1, I2 e I3 são cortadas nos primeiros dois estágios.

O termo "Multiestágio "é sobrecarregado, particularmente em pesquisa operacional e áreas do PCE. Gilmore e Gomory (1965), por exemplo, se referem a um PCE bidimensional resolvido cortando-se, primeiramente, em tiras (ou faixas) e então cortando-se estas tiras transversalmente, como um problema em 2-estágios ou multiestágio, quando não há limitação sobre o número de estágios. Em Zak (2002), todos os cortes são longitudinais, o 


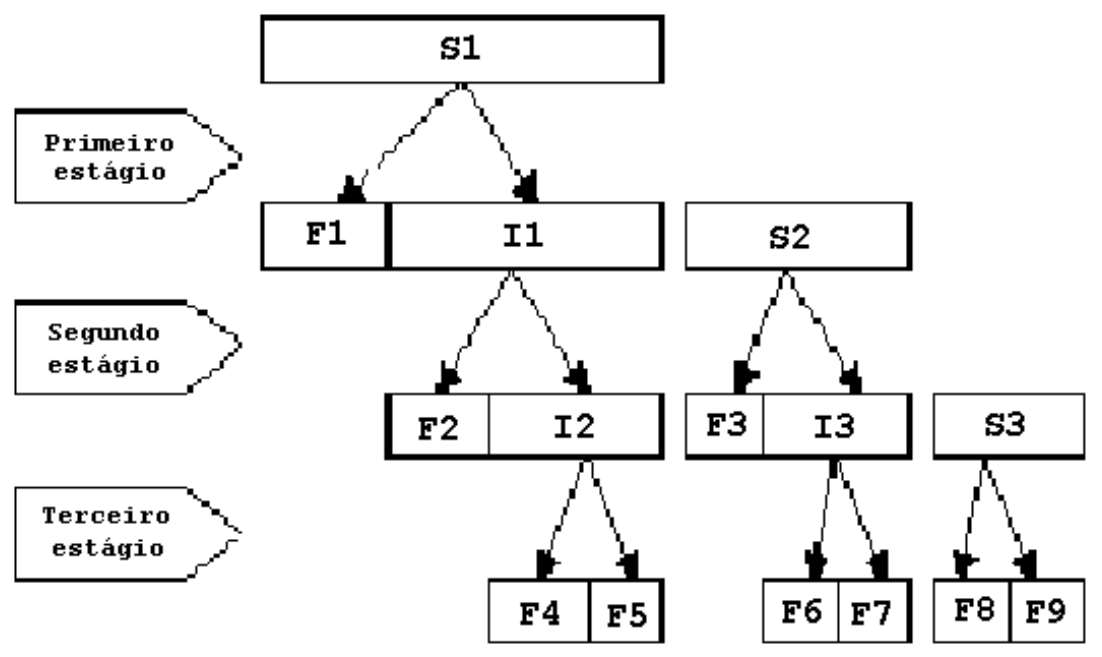

Figura 1.2: Processo de corte em três estágios

problema é unidimensional e o termo multiestágio surge no sentido anteriormente descrito.

Carvalho \& Rodrigues (1995) seguem uma abordagem por otimização linear. O problema deles, no entanto, está sujeito a uma restrição tecnológica - bobinas intermediárias devem ser formadas por um único tipo de bobina final (padrão homogêneo). A restrição permite enumerar as possíveis bobinas intermediárias.

Zak (2002) apresenta a formulação de dois modelos básicos para o PCE com processo em 2-estágios: modelo com bobinas intermediárias conhecidas e com bobinas intermediárias desconhecidas. No dois casos, o autor utiliza o método simplex com geração de colunas proposto por Gilmore e Gomory (1961, 1963), com algumas modificações. No primeiro caso, dois problemas auxiliares devem ser resolvidos. O primeiro problema auxiliar é a geração de um padrão de corte ao estágio da produção das bobinas intermediárias. Ou seja, a cada iteração do método simplex, um problema da mochila deve ser resolvido para determinar a coluna a entrar na base. O segundo problema auxiliar está associado aos padrões de corte gerados pelas bobinas finais utilizando-se as bobinas intermediárias existentes. Ou seja, para cada bobina intermediária, um segundo problema da mochila deve ser resolvido.

Se o número de bobinas intermediárias é desconhecido, então estamos livres para selecionar qualquer largura de bobina intermediária, o que torna o problema mais complicado. Como cada bobina intermediária e cada bobina final estão associadas à linhas da 
matriz do modelo, então ela pode ser aumentada em ambas as direções: linhas e colunas. Dessa forma, Zak (2002) propõe uma abordagem para gerar bobinas intermediárias, assim como pode ser feito com padrões de corte (apenas quando necessário), chamada técnica de geração de linhas e colunas. Neste caso, juntamente com os dois problemas da mochila mencionados anteriormente, aparece um terceiro tipo de problema auxiliar associado à geração simultânea de novas bobinas intermediárias e padrões de corte. Então, o autor adapta o método simplex para, além de gerar uma nova coluna a cada iteração, gerar também uma nova linha, que representa uma nova bobina intermediária. No entanto, o terceiro problema auxiliar é uma mochila não linear com restrições adicionais. $\mathrm{O}$ autor sugere um método para resolver essa mochila, cuja idéia é particionar o problema em vários sub-problemas mais simples, resolvê-los separadamente, e então escolher a melhor solução. Os resultados apresentados, especialmente a técnica de geração de linhas e colunas, mostraram-se promissores para resolver grandes modelos multiestagiados.

\subsection{Problema de dimensionamento de lotes}

O problema de dimensionamento de lotes, que surge no contexto do planejamento da produção, é um problema de otimização que consiste em determinar a quantidade de itens a serem produzidos em várias (ou única) máquinas, em cada período ao longo de um horizonte de tempo finito, de modo a atender uma certa demanda e otimizar uma função objetivo, como por exemplo, minimizar custos, atrasos, etc.

De acordo com Bahl et al. (1987), os problemas de dimensionamento de lotes podem ser divididos em dois grupos básicos: modelos monoestágio, em que a produção de um item não depende da produção de outros itens, e modelos multiestágios, sendo a produção dependente, ou seja, para se produzir um item é necessário que se tenha produzido outros itens que serão utilizados na produção deste último. Os autores apresentam uma classificação simplificada de tipos de problemas de dimensionamento de lotes, como mostra a figura (1.3). Em karimi et al. (2003) é feita uma classificação do problema de forma mais detalhada, considerando-se diversas características, tais como: tipo de horizonte de planejamento, número de estágios, número de itens, restrição de capacidade, deterioração dos itens, tipo de demanda, estrutura do tempo e custo de preparação e permissão de 
atraso no atendimento a demanda. Outras boas revisões podem ser encontradas em Kuik et al. (1994), Drexl \& kimms (1997), Wolsey (1995) e Brahimi et al. (2006), sendo os dois últimos restritos a um único item.

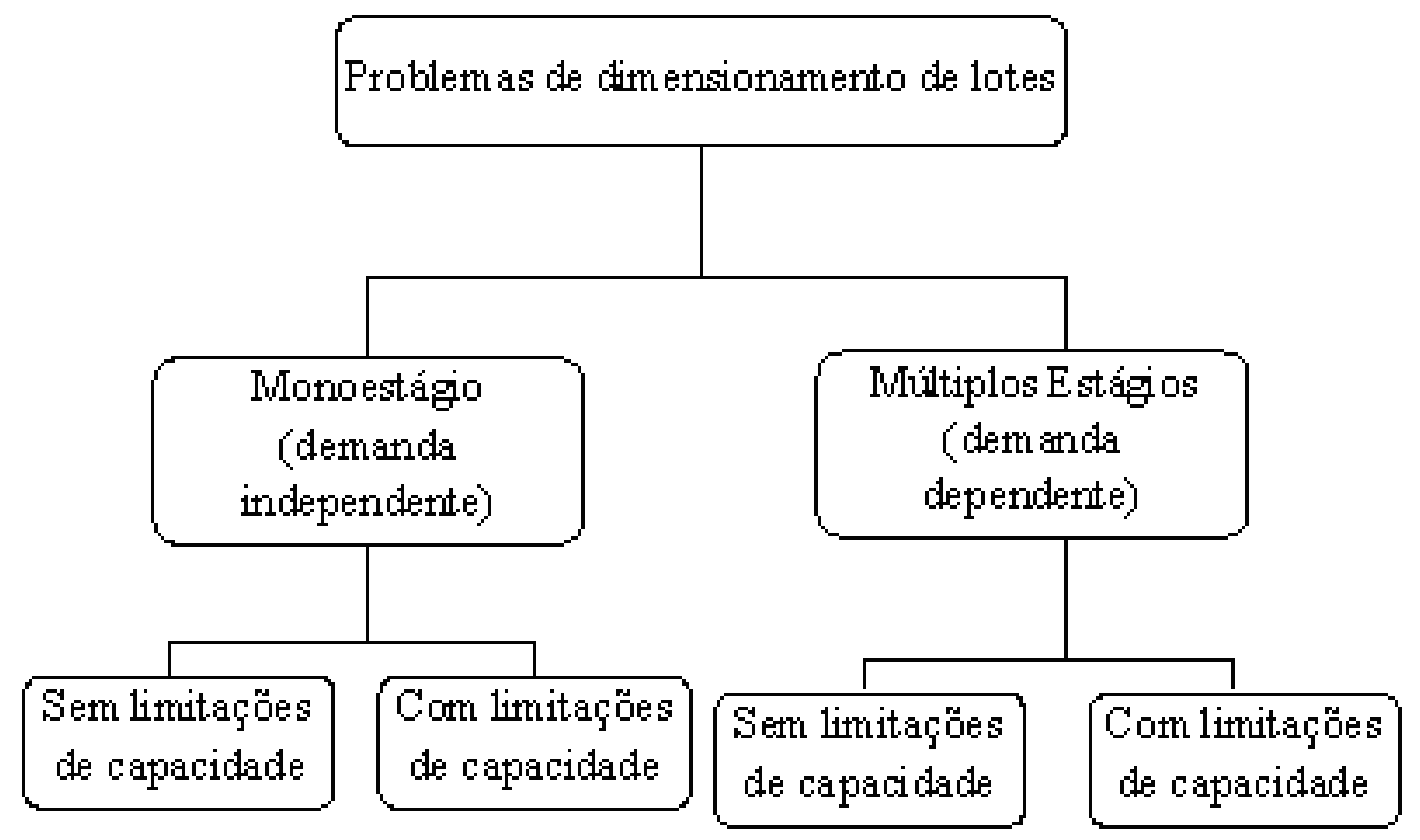

Figura 1.3: Uma classificação simplificada dos problemas de dimensionamento de lotes.

\subsubsection{Problema de dimensionamento de lotes monoestágio}

O problema de dimensionamento de lotes monoestágio pode ser formulado como um problema de programação inteira mista. Quando o tempo e os custos de preparação são irrelevantes (baixos quando comparados com os custos de produção, estoque e mãode-obra), o problema é modelado como um programa linear e resolvido por alguma técnica padrão de programação linear.

Considerando os custos de preparação relevantes e capacidade infinita de produção, a minimização dos custos totais trata do balanceamento dos custos de produção, de preparação e dos custos de estocagem. Seja $T$ o número de períodos do horizonte de planejamento, $M$ o número de diferentes tipos de itens (produtos finais) a serem produzidos e os dados do problema definidos a seguir. 
Parâmetros:

$c_{i t}$ : custo de produção do item $i$ no período $t$;

$h_{i t}$ : custo de estoque do item $i$ no período $t$;

$s_{i t}:$ custo de preparação do item $i$ no período $t$;

$d_{i t}$ : demanda do item $i$ no período $t$;

$Q$ : limitante superior para qualquer lote.

Variáveis de decisão:

$x_{i t}$ : quantidade a ser produzida do item $i$ no período $t$

$I_{i t}$ : estoque do item $i$ no fim do período $t ;$

$z_{i t}$ : variável binária que indica a produção ou não do item $i$ no período $t$.

O problema de dimensionamento de lotes monoestágio com capacidade infinita de produção pode ser formulado como:

$$
\begin{aligned}
& \text { Minimizar } \sum_{t=1}^{T} \sum_{i=1}^{M}\left(c_{i t} x_{i t}+h_{i t} I_{i t}+s_{i t} z_{i t}\right) \\
& \text { sujeito a: } \quad x_{i t}+I_{i, t-1}-I_{i t}=d_{i t}, \quad i=1, \cdots, M ; t=1, \cdots, T \text {; } \\
& x_{i t} \leq Q \cdot z_{i t}, \quad i=1, \cdots, M ; t=1, \cdots, T ; \\
& x_{i t}, I_{i t} \geq 0, \quad i=1, \cdots, M ; t=1, \cdots, T ; \\
& I_{i 0}=0, z_{i t} \in\{0,1\}, \quad i=1, \cdots, M ; t=1, \cdots, T .
\end{aligned}
$$

A função objetivo (1.11) minimiza a soma dos custos de produção, de estoque e de preparação. As restrições (1.12) são de balanceamento de estoque, ou seja, a quantidade 
produzida num período mais a quantidade disponível em estoque no início do período, menos o que sobrar em estoque no fim do período, deve ser igual à demanda do período. As restrições (1.13) asseguram que o custo de preparação é considerado apenas quando existe produção e, por fim, (1.14) e (1.15) são restrições de não negatividade. Sem perda de generalidade, o estoque inicial é considerado igual a zero.

Como não existem restrições sobre a capacidade da máquina, o problema monoestágio com vários itens pode ser decomposto em $M$ subproblemas, um para cada item, e cada subproblema pode ser resolvido utilizando um algoritmo ótimo de programação dinâmica. A referência clássica para a resolução desses $M$ subproblemas é o artigo de Wagner \& Whitin (1958), que propõe um método ótimo com tempo polinomial $\left(O\left(T^{2}\right)\right)$. Evans (1985) propõe um algoritmo com a mesma complexidade do algoritmo de Wagner \& Whitin (1958) porém, testes computacionais mostraram que o algoritmo de Evans (1985) é mais eficiente. Posteriormente, três grupos de pesquisa independentes, Ferdergruen \& Tzur (1991), Wagelmans et al. (1992) e Aggarwal \& Park (1993), propuseram algoritmos com complexidade $O(T \log T)$ para o problema.

Entretanto, o que predomina na maioria dos problemas de dimensionamento de lotes são modelos que consideram demanda dinâmica e restrições de capacidade simultaneamente. No modelo apresentado a seguir (Trigeiro et al., 1989), a demanda é conhecida sobre os $T$ períodos do horizonte de planejamento, a capacidade disponível é limitada e são considerados tempo e custo de preparação de máquina. O objetivo do modelo é determinar um plano de produção que minimize os custos, sujeito a um conjunto de restrições que inclui o atendimento de uma demanda preestabelecida.

Parâmetros adicionais ao problema (1.11)-(1.15):

$b_{i}$ : tempo necessário para produzir uma unidade do item $i$;

$f_{i}$ : tempo de prepraração para a produção do item $i$;

$C_{t}$ : limite de capacidade (em unidade de tempo) no período $t$. 
Modelo matemático:

$$
\begin{aligned}
& \text { Minimizar } \sum_{t=1}^{T} \sum_{i=1}^{M}\left(c_{i t} x_{i t}+h_{i t} I_{i t}+s_{i t} z_{i t}\right) \\
& \text { sujeito a: } \quad x_{i t}+I_{i, t-1}-I_{i t}=d_{i t}, \quad i=1, \cdots, M ; t=1, \cdots, T ; \\
& \\
& \sum_{i=1}^{M}\left(b_{i} x_{i t}+f_{i} z_{i t}\right) \leq C_{t}, \quad t=1, \cdots, T ; \\
& \quad x_{i t} \leq Q \cdot z_{i t}, \quad i=1, \cdots, M ; t=1, \cdots, T ; \\
& x_{i t}, I_{i t} \geq 0, \quad i=1, \cdots, M ; t=1, \cdots, T ; \\
& I_{i 0}, z_{i t} \in\{0,1\}, \quad i=1, \cdots, M ; t=1, \cdots, T .
\end{aligned}
$$

No modelo (1.16)-(1.21) são acrescentadas as restrições de capacidade, que levam em consideração o tempo despendido para a produção dos itens e preparação das máquinas.

Segundo Maes et al. (1991), encontrar uma solução factível para problemas de dimensionamento de lotes com capacidade limitada que considere tempo de preparação (setup time) é NP-completo. Por esta razão, a maioria das técnicas de resolução encontradas na literatura são heurísticas dedicadas a resolver problemas específicos (Billington et al., 1983 e Bahl et al., 1987).

Para o problema matemático inteiro-misto (1.16)-(1.21), Trigeiro et al. (1989) formulou um método heurístico de resolução baseado na relaxação lagrangiana. Observe que as únicas restrições que ligam os itens são as restrições de capacidade. Assim, ao aplicarse a relaxação lagrangiana nestas restrições, o problema torna-se do tipo (1.11)-(1.15), podendo então ser resolvido via programação dinâmica. O valor da função objetivo do problema relaxado (lagrangiano) produzirá um limitante inferior para o problema original (1.16)-(1.21) e o método do subgradiente é utilizado para atualizar os multiplicadores de lagrange, visando determinar o maior dos limitantes inferiores. Provavelmente, a solução do problema relaxado será infactível, violando as restrições de capacidade. Para isso, 
Trigeiro et al. (1989) desenvolveram uma heurística de factibilização que parte da solução obtida pelo algoritmo de programação dinâmica, tentando ajustar os lotes (transferindo-os para períodos anteriores ou posteriores, se possível) de acordo com a capacidade disponível em cada período. Finalmente, atualiza-se os multiplicadores duais utilizando o método do subgradiente (Held et al., 1974 e Camerini et al.,1975).

Araújo e Arenales (2000) propõem uma modificação no método desenvolvido por Trigeiro et al (1989). Esta modificação é feita no procedimento de factibilização, mais exatamente, na forma de transferência de produção entre períodos. Testes computacionais mostraram resultados melhores que os obtidos por Trigeiro et al (1989).

Toledo et al. (2005) propõem uma heurística lagrangiana para o problema de dimensionamento de lotes capacitado com tempos e custos de preparação, envolvendo a produção de múltiplos itens em máquinas paralelas. O objetivo é determinar um plano de produção que atenda a demanda ao longo do horizonte de planejamento, sem exceder a capacidade das máquinas, minimizando a soma dos custos de produção, preparação e estoque. A heurística baseia-se na relaxação lagrangiana das restrições de capacidade e utiliza o método do subgradiente para resolver o problema relaxado, assim como em Trigeiro et al. (1989). Além disso, são realizados passos de factibilização e melhoramento da solução. Os testes computacionais foram realizados para uma única máquina e para máquinas paralelas. No primeiro caso, os resultados foram comparados com Trigeiro et al. (1989), para o qual a heurística se mostrou bastante competitiva. Para máquinas paralelas, os resultados foram comparados com um limitante inferior, produzido pela relaxação lagrangiana, mostrando que a heurística é rápida e capaz de encontrar um número grande de soluções factíveis de boa qualidade. 


\section{Capítulo 2}

\section{Modelos integrados}

Neste capítulo, revisamos alguns trabalhos que contêm aspectos similares ao nosso problema-chave. Estes trabalhos situam-se no nível tático-operacional e buscam integrar decisões de corte à programação da produção, uma vez que, em muitas aplicações da vida real, o problema de corte de estoque aparece como um subproblema de um problema de planejamento de produção mais amplo. Aplicações relativas à integração dos dois problemas parecem ter sido ignoradas na literatura, sendo tratados separadamente.

O primeiro trabalho a ser revisado, Gramani [24], foi motivado por problemas que aparecem em indústrias de móveis, onde placas retangulares de madeira são cortadas em peças retangulares menores para a produção dos móveis. A proposta é trabalhar com os problemas de dimensionamento de lotes e corte de estoque de forma integrada, analisando o compromisso entre adiantar ou não a produção de certos lotes de produtos finais, o que aumenta os custos de estoque, mas possibilita perdas menores.

A seguir apresentamos o trabalho de Respício e Captivo [45], que considera o problema de planejamento de capacidade integrado ao problema de corte de estoque aplicado em indústrias papeleiras.

O terceiro trabalho revisado, Hendry et al. (1996), considera o problema de corte acoplado ao problema de planejamento da produção em indústrias de cobre. A operação de fundição básica consiste em derreter pedaços de cobre numa fornalha, produzindo barras com diâmetros específicos, que são cortadas em itens menores de diâmetros e quantidades específicas. Os autores apresentam métodos de solução em dois estágios, baseados no desacoplamento dos problemas. 
Também fazemos uma revisão do trabalho de Menon \& Schrage (2002), que estudam o problema composto de alocação de pedidos às máquinas e corte de bobinas em indústrias de papel. A abordagem proposta baseia-se na construção de bons limitantes inferiores para o problema de corte, com o objetivo de obter bons valores para as variáveis de alocação.

Finalmente, revisamos o trabalho de Correia et al. (2004), que estudou um problema de planejamento da produção e otimização do corte de bobinas e resmas, com aplicações numa indústria papeleira portuguesa. Foi proposto um modelo matemático que acopla os problemas de alocação, corte e sequenciamento mas máquinas de papel e um método heurístico de decomposição, baseados na proposta de Menon \& Schrage (2002).

\subsection{Um problema de dimensionamento de lotes e pro- gramação de cortes}

O trabalho de Gramani [24] enfoca os problemas de tomada de decisão relacionados ao planejamento tático/operacional. Neste contexto, considere um processo de produção que consiste em cortar placas retangulares em peças menores, necessárias para compor os produtos finais, como mostra a Figura (??).

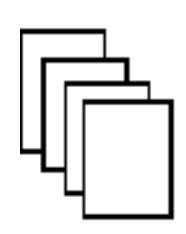

(a)

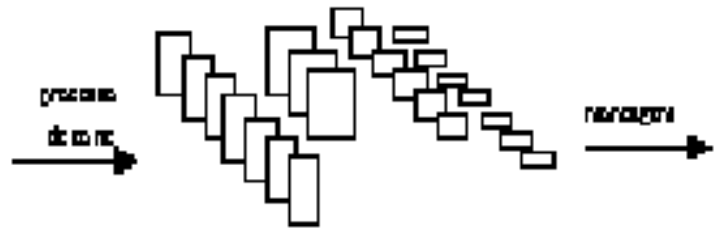

(b)

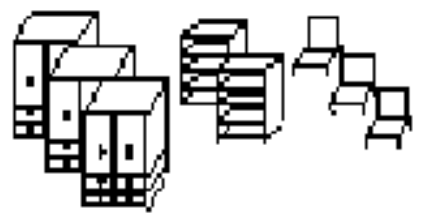

(c)

Figura 2.1: (a) Placa retangular a ser cortada; (b) Peças retangulares; (c) Produtos finais.

O processo de programar a produção consiste de duas etapas, baseadas em uma carteira de pedidos em um horizonte de planejamento (alguns dias, uma semana, um mês, etc.), na qual as quantidades dos produtos finais demandados e suas respectivas datas de entrega estão especificados. A primeira etapa é facilmente obtida convertendo a demanda de produtos finais em demanda de peças, como mostra a figura 2.1 (para um exemplo 
de 3 produtos finais constituídos de 6 diferentes tipos de peças). O produto final 1 é constituído pelas peças tipo 1 e 2 , o produto final 2 é constituído pelas peças do tipo 3 e 4 e o produto final 3 é constituído pelas peças tipo 4, 5 e 6 . Como vemos, um tipo de peça pode ser utilizado por vários produtos finais diferentes. Obviamente, as quantidades das peças necessárias para cada produto final são também fornecidas. Estruturas de produto mais complexas também podem ser consideradas.

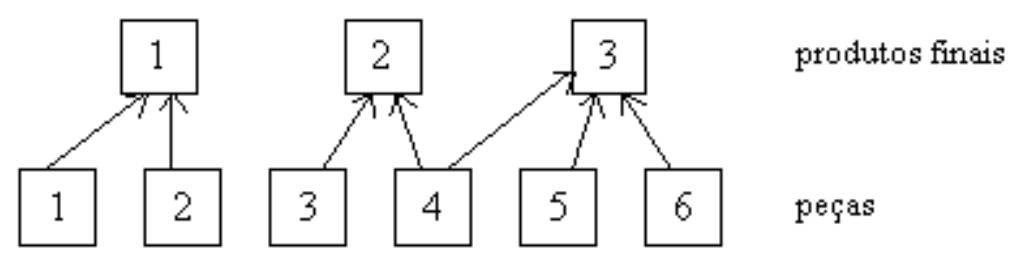

Figura 2.2: Peças necessárias para obter os produtos finais.

A segunda etapa consiste em decidir a quantidade de produtos finais que devem ser produzidos em cada período do horizonte de planejamento, minimizando os custos associados ao estoque e preparação e, além disso, minimizar a perda ocorrida no processo de corte das placas em peças.

O Problema Combinado apresentado por Gramani (2001) focaliza a segunda etapa do processo de programação da produção e consiste em decidir a quantidade de produtos finais a serem produzidos em cada período do horizonte de planejamento, tal que minimize não somente os custos de produção, preparação e estocagem (problema de dimensionamento de lotes), mas também a quantidade de placas a serem cortadas em peças a fim de compor os produtos finais demandados (problema de corte de estoque). É proposto, então, um modelo matemático inteiro-misto que integra estes dois problemas, analisando o compromisso entre antecipar a produção de certos lotes de produtos finais, a fim de minimizar os custos no processo de corte e preparação, e o aumento dos custos de estocagem.

Uma relação importante existente no modelo está entre a demanda de um produto final e a demanda de seus itens (peças). A demanda de um produto final $d_{i t}$ ocorre externamente e as quantidades são determinadas pelo cliente. Tendo conhecida a produção dos produtos finais, é fácil obter a demanda interna dos itens, que é dada por $\sum_{i} r_{p i} x_{i t}$, sendo $r_{p i}$ a quantidade necessária de peças do tipo $p$ para produzir uma unidade do 
produto $i$, e $x_{i t}$ a quantidade produzida do produto final $i$ no período $t$. Desta forma, a demanda interna dos itens é incógnita.

Um outro ponto importante é a inclusão da disponibilidade da serra em cada período. Com a inclusão das restrições de capacidade de serra em cada período, ao se resolver os problemas de forma separada, podem aparecer infactibilidades na produção, enquanto que, resolvendo-se os problemas de forma integrada, pode-se antecipar a produção de certos lotes, de forma a obter uma melhor utilização das máquinas, sem que os limites de capacidade de serra sejam ultrapassados.

Para a modelagem matemática do Problema Combinado a seguinte notação é utilizada:

Índices:

$t=1, \cdots, T:$ número de períodos (ou turnos de trabalho);

$i=1, \cdots, M:$ número de produtos finais demandados;

$p=1, \cdots, P:$ número de tipos de peças a serem cortadas;

$j=1, \cdots, N$ : número de possíveis padrões de corte para a placa LxW.

Parâmetros:

$c_{P}$ : custo unitário da placa em estoque;

$c_{i t}$ : custo de produção do produto final $i$ no período $t$;

$h_{i t}$ : custo de estocagem do produto final $i$ no período $t$;

$h p_{p t}$ : custo de estocagem da peça do tipo $p$ no período $t$

$d_{i t}$ : demanda do produto final $i$ no período $t$;

$r_{p i}:$ número de peças do tipo $p$ necessárias para formar uma unidade do produto final $i$;

$v_{j}$ : tempo gasto para cortar uma placa no padrão de corte $j$;

$b_{t}$ : capacidade de serra (em horas) no período $t$ 
$s_{i t}$ : custo de preparação para produzir o produto final $i$ no período $t$; $a_{p j}$ : número de peças do tipo $p$ no padrão $j$.

Variáveis:

$x_{i t}$ : quantidade do produto final $i$ produzido no período $t$

$I_{i t}$ : quantidade do produto final $i$ em estoque no fim do período $t$;

$I P_{p t}:$ quantidade da peça do tipo $p$ em estoque no fim do período $t$;

$y_{j t}$ : quantidade de placas cortadas usando o padrão de corte $j$ no período $t$; $z_{i t}$ : variável binária: $z_{i t}=1$ se $x_{i t}>0$; zero, caso contrário. 
O modelo matemático inteiro-misto para o Problema Combinado de Corte de Estoque e Dimensionamento de Lotes pode ser descrito como:

$$
\begin{aligned}
& \text { Minimizar } \sum_{i=1}^{M} \sum_{t=1}^{T}\left(c_{i t} x_{i t}+h_{i t} I_{i t}+s_{i t} z_{i t}\right)+\sum_{j=1}^{N} \sum_{t=1}^{T} c p y_{j t}+\sum_{p=1}^{P} \sum_{t=1}^{T} h p_{p t} I P_{p t} \\
& \text { sujeito a: } \\
& x_{i t}+I_{i, t-1}-I_{i t}=d_{i t} \quad i=1, \cdots, M ; t=1, \cdots, T \\
& \sum_{j=1}^{N} a_{p j} y_{j t}+I P_{p, t-1}-I P_{p t}=\sum_{i=1}^{M} r_{p i} x_{i t} \quad p=1, \cdots, P ; \quad t=1, \cdots, T \\
& \sum_{j=1}^{N} v_{j} y_{j t} \leq C_{t} \quad t=1, \cdots, T \\
& x_{i t} \leq Q_{i t} \cdot z_{i t} \quad i=1, \cdots, M ; t=1, \cdots, T \\
& x_{i t}, I_{i t} \geq 0 \quad i=1, \cdots, M ; t=1, \cdots, T \\
& y_{j t} \geq 0 \quad \text { e inteiros } \quad j=1, \cdots, N ; t=1, \cdots, T \\
& I P_{p t} \geq 0 \quad p=1, \cdots, P ; t=1, \cdots, T \\
& z_{i t} \in\{0,1\} \quad i=1, \cdots, M ; t=1, \cdots, T
\end{aligned}
$$

sendo $Q_{i t}$ um limitante superior para a produção do item $i$ no período $t$ (por exemplo, $\left.Q_{i t}=\sum_{\tau=t}^{T} d_{i \tau}\right)$

O conjunto de restrições (2.2) considera o balanço de estoque de produtos finais, assegurando que a demanda de cada período seja atendida sem atraso, $I_{i t} \geq 0$. Sem perda de generalidade, o estoque inicial é considerado nulo.

O conjunto (2.3) assegura que a demanda de peças do tipo $p, \quad p=1, \cdots, P$, que é calculada por $\sum_{i=1}^{M} r_{p i} x_{i t}$, seja atendida. O somatório $\sum_{j=1}^{N} a_{p j} y_{j t}$ fornece o número de peças 
do tipo $p$ que devem ser produzidas em cada período do horizonte de planejamento. $\mathrm{O}$ estoque inicial de peças é considerado nulo. Estas restrições são as únicas que acoplam os dois problemas, pois incluem ambas as variáveis, $x_{i t}$ que definem o tamanho dos lotes e $y_{j t}$ que definem a quantidade de placas utilizadas (cortadas).

Devem ser consideradas, também, a capacidade limite de serra das máquinas. Portanto, as restições (2.4) impedem que o tempo gasto para cortar placas nos diversos padrões de corte exceda o tempo limite $c_{t}$. As restrições (2.5) são restrições de produção que obrigam $z_{i t}=1$, caso $x_{i t}>0$. Caso $x_{i t}=0$, a otimalidade se encarrega de fazer $z_{i t}=0$

O objetivo do modelo é minimizar os custos operacionais (custos de produção, estoque e preparação) e os custos do processo de cortagem (custos das placas e custos de estoque das peças). Ou seja, a meta é encontrar um planejamento de produção ótimo de tal modo que minimize o número de placas a serem cortadas, como também os custos de produção, estoque e preparação.

A alta complexidade do modelo matemático do Problema Combinado deve-se a três fatores:

(1) a integralidade das variáveis $y_{j t}$;

(2) as variáveis binárias de preparação $z_{i t}$;

(3) a grande quantidade de padrões de corte $a_{p j}$.

Devido a estas dificuldades, na prática, as indústrias resolvem o problema combinado decompondo-o em dois subproblemas: problema de dimensionamento de lotes e problema de corte de estoque, e utilizam métodos heurísticos para resolver cada um deles. Mas resolvendo-se o problema decomposto, mesmo obtendo a solução ótima para os dois problemas e agregando suas soluções, pode não ser compensador do ponto de vista do custo de produção global. Gramani (2001) propõe a resolução do problema combinado de forma conjunta e compara suas soluções com as obtidas, resolvendo os problemas de forma separada, obtendo até $13 \%$ de ganho global.

Por causa da alta complexidade do Modelo Combinado, o desenvolvimento dos métodos de solução propostos por Gramani envolveu três simplificações distintas sobre o 
modelo (2.1)-(2.9), como mostra a figura (2.3).

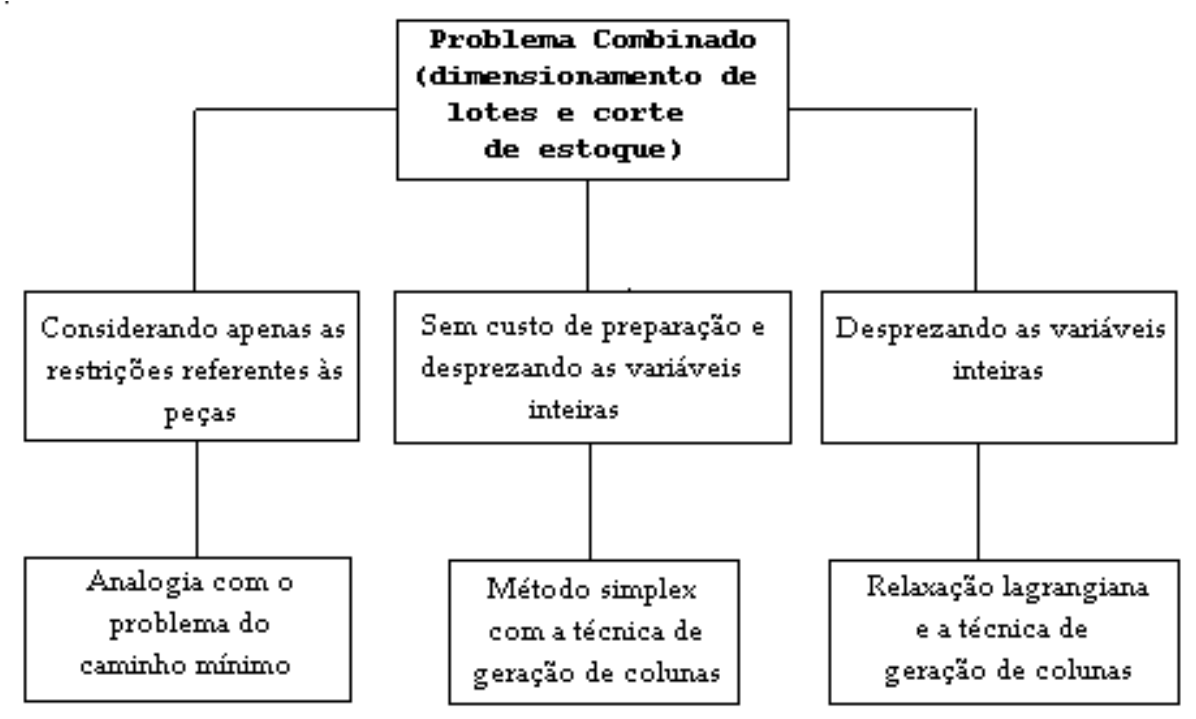

Figura 2.3: Três simplificações distintas do Modelo Combinado e seus respectivos métodos de resolução.

A primeira simplificação considera apenas as restrições referentes às peças, e é proposto um método heurístico de resolução baseado na reformulação do problema como um problema do caminho mínimo. Resultados computacionais são apresentados comparando as soluções obtidas pela heurística proposta com as soluções obtidas pelo método de decomposição (que trata os problemas de dimensionamento de lotes e corte de estoque separadamente).

A outra simplificação consiste em relaxar as restrições de preparação e a condição de integralidade sobre as variáveis. O problema continua sendo um problema combinado de corte de estoque e dimensionamento de lotes e é proposto um método de resolução ótimo para resolvê-lo. Essa abordagem estende o método simplex com a geração de colunas proposta por Gilmore e Gomory (1965).

A terceira abordagem propõe um método de resolução heurístico para o Problema Combinado, relaxando-se apenas as restrições de integralidade sobre as variáveis $y_{j t}$. A heurística desenvolvida baseia-se na relaxação lagrangiana e no método do subgradiente utilizado para atualizar o vetor multiplicador de lagrange. Testes computacionais são 
apresentados analisando a qualidade das soluções obtidas pelo desvio percentual entre os limitantes inferior e superior.

\subsection{Um problema de corte de estoque integrado ao planejamento}

\subsubsection{Descrição do problema}

Nesta seção revisamos o trabalho de Respício e Captivo (2002), que considera um sistema de produção produzindo diferentes tipos de papel referidos como famílias. Bobinas mestre de diferentes famílias são produzidas e depois cortadas em bobinas menores referidas como itens, os quais pertencem a uma família.

Em geral, a capacidade produtiva é menor que a demanda média, levando a longos prazos de entrega. O objetivo é encontrar um plano de produção que determine as quantidades a serem produzidas das diferentes famílias e maximize a utilização do sistema. Estoques são feitos para superar a falta de capacidade e o problema de planejamento deve incorporar as decisões de corte de estoque. A formulação do problema de corte de estoque clássico de Gilmore e Gomory (1963) é estendida nesse trabalho para considerar demanda acumulada e as respectivas restrições de demanda sobre um horizonte de planejamento dividido em períodos de produção. Parte das colunas representa um padrão de corte factível para cortar bobinas mestre de uma dada família em um dado período de produção. São introduzidas restrições de capacidade, limitando o tempo de processamento total de bobinas mestre produzidas e cortadas em cada período. Tempos de corte não são considerados relevantes neste planejamento. Variáveis de estoque iniciais, com custos muito altos, são introduzidas para assegurar a factibilidade do modelo, que correspondem às variáveis artificiais. 


\subsubsection{Formulação do problema}

Considere a seguinte notação:

Índices:

$t=1, \cdots, T:$ horizonte de planejamento;

$i=1, \cdots, M:$ número de itens demandados;

$f=1, \cdots, F$ : número de famílias de produtos.

Parâmetros:

$C_{t}$ : capacidade (em horas) de produção disponível no período $t ;$

$d_{i t}$ : demanda acumulada do item $i$ no período $t$;

$h_{i}$ : custo de estoque unitário inicial do item $i$;

$b_{f}:$ tempo (em horas) de processamento de uma bobina mestre da família $f$

$q_{i j t}$ : número de vezes que o item $i$ é produzido no padrão $j$, usado no período $t$;

Variáveis:

$x_{j f t}$ : número de bobinas mestre da família $f$ cortadas pelo padrão $j$ no período $t$.

$I_{i}$ : estoque inicial do item $i$

As autoras propõem a seguinte formulação, denominada de Problema Mestre: 


$$
\begin{array}{r}
\text { Minimizar } \sum_{i} h_{i} I_{i}+\sum_{t} \sum_{f} \sum_{j} x_{j f t} \\
\text { sujeito a: } \\
\sum_{k=1}^{t} \sum_{j} q_{i j k} x_{j f k}+I_{i} \geq d_{i t}, \quad \forall i, t \neq T \\
\sum_{k=1}^{T} \sum_{j} q_{i j k} x_{j f k}+I_{i}=d_{i T}, \quad \forall i \\
\sum_{f} \sum_{j} b_{f} x_{j f t} \leq C_{t}, \quad \forall t \\
x_{j f t} \geq 0 \text { e inteiro, } \quad \forall j, f, t \\
I_{i} \geq 0 \text { e inteiro, } \quad \forall i
\end{array}
$$

A família $f$ nas restrições (2.11) e (2.12) é tal que contenha o item $i$. Não fosse pelas restrições (2.13), o problema poderia ser decomposto por família (veja tabela 2.1).

A função objetivo a ser minimizada consiste na soma dos custos de estoques iniciais e o número total de bobinas mestre a serem cortadas num horizonte de planejamento. A antecipação na produção pode aumentar os custos de estoque mas, por outro lado, permite uma melhor combinação dos itens a serem cortados, levando a um melhor aproveitamento das bobinas, o que minimiza as perdas.

As restrições de demanda asseguram que a demanda acumulada é satisfeita pela produção acumulada ou pelos níveis de estoque inicial. O estoque não será aumentado no final do horizonte devido às restrições (2.12) assegurando que a demanda acumulada no final do período será cumprida exatamente.

O modelo expressa a integração de um conjunto de problemas de corte de estoque "menores", um para cada família e cada período. As restrições de capacidade em (2.13) integra os problemas de corte de estoque "menores" do mesmo período. As restrições de demanda em (2.11) e (2.12) estabelecem esta conexão no tempo, devido ao manuseio 
da produção acumulada e estoques iniciais. A solução do problema mestre, $\left(x_{j f t}^{*}, I_{i}^{*}\right)$, permite computar o número de bobinas mestre da família $f$ a serem cortadas no período $t$, que é dado por $\sum_{j} x_{j f t}^{*}$, expressando as quantidades a serem produzidas de cada família em cada período.

Não sabemos se há vantagens em se trabalhar com demanda acumulada, como é feito em Respício e Captivo (2002). As restrições (2.11) e (2.12) poderiam ser escritas na forma clássica, como segue:

$$
\sum_{j} q_{i j t} x_{j f t}+I_{i, t-1}-I_{i, t}=d_{i t} \quad \forall i, t
$$

Além disso, este modelo não inclui o sequenciamento entre as famílias de bobinas a serem produzidas, o que apresenta um custo de preparação das máquinas não desprezível.

Para ilustrar a estrutura da matriz de restrições do modelo matemático (2.10)(2.15), considere um exemplo com $F=2, T=2$ e $m=10$. Itens da família 1 são indexados por $i=1, \ldots, 4$ e os da família 2 por $i=5, \ldots, 10$. A tabela 2.1 mostra esta estrutura. 
Tabela 2.1: Estrutura da matriz de restrições do modelo (2.10)-(2.15).

\begin{tabular}{|c|c|c|c|c|c|c|c|}
\hline$(\mathrm{i}, \mathrm{t})$ & $x_{111} x_{211} \ldots$ & $x_{121}$ & $x_{221}$ & .. & $x_{112} x_{212} \ldots$ & $x_{122}$ & $x_{222}$ \\
\hline$(1,1)$ & $q_{111} \quad q_{121} \ldots$ & & & & & & \\
\hline$(2,1)$ & $\begin{array}{lll}q_{211} & q_{221} & \ldots\end{array}$ & & & & & & \\
\hline$(3,1)$ & $q_{311} \quad q_{321} \ldots$ & & & & & & \\
\hline$(4,1)$ & $\begin{array}{lll}q_{411} & q_{421} & \ldots\end{array}$ & & & & & & \\
\hline$(5,1)$ & & $q_{511}$ & & & & & \\
\hline$(6,1)$ & & $q_{611}$ & $q_{621}$ & & & & \\
\hline$(7,1)$ & & $q_{711}$ & $q_{721}$ & & & & \\
\hline$(8,1)$ & & $q_{811}$ & $q_{821}$ & & & & \\
\hline$(9,1)$ & & $q_{511}$ & $q_{921}$ & & & & \\
\hline$(10,1)$ & & $q_{10,1,1}$ & $q_{10,2,1}$ & $\ldots$ & & & \\
\hline$(1,2)$ & $\begin{array}{lll}q_{111} & q_{121} & \ldots\end{array}$ & & & & $q_{112} \quad q_{122} \quad \ldots$ & & \\
\hline$(2,2)$ & $\begin{array}{lll}q_{211} & q_{221} & \ldots\end{array}$ & & & & $q_{212} \quad q_{222} \quad \ldots$ & & \\
\hline$(3,2)$ & $\begin{array}{lll}q_{311} & q_{321} & \ldots\end{array}$ & & & & $\begin{array}{lll}q_{312} & q_{322} & \ldots\end{array}$ & & \\
\hline$(4,2)$ & $\begin{array}{lll}q_{411} & q_{421} & \ldots \\
\end{array}$ & & & & $q_{412} \quad q_{422} \quad \ldots$ & & \\
\hline$(5,2)$ & & $q_{511}$ & $q_{521}$ & & & $q_{512}$ & $q_{522}$ \\
\hline$(6,2)$ & & $q_{611}$ & $q_{621}$ & & & $q_{612}$ & $q_{622}$ \\
\hline$(7,2)$ & & $q_{711}$ & $q_{721}$ & ... & & $q_{712}$ & $q_{722}$ \\
\hline$(8,2)$ & & $q_{811}$ & $q_{821}$ & $\cdots$ & & $q_{812}$ & $q_{822}$ \\
\hline$(9,2)$ & & $q_{511}$ & $q_{921}$ & & & $q_{512}$ & $q_{922}$ \\
\hline$(10,2)$ & & $q_{10,1,1}$ & $q_{10,2,1}$ & $\ldots$ & & $q_{10,1,2}$ & $q_{10,2,2}$ \\
\hline 1 & $b_{1} \quad b_{1}$ & $b_{2}$ & $b_{2}$ & $\ldots$ & & & \\
\hline 2 & & & & & $b_{1} \quad b_{1}$ & $b_{2}$ & $b_{2}$ \\
\hline
\end{tabular}


O problema é tratado por Respício e Captivo usando um algoritmo branch-andprice, que combina geração de coluna com branch-and-bound. No nó raiz da árvore de busca, o problema (2.10)-(2.15) é relaxado e resolvido por otimização linear. Um limite inferior para o ótimo do problema relaxado é obtido usando o método simplex com geração de colunas, introduzido por Gilmore e Gomory, em 1961.

Consideremos apenas o problema (2.10)-(2.15) no nó raiz, sem fazer as ramificações do algoritmo branch-and-bound. Sejam $\pi_{i t}$ e $\sigma_{t}$ as variáveis duais (vetor multiplicador), para uma base qualquer, associadas às restrições de demanda do item $i$ no período $t$, e da restrição de capacidade no período $t$, respectivamente.

Suponha que os itens da família $f$ são indexados por $i=r_{f-1}+1, \ldots, r_{f}$, com $r_{0}=0$ e $r_{f}=\left|I_{f}\right|$, sendo $I_{f}$ o conjunto de itens da família $f$. Seja $\mathbf{a}=\left[\begin{array}{lll}\alpha_{1} & \alpha_{2} \cdots \alpha_{i} \cdots\end{array}\right]$ um padrão de corte para as bobinas mestre da família $f$, cortadas no período $t$. Assim, a coluna da variável $x_{j f t}$, como pode ser verificado na tabela 4.1, tem a seguinte forma:

$$
\mathbf{v}_{j f t}^{T}=\left[\begin{array}{lllllllllllllllllll}
0 & \cdots & 0 & \alpha_{1} & \cdots & \alpha_{i} & \cdots & 0 & \cdots & 0 & \alpha_{1} & \cdots & \alpha_{i} & \cdots & 0 & \cdots & b_{f} & \cdots & 0
\end{array}\right]
$$

Os coeficientes da função objetivo relacionados às colunas da matriz são constantes e iguais a 1. Assim, o custo relativo da variável, cuja coluna é dada por $\mathbf{v}_{j f t}$, pode ser determinado por:

$$
\hat{c}_{j f t}=c\left(\mathbf{v}_{j f t}\right)-\left(\begin{array}{ll}
\Pi & \sigma
\end{array}\right)^{T} \mathbf{v}_{j f t}
$$

Então:

$$
\begin{aligned}
& \hat{c}_{j f t}=1-\left[\begin{array}{lllllllllllllllll}
* & \cdots & * & \pi_{1 t} & \cdots & \pi_{i t} & \cdots & * & \cdots & * & \pi_{1 s} & \cdots & \pi_{i s} & \cdots & \sigma_{1} & \cdots & \sigma_{t} \\
\cdots & \sigma_{T}
\end{array}\right] . \\
& {\left[\begin{array}{lllllllllllllllllll}
0 & \cdots & 0 & \alpha_{1} & \cdots & \alpha_{i} & \cdots & 0 & \cdots & 0 & \alpha_{1} & \cdots & \alpha_{i} & \cdots & 0 & \cdots & b_{f} & \cdots & 0
\end{array}\right]^{T}}
\end{aligned}
$$

ou seja,

$$
\hat{c}_{j f t}=1-\left(\pi_{1 t} \alpha_{1}+\cdots+\pi_{i t} \alpha_{i}+\cdots+\pi_{1 s} \alpha_{1}+\cdots+\pi_{i s} \alpha_{i}+\cdots \sigma_{t} b_{f}\right)
$$


e o subproblema para determinar a coluna da matriz a entrar na base pode ser reescrito como:

$$
\min _{f, t}\left\{1-\left(\sum_{i \in I(f)} \sum_{k=t}^{T} \pi_{i k} \alpha_{i}+\sigma_{t} b_{f}\right): \mathbf{a} \in Q_{f}\right\}
$$

em que $Q_{f}$ é o conjunto de padrões de corte factíveis para as bobinas mestre da família $f$.

Equivalentemente, para uma determinada família $f$ e um período $t$, tem-se o problema da mochila clássico:

$$
\varphi_{f t}(\mathbf{a})=\max \left\{\sum_{i \in I(f)}\left(\sum_{k=t}^{T} \pi_{i k}\right) \alpha_{i}+\sigma_{t} b_{f}: \mathbf{a} \in Q_{f}\right\}
$$

Sejam os seguintes parâmetros:

$l_{i}$ : largura do item $i$;

$L_{f}$ : largura das bobinas mestre da família $f$;

$L^{b}$ : largura mínima das bobinas mestre, devido às restrições de máquina.

Assim, o subproblema para a geração de colunas do problema (2.10)-(2.15) é dado por:

$$
\begin{aligned}
& \varphi_{f t}(\mathbf{a})=\max \left\{\sum_{i \in I(f)} \sum_{k=t}^{T} \pi_{i k} \alpha_{i}+\sigma_{t} b_{f}\right\} \\
& \text { sujeito a }\left\{\begin{array}{l}
L^{b} \leq \sum_{i \in I(f)} \alpha_{i} l_{i} \leq L_{f} \\
\alpha_{i} \geq 0 \text { e inteiro. }
\end{array}\right.
\end{aligned}
$$

Se $1-\left\{\operatorname{Max} \varphi_{f t}(\mathbf{a}), \forall f, \forall t\right\} \geq 0$, então a solução atual resolve a relaxação linear do problema (2.10)-(2.15). Caso contrário, a coluna $\mathbf{v}_{j f t}$ é determinada para entrar na base. 


\subsection{O problema de corte de estoque acoplado à pro- gramação da produção em indústrias de cobre}

Hendry et al. (1996) estudaram o problema de corte acoplado ao problema de planejamento e programação da produção em indústrias de cobre. O processo produtivo pode ser dividido em três partes e consiste basicamente em fundir o metal no forno, produzir barras grandes de comprimento fixo e de diâmetros específicos, $d_{k}, k=1, \cdots, K$, e cortar essas barras em pedaços menores de comprimentos específicos $l_{i}, i=1, \cdots, I$. O objetivo principal é a redução de custos, relacionados diretamente com a redução do número de vezes que o forno é utilizado e com a redução das perdas com o corte das barras.

Foi proposto um método de solução em dois estágios, baseado na estratégia de horizonte rolante. No primeiro estágio, um modelo matemático de programação inteira é resolvido heuristicamente, determinando uma solução agregada que indica o número total de barras de cada diâmetro que deve ser produzido para atender a demanda sobre um período de tempo conhecido e os padrões de corte a serem utilizados, com o objetivo de minimizar a perda. Neste estágio, há a necessidade de levar em conta a capacidade do forno e a demanda dos itens menores, sendo considerados aspectos relacionados aos processos de derretimento e corte, ignorando-se os aspectos relacionados à produção das barras. No segundo estágio, outro modelo de programação inteira é resolvido por um método exato, determinando um programa de produção diária para a solução agregada dada pelo primeiro estágio. Portanto, a solução é desagregada para verificar sua factibilidade em termos das restrições de capacidade que aparecem na produção das barras. Considera-se um horizonte de planejamento de duas semanas, sendo que ele deve ser refeito no ínicio de cada semana, tendo em vista a idéia de horizonte rolante.

Apresentamos os modelos matemáticos propostos pelos autores para os problemas que surgem nos dois estágios de planejamento. No primeiro estágio, deve ser resolvido um problema de corte de estoque multiperíodo unidimensional com restrições de capacidade (veja seção 3.3), modelado a seguir. 
Índices:

$i=1, \cdots, I:$ número de tipos de itens demandados;

$j=1, \cdots, N$ : número de possíveis padrões de corte;

$k=1, \cdots, K$ : número de diferentes diâmetros para as barras.

$t=1, \cdots, T:$ número de períodos (semanas).

Parâmetros:

$a_{i j k}$ : número de vezes que o item de comprimento $l_{i}$ aparece no padrão de corte $j$ para barras de diâmetro $d_{k}$;

$C B_{k}$ : quantidade (ton) de cobre necessária para produzir uma barra de diâmetro $d_{k}$;

$D R_{k}$ : número de barras produzidas por lote de diâmetro $d_{k}$;

$D_{i k}^{t}$ : demanda de itens de comprimento $l_{i}$ e diâmetro $d_{k}$ na semana $t$;

$C$ : capacidade máxima de cobre (ton) para a produção de barras ao longo de $T$ semanas;

$C^{1}$ : capacidade máxima de cobre (ton) para a produção de barras na semana 1.

Variáveis de decisão:

$x_{j k}^{t}$ : número de barras de diâmetro $d_{k}$, cortadas pelo padrão $j$ na semana $t$;

$F D_{k}^{t}$ : número de lotes (de barras) de diâmetro $d_{k}$ produzidos na semana $t$. 
Modelo matemático:

$$
\begin{array}{r}
\text { Minimizar } \sum_{t=1}^{T} \sum_{k=1}^{K} \sum_{j=1}^{N} x_{j k}^{t} \\
\sum_{t=1}^{T} \sum_{k=1}^{K} C B_{k} \sum_{j=1}^{N} x_{j k}^{t} \leq C \\
\sum_{k=1}^{K} C B_{k} \sum_{j=1}^{N} x_{j k}^{t} \leq C^{1} \\
\sum_{j=1}^{N} a_{i j k} x_{j k}^{1} \geq D_{i k}^{1}, \quad k=1, \cdots, K ; \quad i=1, \cdots, I \\
\sum_{t=1}^{T} \sum_{j=1}^{N} a_{i j k} x_{j k}^{t} \geq \sum_{t=1}^{T} D_{i k}^{t}, \quad k=1, \cdots, K ; \quad i=1, \cdots, I \\
F D_{k}^{t}=\frac{1}{D R_{k}} \sum_{j=1}^{N} x_{j k}^{t}, \quad k=1, \cdots, K ; \quad t=1, \cdots, T \\
x_{j k}^{t}, F D_{k}^{t} \geq 0 \text { e inteiros, } k=1, \cdots, K, j=1, \cdots, N, t=1, \cdots, T
\end{array}
$$

O objetivo é minimizar o número de barras usadas o que, consequentemente, minimiza a perda. As restrições (2.19) asseguram que a quantidade de cobre derretido utilizado é menor que a sua disponibilidade ao longo das duas semanas. A quantidade disponível inclui aquela que foi estocada na semana anterior. As restrições (2.20) são similares, mas considera apenas a primeira semana. As restrições (2.21) garantem que a demanda da primeira semana será atendida; da mesma forma, as restrições (2.22) consideram a demanda no período de duas semanas. Finalmente, as restrições (2.23) são acrescentadas para garantir que o número de lotes de barras produzidas seja inteiro.

Os autores propõem métodos heurísticos para resolver o problema de corte modelado em (2.18)-(2.24), obtendo uma solução agregada ao longo do horizonte de planejamento. Posteriormente, essa solução é desagregada e um problema de dimensionamento de lotes deve ser resolvido para obter uma programação diária da produção. O modelo proposto 
pelos autores é apresentado a seguir.

Índices:

$m=1, \cdots, M:$ número de dias;

$k=1, \cdots, K$ : número de diâmetros para as barras.

Parâmetros:

$M D_{k}$ : número máximo de lotes (de barras) de diâmetro $d_{k}$ por dia;

$D W_{k}$ : quantidade (em peso) de cobre necessário para produzir um lote de diâmetro $d_{k}$;

$E_{1}$ : estoque de cobre derretido mantido até o primeiro dia;

$T_{k}$ : tempo necessário para produzir um lote de diâmetro $d_{k}$;

$C O$ : tempo gasto na mudança da produção de barras de um diâmetro para outro;

$C A P$ : capacidade diária de produção de barras (em minutos);

$\beta$ : porcentagem de cobre derretido que pode ser usado;

$M S$ : quantidade máxima de cobre derretido que pode ser armazenado;

$M A X$ : quantidade máxima de pedaços de cobre que pode ser derretida diariamente;

MIN : quantidade mínima de pedaços de cobre que pode ser derretida diariamente.

Variáveis de decisão:

$M C_{m}$ : peso dos pedaços de cobre derretidos no dia $m$;

$Y_{k m}$ : número de lotes de barras de diâmetro $d_{k}$ produzidos no dia $m$;

$E_{m}$ :estoque de cobre derretido disponível no final do dia $m$;

$M C_{m}^{\prime}$ : variável binária, sendo $M C_{m}^{\prime}=1$ se $M C_{m}>0$ e zero, caso contrário.

$Z_{k m}$ : variável binária: 1 se as barras de diâmetro $d$ são produzidas na dia $m$ e 0 caso contrário. 
Modelo matemático:

$$
\begin{aligned}
& \text { Minimizar } \sum_{m=1}^{M}\left(\sum_{k=1}^{K} Y_{k m} T_{k}+I D_{k m} C O\right) \\
& \text { sujeito a: } \\
& \sum_{m=1}^{M} Y_{k m}=F D_{k}^{1}, \quad k=1, \cdots, K \\
& \sum_{k=1}^{K} D W_{k} Y_{k m}+E_{m-1}-E_{m}=\beta M C_{m}, \quad m=1, \cdots, M \\
& E_{m} \leq M S, \quad m=1, \cdots, M \\
& M C_{m} \geq M I N-M A X\left(1-M C_{m}^{\prime}\right), \quad m=1, \cdots, M \\
& M C_{m} \leq M C_{m}^{\prime} M A X, \quad m=1, \cdots, M \\
& \sum_{k=1}^{K} T_{k} Y_{k m}+I D_{k m} C O \leq C A P, \quad m=1, \cdots, M \\
& Y_{k m} \leq M D_{k} Z_{k m}, \quad m=1, \cdots, M ; \quad k=1, \cdots, K \\
& Y_{k m} \geq Z_{k m}, \quad m=1, \cdots, M ; \quad k=1, \cdots, K \\
& M C_{m}, E_{m} \geq 0, \quad m=1, \cdots, M ; \quad k=1, \cdots, K \\
& Y_{k m} \geq 0 \quad \text { e inteiro, } \quad m=1, \cdots, M ; \quad k=1, \cdots, K \\
& M C_{m}^{\prime}, Z_{m} \in\{0,1\}, \quad m=1, \cdots, M ; \quad k=1, \cdots, K
\end{aligned}
$$

O objetivo é minimizar o tempo necessário para produzir as barras, incluindo o tempo de preparação para a mudança de um diâmetro para outro. A rigor, qualquer solução factível para este segundo problema viabiliza o plano de produção do estágio 
anterior. A função objetivo do segundo modelo busca atender ao plano com o mínimo de tempo necessário, que pode ser visto como um objetivo secundário, mas de interesse operacional.

As restrições (2.26) asseguram que o número total de lotes produzidos durante a primeira semana é igual ao número indicado na solução do primeiro estágio. As restrições (2.27) garantem que a quantidade de cobre derretido num dia, multiplicado pelo fator de correção $\beta$, é igual à quantidade utilizada na produção das barras mais o estoque do dia anterior menos o que vai ficar estocada para o próximo dia. O conjunto de restrições (2.28) garante que a quantidade armazenada de um dia para outro é limitada pela capacidade máxima de armazenagem. As restrições (2.29) e (2.30) asseguram que o peso de cobre derretido por dia é nulo ou está entre as quantidades mínima e máxima. As restrições (2.31) garantem que o tempo total necessário para produzir as barras é menor ou igual à capacidade diária. O procedimento de solução para o problema integrado se assemelha ao procedimento Corte-Lote (veja seção 5.3), o qual decompõe o problema. Os autores não discutem um possível processo iterativo, como no procedimento Lote-Corte (veja seção $5.2)$.

\subsection{O problema de alocação de pedidos às máquinas em indústrias papeleiras}

Menon \& Schrage (2002) consideram o problema composto de alocação de pedidos às máquinas de papel e corte de bobinas em itens finais (bobinas menores) e propõem uma abordagem de decomposição, baseada na construção de limitantes inferiores que estimam a necessidade de bobinas para atender a demanda, sem a necessidade de resolver problemas de corte.

Considera-se um ciclo de produção de 6 semanas (único período), ou seja, o problema é estático. No contexto adotado, um pedido é definido como uma lista de itens finais de diferentes larguras e demandas especificadas. Cada pedido pode ser, por exemplo, itens de mesma gramatura, embora esta questão não foi abordada pelos autores. Na próxima seção, este modelo é estendido para considerar a gramaturaCada pedido deve ser alocado à uma das máquinas e os problemas de corte resolvidos para cada máquina. Por questões 
operacionais, como, por exemplo, uniformidade do produto, identificação dos pedidos, distribuição das máquinas na indústria e distribuição dos produtos para os clientes, um pedido deve ser feito exclusivamente por uma única máquina de papel.

O problema composto é formulado como um problema de programação inteira, com o objetivo de minimizar o custo total de produção. O modelo matemático é apresentado a seguir.

Índices:

$m=1, \cdots, M$ : número de máquinas;

$i=1, \cdots, I:$ número de itens demandados;

$j=1, \cdots, N_{m}$ : número de possíveis padrões de corte para bobinas produzidas pela máquina $m$;

$k=1, \cdots, K:$ número de pedidos.

Parâmetros:

$c_{m}$ : custo de cada bobina na máquina $m$;

$u_{m}$ : número máximo de bobinas que podem ser produzidas e cortadas na máquina $m$;

$d_{i k}$ : demanda de itens de largura $i$ no pedido $k$;

$a_{i j m}$ : número de itens de largura $l_{i}$ cortados pelo padrão $j$ da bobina da máquina m.

Variáveis de decisão:

$x_{j m}$ : número de bobinas produzidas pela máquina $m$, cortadas pelo padrão $j$;

$y_{k m}=1$ : variáveis binárias que indicam se o pedido $k$ é alocado ou não à máquina $m$.

Observação: Embora não tenha sido explicitado pelos autores, as bobinas são padronizadas e cada uma delas é cortada segundo um único padrão de corte. Esta discussão será detalhada na seção 3.2, e tais bobinas padronizadas são chamadas bobinas-mestre. 
Modelo matemático:

$$
\begin{aligned}
& \text { Minimizar } \sum_{j=1}^{N_{m}} \sum_{m=1}^{M} c_{m} x_{j m} \\
& \text { sujeito a: } \\
& \sum_{j=1}^{N_{m}} x_{j m} \leq u_{m}, \quad m=1, \cdots, M \\
& \sum_{j=1}^{N_{m}} a_{i j m} x_{j m} \geq \sum_{k=1}^{K} d_{i k} y_{k m}, \quad i=1, \cdots, I, m=1, \cdots, M \\
& \sum_{m=1}^{N_{m}} y_{k m}=1, \quad k=1, \cdots, K \\
& y_{k m} \in\{0,1\}, \quad k=1, \cdots, K, m=1, \cdots, M \\
& x_{j m} \in\{0,1,2, \cdots\}, \quad j=1, \cdots, N_{m}, m=1, \cdots, M
\end{aligned}
$$

O conjunto de restrições (2.38) garantem que a produção em cada máquina não exceda a sua capacidade. As restrições (2.39) garantem o atendimento da demanda e as restrições (2.40) obrigam que cada pedido deve ser alocado em apenas uma máquina. Dado um vetor de alocação $\mathbf{y}$, o problema fica decomposto em $m$ subproblemas de corte, um para cada máquina.

A título ilustrativo, considere um exemplo com duas máquinas de papel e dois pedidos de diferentes itens, como mostra a tabela 2.2. Os pedidos podem ser, por exemplo, de dois clientes e envolvem itens de mesma gramatura.

Tabela 2.2: Dados dos itens demandados.

\begin{tabular}{|c|c|c||c|c|c|}
\hline \multicolumn{3}{|c||}{ Pedido 1 } & \multicolumn{3}{c|}{ Pedido 2 } \\
\hline \hline Tipo de item & Demanda & Largura & Tipo de item & Demanda & Largura \\
\hline 1 & 30 & 21 & 1 & 20 & 21 \\
2 & 50 & 33 & 3 & 10 & 50 \\
3 & 20 & 50 & 4 & 35 & 31 \\
\hline
\end{tabular}


As variáveis de alocação são $y_{k m}, k=1,2, m=1,2$. Se tivermos $y_{11}=1$ e $y_{21}=0$, então $y_{12}=0$ e $y_{22}=1$, ou seja, o pedido 1 será atendido pela máquina 1 e o pedido 2 pela máquina 2. Entretanto, se $y_{11}=1$ e $y_{21}=1$, isso quer dizer que os dois pedidos serão atendidos pela máquina 1 , que agrupados formam um só pedido para esta máquina, como está representado pela tabela 2.3. Observe que, por definição, não pode ocorrer de parte de um mesmo pedido ser atendido por máquinas diferentes, por exemplo, 50 unidades do item 1 sendo produzidas a partir de bobinas da máquina 1 e 30 unidades do item 3 produzidas pela máquina 2 .

Tabela 2.3: Novo pedido para a máquina 1.

\begin{tabular}{|c|c|}
\hline Tipo de item & Demanda \\
\hline 1 & 50 \\
2 & 50 \\
3 & 30 \\
4 & 35 \\
\hline
\end{tabular}

A abordagem apresentada pelos autores para resolver o problema composto usa limitantes inferiores facilmente calculados para o problema de corte relaxado, considerando a transformação de variável $v_{m}=\sum_{j} x_{j m}$ para toda máquina $m$. Estes limitantes inferiores são usados para formular um problema relaxado para o problema composto (2.37)-(2.42). Quando esses limitantes estão muito próximos do valor ótimo dos subproblemas de corte, o problema relaxado fornece um limitante inferior apertado para o problema composto. Isso quer dizer que o problema relaxado fornece um conjunto de valores para as variáveis $y_{k m}$ próximos do ótimo. O problema relaxado é formulado como: 


$$
\begin{array}{r}
\text { Minimizar } \sum_{m}^{M} c_{m} v_{m} \\
\text { sujeito a: } \\
v_{m} \leq u_{m}, \quad m=1, \cdots, M \\
v_{m} \geq L I_{m}(\mathbf{y}), \quad m=1, \cdots, M \\
\sum_{m}^{M} y_{k m}=1, \quad k=1, \cdots, K \\
v_{m} \geq 0, \quad m=1, \cdots, M \\
y_{k m} \in\{0,1\}, \quad k=1, \cdots, K,
\end{array}
$$

sendo $v_{m}$ o número estimado de bobinas a serem produzidas e cortadas na máquina $\mathrm{m}$. As restrições (2.44) conservam a produção estimada dentro da capacidade. O conjunto de restrições (2.45) exige que o número de bobinas produzidas na máquina $m$ seja suficiente para atender a demanda ( $L I_{m}$ é uma estimativa da quantidade mínima necessária).

Os autores propõem seis limitantes para o problema de corte e afirmam que alguns deles são muito bons quando são usados para dados reais. O mais simples de ser obtido e o mais otimista é o limitante baseado na área de papel demandado. O número de bobinas usadas é, no mínimo, igual à área total das larguras demandadas dividida pela largura da máquina, isto é, se $l_{i}$ é a largura do item i, $L$ a largura da máquina de papel e $d_{i}$ a demanda do item $i$, então o limite é dado por:

$$
L A=\left\lceil\frac{\sum_{i=1}^{I} l_{i} d_{i}}{L}\right\rceil
$$

A restrição correspondente à máquina $m$ no modelo (restrição (2.45)) é dada por: 


$$
v_{m} \geq \sum_{k=1}^{K}\left(\frac{\sum_{i=1}^{I} l_{i} d_{i k}}{L_{m}}\right) y_{k m}
$$

Como exemplo, considere os dois pedidos ilustrados na tabela (2.2) e uma máquina $m$ que produz bobinas de largura $L_{m}=100$. Calculando os limites para os pedidos 1 e 2 ( $L A_{1}$ e $L A_{2}$, respectivamente), obtêm-se:

$$
\begin{aligned}
& L A_{1}=\frac{30 * 21+50 * 33+20 * 50}{100}=\frac{3280}{100}=32,8 \\
& L A_{2}=\frac{20 * 21+10 * 50+35 * 31}{100}=\frac{2005}{100}=20,05
\end{aligned}
$$

Sendo assim, a restrição (2.45) para a máquina $m$ fica:

$$
v_{m} \geq 32,80 y_{1 m}+20,05 y_{2 m}
$$

Segundo os autores, se os limitantes obtidos são muito próximos dos valores ótimos (como é o caso do problema na indústria de papel), então é necessário resolver o problema relaxado apenas uma vez para obter o conjunto de variáveis de alocação, e posteriormente resolver cada problema de corte separadamente, uma vez que y tendo sido fixo, o problema (2.37)-(2.42) se decompõe em vários problemas de corte.

\subsection{Alocação, sequenciamento e corte integrados na indústria de papel}

Correia (2005) considera a resolução de forma integrada dos problemas de alocação, sequenciamento e corte na indústria de papel, sob a perspectiva da minimização do desperdício de papel produzido. O objetivo é elaborar um plano de produção de um conjunto de pedidos de mesmo tipo de papel e mesma gramatura, admitindo-se a possibilidade de produção de cada pedido numa das máquinas de papel disponíveis, com características técnicas próprias. Por questões operacionais, assim como é feito em Menon \& Schrage (2002), o atendimento de um pedido deverá ser executado exclusivamente a partir da 
produção de uma única máquina. A produção contínua de um determinado tipo de papel é feita em gramaturas crescentes ou decrescentes, sendo que a transição entre as gramaturas produz papel em quantidade dependente da sequencia e que, por ser de baixa qualidade, deve ser considerado como desperdício. Nestas condições, a autora propõe o planejamento da produção integrando a resolução de três sub-problemas: alocação dos pedidos às várias máquinas, sequenciamento das diversas gramaturas em cada uma das máquinas e definição de quantidades e padrões de corte envolvendo itens de pedidos de mesma gramatura.

Considerando, inicialmente, a alocação dos pedidos às diversas máquinas de papel, a autora propõe uma adaptação do modelo apresentado por Menon \& Schrage (2002), revisado na seção 2.4, que integra o problema de alocação dos pedidos às máquinas com o processo de corte, com o objetivo de minimizar o custo total de produção. Este modelo foi construído com base no problema de corte, ao qual foram acrescentadas restrições de capacidade das máquinas e incluídas variáveis binárias para representar a alocação dos pedidos (modelo (2.37)-(2.42)).

A alocação de pedidos de diferentes gramaturas a uma mesma máquina implica na necessidade de definir o sequenciamento a ser adotado na produção de tais gramaturas. Neste contexto, a autora propõe uma extensão do modelo (2.37)-(2.42), integrando também o problema de sequenciamento dos produtos numa máquina ao problema de alocação dos pedidos. Para o problema de sequenciamento, em que se pretende considerar o conjunto completo de permutações entre as diversas gramaturas, a modelagem identifica-se com a formulação teórica do problema conhecido na literatura como Problema do Caixeiro Viajante. A solução deste problema tem como objetivo determinar o menor percurso fechado que um vendedor deve fazer para visitar um conjunto de cidades (vértices), sendo que cada cidade deve ser visitada uma única vez. Na sua formulação como um problema de programação inteira, é definida uma matriz de custos associados aos diversos arcos do grafo $T=\left(t_{p q}\right)$, e as variáveis binárias $\tau_{p q}$, da seguinte forma:

$$
\tau_{p q}= \begin{cases}1, & \text { se a cidade } q \text { é visitada imediatamente após a cidade } p \\ 0, & \text { caso contrário. }\end{cases}
$$


A formulação matemática adotada para o problema do caixeiro viajante é a seguinte:

$$
\begin{gathered}
\text { Minimizar } \sum_{p \in V} \sum_{q \in V} t_{p q} \tau_{p q} \\
\sum_{q \in V} \tau_{p q}=1, \quad \forall p \in V \\
\text { sujeito a: } \\
\sum_{p \in V} \tau_{p q}=1, \quad \forall q \in V, \\
\forall W: 1 \leq|W| \leq n-1 \in V, \\
\sum_{p \in V} \sum_{q \in V} \tau_{p q} \leq|W|-1, \quad \forall p, \quad \forall p \in V,
\end{gathered}
$$

considerando o grafo orientado $G=(V, A)$, sendo $V$ o conjunto dos $n$ vértices, $A$ o conjunto dos arcos e $W \subset V$.

As restrições (2.50) e (2.51) definem o conjunto completo de permutações entre os $n$ vértices a serem visitados e as restrições (2.52) elimina a possibilidade de sub-rotas entre um subconjunto $W$ de vértices.

A integração do problema de sequenciamento das gramaturas na formulação apresentada anteriormente para o problema de alocação e corte de encomendas ((2.37)-(2.42)) torna necessário a definição matemática de um subconjunto de gramaturas associadas aos pedidos alocados a uma mesma máquina. Sendo $G$ o conjunto dos índices das gramaturas incluídas no plano de produção, para cada máquina $m$ define-se:

$$
G_{m}=\left\{g \in G: y_{k m}=1 \text { e } k \text { é um pedido de gramatura } g\right\}, m=1, \cdots, M \text {. }
$$

Ou seja, $G_{m}$ é o conjunto de gramaturas alocadas à máquina $m$ que depende da solução y.

Dessa forma, a autora propõe o seguinte modelo de programação inteira mista que integra os problemas de sequenciamento, alocação e corte de papel: 


$$
\begin{aligned}
& \text { Minimizar } \sum_{j} \sum_{m} c_{m} x_{j m}+\sum_{m} \sum_{p \in G_{m}} \sum_{q \in G_{m}} c_{m} t_{p q m} \tau_{p q m} \\
& \text { sujeito a: } \\
& \sum_{j} x_{j m}+\sum_{p \in G_{m}} \sum_{q \in G_{m}} t_{p q m} \tau_{p q m} \leq u_{m}, \quad \forall m \\
& \sum_{j} a_{i j m} x_{j m} \geq \sum_{k} d_{i k} y_{k m}, \quad \forall i, m \\
& \sum_{m} y_{k m}=1, \quad \forall k \\
& \sum_{q \in G_{m}} \tau_{p q m}=1, \quad \forall p \in G_{m}, \forall k \\
& \sum_{p \in G_{m}} \tau_{p q m}=1, \quad \forall q \in G_{m}, \forall k \\
& \sum_{p \in G_{m}} \sum_{q \in G_{m}} \tau_{p q m} \leq|W|-1, \quad \forall k, \forall W \subset G_{m}: 1 \leq|W| \leq n-1 \\
& x_{j m} \geq 0, \quad \forall j, m \\
& y_{k m} \in\{0,1\}, \quad \forall k, m \\
& \tau_{p q m} \in\{0,1\}, \quad \forall p, q \in G_{m}, \forall m
\end{aligned}
$$

sendo:

$t_{p q m}$ : fração da bobina desperdiçada associada à mudança da gramatura $p$ para a gramatura $q$, produzida na máquina $m$;

$\tau_{p q m}= \begin{cases}1, & \text { se a gramatura } q \text { é produzida logo após a gramatura } p, \text { na máquina } m \\ 0, & \text { caso contrário. }\end{cases}$

Diante da complexidade do problema integrado, a autora exclui a possibilidade de aplicação de técnicas convencionais, tais como algoritmos de enumeração implícita. A inclusão das restrições relativas ao sequenciamento das gramaturas resulta num acréscimo de complexidade, por causa da dificuldade de resolução do problema do caixeiro viajante. 
É proposta, então, uma abordagem sequencial, dividida em três passos, que permite obter uma solução heurística para o problema em questão. Esta abordagem está representada esquematicamente na figura 2.4 e descrita a seguir.

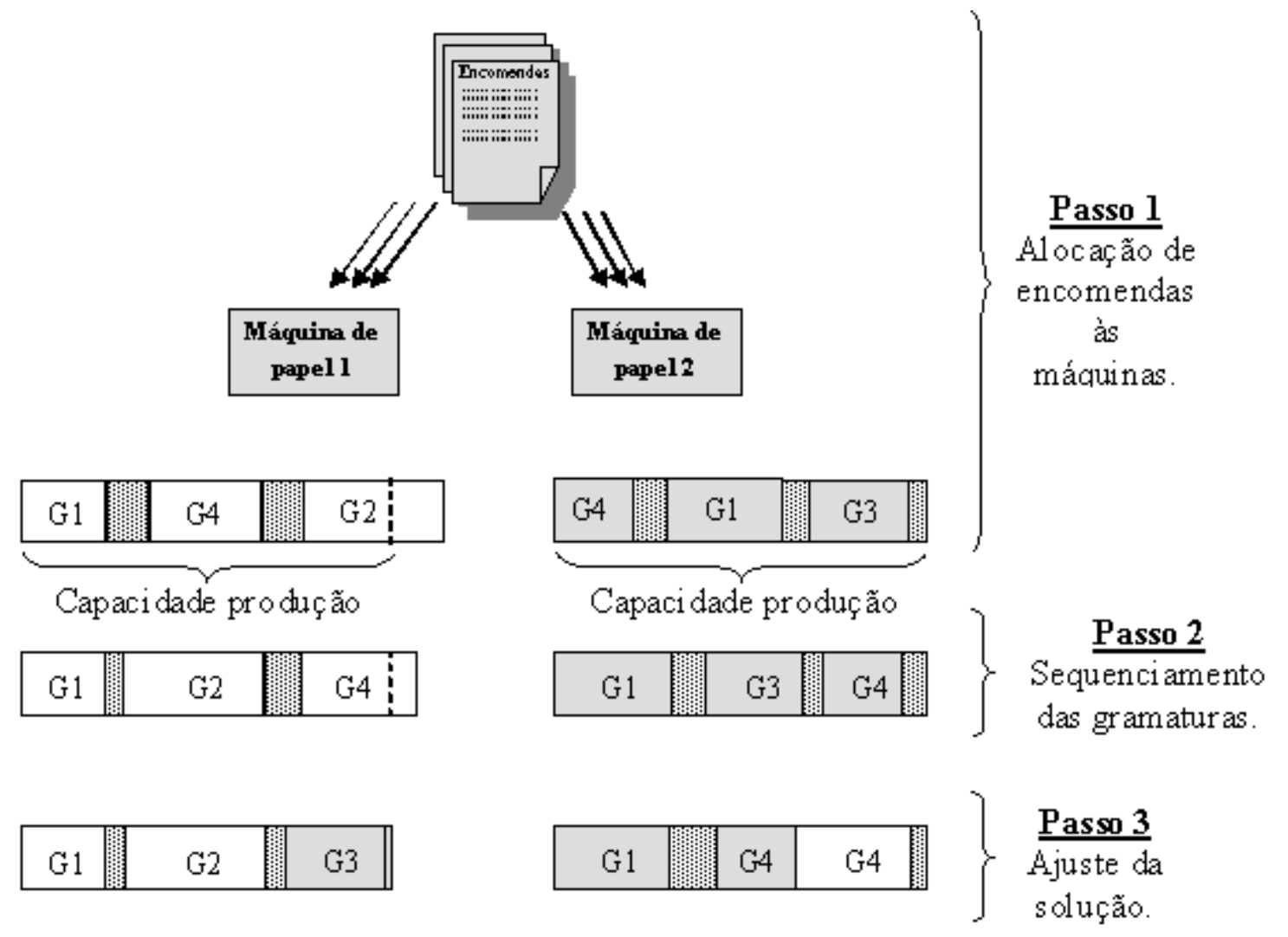

Figura 2.4: Método heurístico para os problemas de sequenciamento, alocação e corte.

\section{Método heurístico:}

Passo 1 : Inicialmente, considera-se apenas os problemas de alocação de pedidos e respectivo corte, ignorando, em termos da quantidade de papel produzido, o impacto associado à mudança de gramaturas numa mesma máquina. A resolução deste problema reduzido, modelado em (2.37)-(2.42), baseia-se na abordagem proposta por Menon \& Schrage (2002). Assumindo uma solução factível y, fica definida uma possível alocação do conjunto de pedidos às máquinas de papel. Apesar dos limites de capacidade das máquinas serem considerados no modelo (2.37)-(2.42), o processo de resolução adotado considera apenas os limites inferiores das quantidade de papel, não garantindo o cumprimento das restrições de capacidade. 
Passo 2 : Com base na solução obtida no passo 1, procede-se ao sequenciamento das gramaturas a serem produzidas, incluindo o desperdício de papel com a transição entre gramaturas na avaliação da quantidade de papel a ser produzida em cada máquina. O processo de sequenciamento adotado orienta-se pelas regras práticas que definem esse procedimento no ambiente industrial que consiste em considerar apenas a possibilidade de produção por ordem crescente ou decrescente das gramaturas. O critério de ordenação é determinado pela solução que apresenta menor quantidade de papel desperdiçado. A solução resultante pode ser admissível para o problema completo, dependendo do cumprimento ou não das restrições relativas às capacidades das máquinas, que, mais uma vez, não estão garantidas.

Passo 3 : O melhoramento da solução obtida no passo 2 é feito pelo ajuste da designação das gramaturas a cada uma das máquinas. Para tal, consideram-se os pedidos de mesma gramatura, cortados numa mesma máquina, como entidades indivisíveis que são realocados à máquinas diferentes. A heurística proposta usa as características particulares do problema, tentando simultaneamente garantir o cumprimento das restrições de capacidade das máquinas e atingir soluções com menor quantidade de papel utilizado. 


\section{Capítulo 3}

\section{O problema de corte de estoque}

\section{integrado à produção de bobinas de papel}

\subsection{Processo produtivo}

No processo de produção e corte de papel, o problema de dimensionamento de lotes (PDL) deve ser considerado inicialmente para decidir qual deve ser o peso de jumbos (bobinas grandes de papel) produzidos em cada período de um horizonte de planejamento. Os jumbos são produzidos em máquinas paralelas, que têm capacidades limitadas e desempenhos próprios.

A largura e o peso máximo de cada jumbo depende da máquina na qual é produzido. Por exemplo, uma máquina pode produzir jumbos de $460 \mathrm{~cm}$ de largura pesando cerca de 12 toneladas e outra máquina pode produzir jumbos de $540 \mathrm{~cm}$ de largura pesando acima de 24 toneladas.

Diferentes tipos de papel (de diferentes gramaturas) devem ser produzidos para atender a demanda e a mudança de uma gramatura para outra causa perda relevante de papel e perda de tempo de máquina, sendo o custo e o tempo de preparação (setup) dependentes da sequência. Por simplicidade, consideramos custo e tempo de preparação independentes da sequência.

Na prática, um jumbo pode consistir de diferentes tipos de papel (gramaturas), 
incluindo um papel de qualidade inferior (considerado como perda) devido à transição de uma gramatura para outra (veja Fig. 3.1). Entretanto, para efeito de modelagem e sem perda de generalidade, podemos considerar que cada jumbo consiste de apenas um tipo de papel. Então, a Figura 3.1 seria de dois jumbos, um de gramatura $i$ e outro de gramatura $j$.

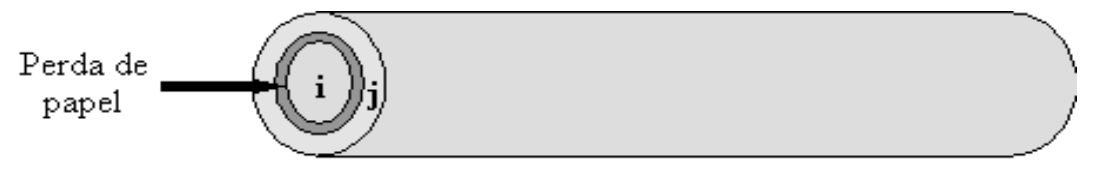

Figura 3.1: Bobina-jumbo: gramatura $i$, perda e gramatura $j$.

Posteriormente os jumbos são cortados em bobinas menores de larguras dadas (que podem ser cortadas em retângulos) para atender a demanda com perda mínima. Trata-se, dessa forma, de um problema de corte de estoque (PCE) usual.

O processo de produção e corte de jumbos numa indústria de papel é ilustrado de forma simplificada na Figura 3.2.

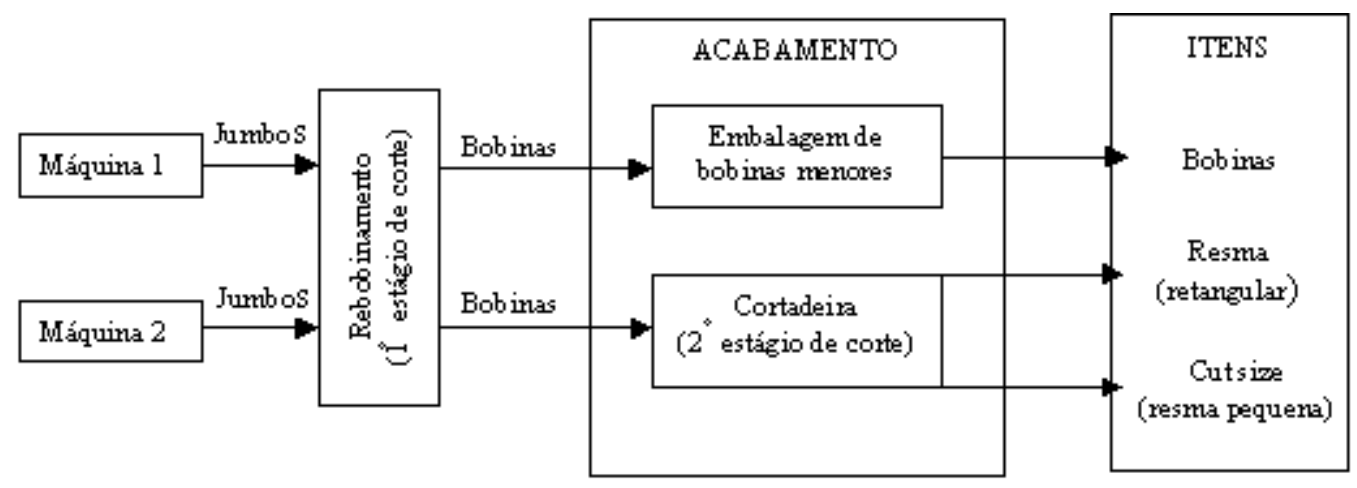

Figura 3.2: Processo de produção simplificado de uma indústria de papel

A produção é baseada numa carteira de pedidos e em itens para estoque. Estão disponíveis para produção máquinas que produzem jumbos (bobinas grandes de papel) de diferentes larguras. Os jumbos passam, então, para o setor de rebobinamento, onde são realizados cortes longitudinais, que fornecem bobinas menores (intermediárias). Já no setor de acabamento, uma parte dessas bobinas intermediárias é embalada e despachada. As demais passam pela cortadeira que, por cortes transversais e longitudinais, produzem 
resmas de vários tamanhos (retângulos, que podem ser A4 $29,7 \times 21 \mathrm{~cm}), \mathrm{A} 5(21 \times 14,8 \mathrm{~cm})$, entre outros), de acordo com a demanda. Supõe-se que, em cada período, a cortadeira tem capacidade suficiente para cortar todos os jumbos produzidos neste período. Dessa forma, o que limita a quantidade de itens finais cortados em cada período é a capacidade das máquinas de produção dos jumbos.

Tipicamente, o problema da produção de jumbos é resolvido empiricamente por gerentes peritos em produção, que objetivam principalmente a minimização do setup. Sendo assim, lotes de jumbos são produzidos sem dar atenção ao próximo estágio, que é o corte desses jumbos e cuja perda durante o processo depende das características dos jumbos (larguras e quantidades) produzidos previamente.

As melhores larguras e quantidades de jumbos em termos do processo de corte podem introduzir setups altos no processo de produção, de modo que esses dois problemas, o problema de dimensionamento de lotes e o problema de corte de estoque, são interdependentes e devem ser resolvidos de uma maneira integrada.

A título de ilustração, a Tabela 3.1 dá uma parte das informações da demanda de um cliente com 5 diferentes tipos de itens (bobinas menores: itens 1 e 2, ou retângulos: itens 3,4 e 5) e as características relevantes num período de tempo fixo $t$.

Tabela 3.1: Demanda de um cliente no período t.

\begin{tabular}{|c|c|c|c|}
\hline Itens & Tamanho & Tipo & Quantidade (ton) \\
\hline \hline 1 & $l_{1}$ & 1 & $d_{1 t}$ \\
\hline 2 & $l_{2}$ & 2 & $d_{2 t}$ \\
\hline 3 & $l_{3} \times w_{3}$ & 2 & $d_{3 t}$ \\
\hline 4 & $l_{4} \times w_{4}$ & 3 & $d_{4 t}$ \\
\hline 5 & $l_{5} \times w_{5}$ & 1 & $d_{5 t}$ \\
\hline
\end{tabular}

Note na Tabela 3.1 que alguns itens são do mesmo tipo de papel, por exemplo, os itens 2 e 3 são do tipo 2. Além disso, a demanda do papel tipo 2 no período $t$, de acordo com a Tabela 3.1, é $d_{2 t}+d_{3 t}$. Isso deve ser levado em conta na decisão da produção dos jumbos, entretanto, em qual máquina os jumbos de cada tipo devem ser produzidos? (As máquinas produzem larguras particulares e têm diferentes desempenhos). Mais ainda, 
qual deve ser a quantidade de papel de cada tipo produzida em cada máquina? Essas questões devem ser respondidas com o intuito de minimizar, por um lado, os custos e tempos de setups e custos de produção e, por outro, a perda no processo de corte.

\subsection{Modelagem matemática}

Para tornar mais fácil a construção de um modelo matemático, consideramos um jumbo do tipo $k$ e largura $L_{s} \mathrm{~cm}$ (lembre-se que essa largura depende da máquina em que o jumbo foi produzido) representado por um número de bobinas-mestre, todas elas de mesmo peso específico $\rho_{k}$ definido previamente como ilustrado na Fig. 3.3.

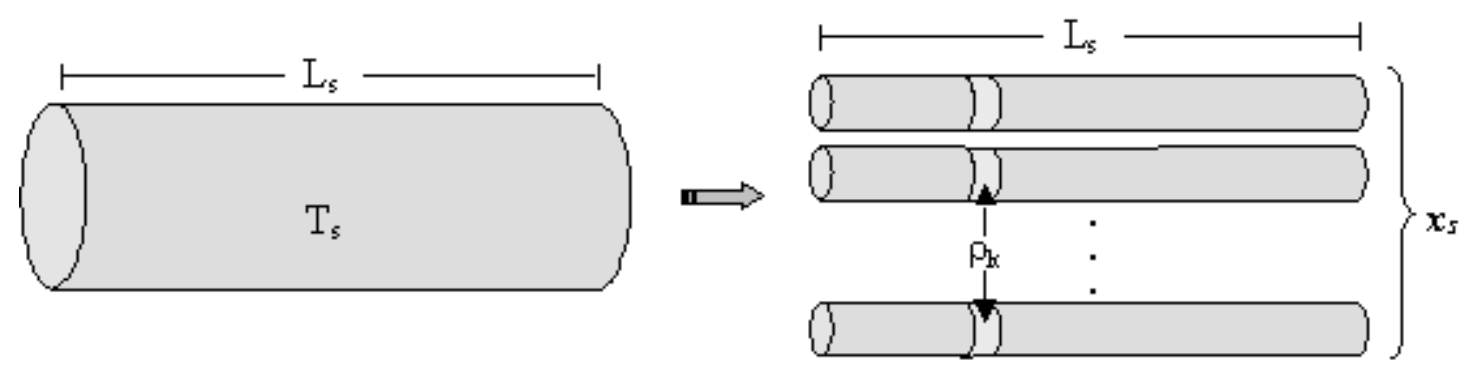

Figura 3.3: Um jumbo do tipo $k$ discretizado em um número de bobinas-mestre.

Por exemplo, se definimos previamente que as bobinas-mestre do tipo $k$ devem ser de tal forma que seu peso específico seja $\rho_{k}=0.1 \frac{\mathrm{kg}}{\mathrm{cm}}$, então cada bobina-mestre de $540 \mathrm{~cm}$ de largura deve pesar $54 \mathrm{~kg}$ e cada bobina-mestre de $460 \mathrm{~cm}$ de largura deve pesar $46 \mathrm{~kg}$.

Além disso, suponha que $x_{s}$ é o número de bobinas-mestre de largura $L_{s} \mathrm{~cm}$, então o peso do jumbo correspondente, $T_{s}$, é dado por $T_{s}=L_{s} \rho_{k} x_{s}$. Por exemplo, $x_{s}=20$ bobinasmestre de $540 \mathrm{~cm}$ de largura corresponde a um jumbo de $540 \mathrm{~cm}$ de largura pesando 1.080 $\mathrm{kg}$ (considerando $\left.\rho_{k}=0.1 \frac{\mathrm{kg}}{\mathrm{cm}}\right)$.

Note que, se cortarmos um item de $l_{i}=30 \mathrm{~cm}$ de largura de qualquer bobina-mestre ele pesará $l_{i} \rho_{k}=3 \mathrm{~kg}$. Sendo assim, se a demanda de um item de $30 \mathrm{~cm}$ de largura do tipo $k$ é $300 \mathrm{~kg}$, então precisamos de 100 deles cortados de bobinas-mestre do tipo k, mas de qualquer largura, como ilustra a Fig. 3.4. Além disso, as bobinas-mestre fornecem uma maneira de tratar o problema 1,5-dimensional, ou seja, se um jumbo corresponde, como antes, a $x_{s}=20$ bobinas-mestre (isto é, um jumbo de 1,080 kg é visto como 20 bobinas-mestre) e 5 delas forem cortados segundo um padrão de corte e as 15 restantes 
forem cortadas segundo outro padrão de corte, então isso significa que o jumbo inteiro (que pesa $1,080 \mathrm{~kg}$ ) teve $270 \mathrm{~kg}$ cortados segundo o primeiro padrão de corte e $810 \mathrm{~kg}$ cortados de acordo com o segundo padrão de corte.

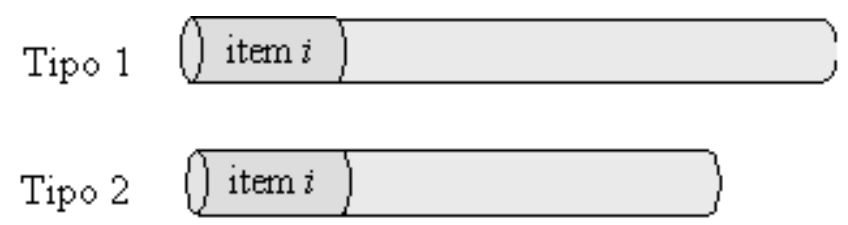

Figura 3.4: Bobinas-mestre do tipo $k$ fixo e larguras diferentes.

Essa abordagem introduz uma dificuldade ao problema de dimensionamento de lotes, pois exige que a variável de decisão seja inteira. Porém, quanto menor $\rho_{k}$ maior é $x_{s}$ e, sendo assim, a discretização do jumbo em bobinas-mestre tende a representar o jumbo de forma contínua.

Para descrever o modelo matemático consideramos a seguinte notação e os seguintes dados.

Índices:

$t=1, \cdots, T:$ número de períodos no horizonte de planejamento;

$k=1, \cdots, K$ : número de tipos de papel (gramatura);

$m=1, \cdots, M:$ número de máquinas (máquina $m$ produz bobinas-mestre de largura $L_{m}$ );

$j=1, \cdots, N_{m}$ : número de padrões de corte para as bobinas-mestre do tipo $m$;

$i=1, \cdots, N f:$ número de itens demandados;

$\{1, \cdots, N f\}=S(1) \cup S(2) \cup \ldots S(K)$, sendo $S(k)=\{i$ tal que o item $i$ é de gramatura $k\}$.

Parâmetros:

$c_{k m t}:$ custo de produção da bobina-mestre de tipo $k$ na máquina $m$ no período $t ;$

$h_{k t}:$ custo/ton de estocar bobinas-mestre de tipo $k$ no final do período $t$; 
$s_{k m t}:$ custo de preparação da máquina $m$ para produzir uma bobina-mestre de tipo $k$ no período $t$;

$c p_{k t}:$ custo/cm de perda de papel de tipo $k$ durante o processo de corte, no período $t$;

$\sigma_{i t}:$ custo/ton de estocagem de itens finais do tipo $i$ no período $t$;

$C_{m t}$ : capacidade (ton) da máquina $m$ no período $t$

$\mathbf{d}_{k t}$ : vetor da demanda de itens finais de papel de tipo $k$ no período $t$. Sua dimensão é igual $|S(k)|$;

$\rho_{k}$ : peso específico da bobina-mestre de tipo $k$;

$\eta_{k}$ : vetor de pesos dos itens finais de papel de tipo $k$ (o peso do item final $i$ de tipo $k$ e largura $l_{i}$ é dado por $\left.\eta_{i k}=\rho_{k} l_{i}\right)$;

$D_{k t}$ : demanda (ton) de papel de tipo $k$ no período $t$

$b_{k m}$ : peso da bobina-mestre de tipo $k$ produzida na máquina $m\left(b_{k m}=L_{m} \rho_{k}\right)$;

$f_{k m}$ : peso do papel desperdiçado na prepraração da máquina $m$ para a produção da bobina-mestre de tipo $k$;

$\mathbf{a}_{j m}$ : vetor associado ao padrão de corte $j$ para a bobina-mestre de largura $L_{m}$. Sua dimensão é $|S(k)|$ e cada componente $a_{i j m}$ representa o número de itens $i, i \in S(k)$, cortados pelo padrão $j$ da bobina-mestre de largura $L_{m}$;

$p_{j m}:$ perda de papel $(\mathrm{cm})$ no padrão de corte $j$ usado para cortar uma bobina-mestre de largura $L_{m}$

$Q$ : número grande.

Variáveis de decisão:

$x_{k m t}:$ número de bobinas-mestre de tipo $k$ produzidas na máquina $m$ no período $t$;

$w_{k m t}$ : número de bobinas-mestre de tipo $k$ produzidas na máquina $m$ estocadas no fim do período $t$ 
$z_{k m t}$ : variáveis binárias que indicam a produção ou não da bobina-mestre de tipo $k$ na máquina $m$ no período $t$;

$y_{k m t}^{j}$ : número de bobinas-mestre de tipo $k$ produzidas na máquina $m$ no período $t$, que são cortadas usando o padrão de corte $j$;

$\mathbf{e}_{k t}$ : vetor de itens finais de tipo de papel $k$ que são estocados no final do período $t$. Sua dimensão é $|S(k)|$ e cada componente $e_{i k t}$ representa o número de itens finais $i$, $i \in S(k)$ em estoque no final do período $t$.

\section{Observações:}

1. O parâmetro $D_{k t}$, que representa a quantidade total de papel do tipo $k$ que deve estar disponível no período $t$, não é um dado do problema, pois depende da perda que ocorre durante o processo de corte. Por definição, ele deve ser: $D_{k t}=\sum_{i \in S(K)} \eta_{i k} d_{i k t}+$ perda. Como a perda é desconhecida, inicialmente, introduzimos um novo parâmetro $\theta$, que é uma estimativa para a perda.

2. Por outro lado, o parâmetro $D_{k t}$ pode ser expresso em termos das variáveis que determinam o número de bobinas-mestre do tipo $k$ que deve ser cortada no período $t$, isto é, $D_{k t}=\sum_{m=1}^{M} \sum_{j=1}^{N_{m}} b_{k m} y_{k m t}^{j}$.

Portanto, um modelo para o problema de corte acoplado à programação da produção de jumbos pode ser formulado como: 


$$
\begin{aligned}
& \text { Minimizar } \sum_{t=1}^{T} \sum_{m=1}^{M} \sum_{k=1}^{K}\left(c_{k m t} x_{k m t}+h_{k t} b_{k m} w_{k m t}+s_{k m t} z_{k m t}\right)+\sum_{t=1}^{T} \sum_{k=1}^{K} c p_{k t} F(k, t)+ \\
& +\sum_{t=1}^{T} \sum_{k=1}^{K} \sum_{i \in S(k)} \sigma_{i t} \eta_{i k} e_{i k t} \\
& \text { sujeito a: } \quad \sum_{m=1}^{M}\left(b_{k m} x_{k m t}+b_{k m} w_{k, m, t-1}-b_{k m} w_{k m t}\right)=D_{k t}, \quad k=1, \cdots, K ; t=1, \cdots, T \\
& \sum_{k=1}^{K}\left(b_{k m} x_{k m t}+f_{k m} z_{k m t}\right) \leq C_{m t}, \quad m=1, \cdots, M ; t=1, \cdots, T \\
& x_{k m t} \leq Q z_{k m t}, \quad k=1, \cdots, K ; m=1, \cdots, M ; t=1, \cdots, T \\
& \sum_{m=1}^{M} \sum_{j=1}^{N_{m}} \mathbf{a}_{j m} y_{k m t}^{j}+\mathbf{e}_{k, t-1}-\mathbf{e}_{k t}=\mathbf{d}_{k t}, \quad k=1, \cdots, K ; t=1, \cdots, T \\
& \sum_{j=1}^{N_{m}} y_{k m t}^{j}=x_{k m t}+w_{k, m, t-1}-w_{k m t}, k=1, \cdots, K ; m=1, \cdots, M ; t=1, \cdots, T(3 \\
& w_{k m 0}=0, \mathbf{e}_{k 0}=0, \quad k=1, \cdots, K ; m=1, \cdots, M \\
& x_{k m t} \geq 0, w_{k m t} \geq 0 \text { e inteiros, } \quad k=1, \cdots, K ; m=1, \cdots, M ; t=1, \cdots, T \\
& z_{k m t} \in\{0,1\}, \quad k=1, \cdots, K ; m=1, \cdots, M ; t=1, \cdots, T \\
& y_{k m t}^{j} \geq 0 \text { e inteiros, } e_{k t} \geq 0 \\
& j=1, \cdots, n_{m} ; k=1, \cdots, K ; m=1, \cdots, M ; t=1, \cdots, T
\end{aligned}
$$

As restrições de balanceamento de estoque (3.2) descrevem que, para cada tipo de papel e, em cada período, a quantidade total produzida (ton) (em qualquer máquina m) mais o estoque do período anterior deve atender a demanda mais o estoque para o próximo período. As restrições (3.3) indicam que a quantidade total de papel produzido, de qualquer tipo $k$, mais a perda de papel devido à mudança de gramatura, é limitada pela capacidade da máquina $m$ em qualquer período. Observe que as variáveis $x_{k m t}$ e $w_{k m t}$ estão multiplicadas por $b_{k m}=L_{m} \rho_{k}$, pois a demanda de papel é dada em peso. 
Nas restrições (3.4), temos $z_{k m t}=1$ no caso de $x_{k m t}>0$. Se $x_{k m t}=0$, então a otimalidade força $z_{k m t}=0$. Em (3.5), note que $\sum_{m=1}^{M} \sum_{j=1}^{N_{m}} \mathbf{a}_{j m} y_{k m t}^{j}$ fornece um vetor com o total de itens de cada tipo cortados no período $t$ e as restrições (3.5) são as equações de balanceamento de estoque de itens. As restrições (3.6) limitam o número de bobinasmestre cortadas àquelas que foram produzidas anteriormente. São estas as restrições de acoplamento que envolvem decisões relativas à produção e ao corte de jumbos.

Os estoques iniciais são considerados nulos em (3.7) sem perda de generalidade. Isto porque, se o estoque inicial for diferente de zero, ele pode ser abatido das demandas dos primeiros períodos até que se torne nulo. As demais restrições garantem a não negatividade, a integralidade e binaridade das variáveis de decisão.

A função objetivo (3.1) é uma composição de vários objetivos, tais como custos de produção e estoque, custos de setup, custo de perda no processo de corte, sendo que a perda é dada por $F(k, t)=\sum_{m=1}^{M} \sum_{j=1}^{N_{m}} p_{j m} y_{k m t}^{j}$, e custos de estoque dos itens finais.

Um dos problemas que aparece no modelo acoplado é um problema de dimensionamento de lotes capacitado, em um ambiente com máquinas paralelas distintas. Segundo Maes et al. (1991), o problema de encontrar uma solução factível quando consideramos perdas na preparação da máquina é NP-completo. Devido à dificuldade de resolver este problema, a maioria dos métodos encontrados na literatura são heurísticos (Trigeiro et al., 1989; Lozano et al., (1991); Hindi et al., 2003). Além disso, as restrições de corte possuem dois fatores que tornam essa formulação muito difícil. O primeiro é a condição de integralidade das variáveis $y_{k m t}^{j}$ e o segundo fator é o grande número de variáveis (há uma variável para cada padrão). Gilmore e Gomory $(1961,1963)$ propuseram uma técnica de geração de colunas no método simplex para o problema com a condição de integralidade relaxada, que é um método poderoso para o problema de corte de estoque. Boas heurísticas de arredondamento da solução, com o intuito de obter uma solução inteira, podem ser desenvolvidas (Wäscher and Gau, 1996).

Também podemos observar pelas restrições (3.5) que o problema de corte de estoque que aparece no modelo acoplado deve ser resolvido num horizonte de planejamento dividido em períodos, considerando-se o estoque de itens no final de cada período $t$, para cada gramatura $k$, dado pelo vetor de variáveis $\mathbf{e}_{k t}$. Ou seja, existe uma interdependência entre as decisões de corte nos diferentes períodos por causa dessas variáveis de estoque. 
A esse problema chamamos de problema de corte multiperíodo, o qual definimos a seguir.

\subsection{Problema de corte de estoque multiperíodo}

O problema de corte de estoque multiperíodo surge em várias situações práticas, por exemplo na indústria de papel, onde considera-se um horizonte de planejamento da produção dividido em períodos, sendo que, em cada período, uma demanda de itens, dividida por gramatura, deve ser atendida. Dessa forma, procurando otimizar o processo de corte geral, é permitido ou não antecipação de itens. Isto permite que novas combinações sejam consideradas, pois um item de largura $l_{i}$ que não é demandado em determinado período, pode ser antecipado se sua combinação com os demais itens do período faz diminuir a perda de material. São consideradas variáveis de estoque dos itens finais e o objetivo é minimizar a perda de papel e os custos com o estoque dos itens e das bobinas-mestre ao longo do horizonte de planejamento. Aqui, supomos que a cortadeira tem capacidade suficiente para cortar todas as bobinas-mestre produzidas em cada período, ou seja, o que limita a quantidade de itens finais cortados em cada período é a capacidade das máquinas de produção das bobinas. O estoque de bobinas-mestre não utilizados em um período, fica disponível no próximo, juntamente com os jumbos produzidos ou adquiridos.

Considerando-se os índices, parâmetros e variáveis já definidos na seção 3.2 para o problema acoplado, o problema de corte de estoque multiperíodo, para uma gramatura fixa $k$, pode ser modelado como: 


$$
\begin{aligned}
& \text { Minimizar } \sum_{t=1}^{T} c p_{k t} \sum_{m=1}^{M} \sum_{j=1}^{N_{m}} p_{j m} y_{k m t}^{j}+\sum_{t=1}^{T} \sum_{i \in S(k)} \sigma_{i t} e_{k t}+\sum_{t=1}^{T} \sum_{m=1}^{M} h_{k t} b_{k m} w_{k m t} \\
& \text { sujeito a: } \sum_{m=1}^{M} \sum_{j=1}^{N_{m}} \mathbf{a}_{j m} y_{k m t}^{j}+\mathbf{e}_{k, t-1}-\mathbf{e}_{k t}=\mathbf{d}_{k t}, \quad t=1, \cdots, T \\
& \sum_{j=1}^{N_{m}} y_{k m t}^{j}=x_{k m t}+w_{k, m, t-1}-w_{k m t}, \quad m=1, \cdots, M ; t=1, \cdots, T \\
& w_{k m 0}=0, e_{k 0}=0, \quad k=1, \cdots, K ; m=1, \cdots, M \\
& y_{k m t}^{j} \geq 0 \text { e inteiros, } \mathbf{e}_{k t} \geq 0, \quad j=1, \cdots, N_{m} ; m=1, \cdots, M ; t=1, \cdots, T
\end{aligned}
$$

A função objetivo (3.11) minimiza a soma dos custos com a perda de papel durante o processo de corte no horizonte de planejamento e os custos com o estoque das bobinasmestre e dos itens cortados antecipadamente, em cada período. Aqui, $p_{j m}$, que consiste na perda de papel com o corte de uma bobina-mestre de largura $L_{m}$, segundo o padrão $j$, é dada por: $p_{j m}=L_{m}-\sum_{i=1}^{N f} l_{i} a_{i j m}$.

A antecipação do corte de alguns itens pode aumentar os custos de estoque $\left(e_{i k t}\right)$ mas, por outro lado, pode permitir uma melhor combinação dos itens, o que minimiza a perda de papel e, consequentemente, o custo associado. As restrições no modelo asseguram que a demanda original seja cumprida e a disponibilidade de bobinas-mestre em estoque, em cada período, não seja ultrapassada. Nas restrições $(3.13), x_{k m t}$ representa a quantidade de bobinas-mestre de largura $L_{m}$ disponíveis no período $t$, sendo, assim, um dado do problema. Observe que, no modelo acoplado (3.1)-(3.10), $x_{k m t}$ representa o número de bobinas-mestre produzidas, tratando-se de uma variável (de acoplamento) do problema. As bobinas-mestre disponíveis em estoque no período $t$ e não utilizadas, são adicionadas as que estarão disponíveis no período $t+1$, considerando-se o custo de estoque $h_{k t}$ na função objetivo.

A tabela 3.2 mostra a estrutura matricial das restrições do modelo, considerando-se 3 períodos $(t=1,2,3)$ e bobinas-mestre de 2 diferentes larguras $(m=1,2)$. Considere $\mathbf{u}^{T}=(1 \cdots 1)$ e o vetor das frequências dos padrões de corte $\mathbf{y}_{k m t}$, cujas componentes são $y_{k m t}^{j}$. 
Tabela 3.2: Estrutura matricial do modelo (3.11)-(3.15) para $T=3$ e $M=2$.

\begin{tabular}{|c|c|c|c|c|c|c|}
\hline $\mathbf{A}_{111} \mathbf{y}_{k 11}+\mathbf{A}_{21} \mathbf{y}_{k 21}$ & $-\mathbf{e}_{k 1}$ & & & & & $=\mathbf{d}_{k 1}$ \\
\hline $\mathbf{u}^{T} \mathbf{y}_{k 11}$ & $+w_{k 11}$ & & & & & $=x_{k 11}$ \\
\hline \multirow[t]{7}{*}{$\mathbf{u}^{T} \mathbf{y}_{k 21}$} & $+w_{k 21}$ & & & & & $=x_{k 21}$ \\
\hline & $+\mathbf{e}_{k 1}$ & $+\mathbf{A}_{12} \mathbf{y}_{k 12}+\mathbf{A}_{22} \mathbf{y}_{k 22}$ & $-\mathbf{e}_{k 2}$ & & & $=\mathbf{d}_{k 2}$ \\
\hline & $-w_{k 11}$ & $+\mathbf{u}^{T} \mathbf{y}_{k 12}$ & $+w_{k 12}$ & & & $=x_{k 12}$ \\
\hline & $-w_{k 21}$ & $\mathbf{u}^{T} \mathbf{y}_{k 22}$ & $+w_{k 22}$ & & & $=x_{k 22}$ \\
\hline & & & $+\mathbf{e}_{k 2}$ & $+\mathbf{A}_{13} \mathbf{y}_{k 13}+\mathbf{A}_{23} \mathbf{y}_{k 23}$ & $-\mathbf{e}_{k 3}$ & $=\mathbf{d}_{k 3}$ \\
\hline & & & $-w_{k 12}$ & $+\mathbf{u}^{T} \mathbf{y}_{k 13}$ & $+w_{k 13}$ & $=x_{k 13}$ \\
\hline & & & $-w_{k 22}$ & $+\mathbf{u}^{T} \mathbf{y}_{k 23}$ & & $3=x_{k 23}$ \\
\hline
\end{tabular}

Embora o problema de corte com vários tipos de objetos em estoque e múltiplos períodos aparece frequentemente no planejamento e programação da produção em indústrias, são raros os trabalhos na literatura que integram o corte dos itens nos vários períodos, permitindo antecipações (a aplicação na indústria de barras de cobre, seção 2.3, é uma das raras publicações). No próximo capítulo, descrevemos dois métodos de solução para o PCE multiperíodo: solução lote por lote (tipicamente utilizada na prática) e uma heurística de antecipação, procurando verificar o impacto de considerar a possibilidade de antecipação do corte de itens na função objetivo. 


\section{Capítulo 4}

\section{Métodos de solução para o problema de corte de estoque multiperíodo}

\subsection{Solução lote por lote}

O problema de corte de estoque sobre um horizonte de planejamento apresentado na seção 3.3 é composto por $K$ subproblemas independentes, ou seja, um para cada gramatura. Além disso, para cada $k$, as restrições estão acopladas por causa das variáveis de estoque dos itens finais $e_{i k t}$ (que são as componentes do vetor $\mathbf{e}_{k t}$ ). Sendo assim, se ignoramos estas variáveis de acoplamento, obtemos $K T$ subproblemas de corte independentes (um para cada gramatura e cada período). Isso significa que não existe estoque de itens, isto é, nenhum item é produzido além do que foi demandado no período. Esta solução com os estoques de itens nulos não permite combinações melhores dos itens no período, que possam ser examinadas para diminuir a perda de papel. Os PCE's são resolvidos para $t=1, \ldots, T$, e as sobras de bobinas-mestre no período $t$ são adicionadas às quantidades disponíveis de bobinas-mestre no período $t+1$ (no modelo (3.11)-(3.15) da seção 3.3 a disponibilidade é $\left.x_{k, m, t+1}\right)$. Essas idéias são organizadas a seguir.

$\underline{\text { Solução lote por lote: }}$

Seja $W_{k m t}$ a quantidade de bobinas-mestre de gramatura $k$ e de largura $L_{m}$ disponíveis 
no período $t$.

Faça $W_{k m 1}=x_{k m 1}$ (supomos que não há estoque de bobinas-mestre no início do planejamento).

Para $k=1$ até $K$ faça:

Para $t=1$ até $T$ faça:

- Resolva o PCE:

$$
\begin{aligned}
\text { minimizar } & \sum_{m=1}^{M} \sum_{j=1}^{N_{m}} p_{j m} y_{k m t}^{j} \\
\text { sujeito a } & \sum_{m=1}^{M} \sum_{j=1}^{N_{m}} \mathbf{a}_{j m} y_{k m t}^{j}=\mathbf{d}_{k t} \\
& \sum_{j=1}^{N_{m}} y_{k m t}^{j} \leq W_{k m t} \quad m=1, \cdots, M \\
& y_{k m t}^{j} \geq 0 \quad j=1, \cdots, N_{m} ; m=1, \cdots, M
\end{aligned}
$$

e obtenha $y_{k m t}^{j}$ (número de bobinas-mestre de largura $L_{m}$ cortadas pelo padrão $j$ ).

- Determine $w_{k m t}=W_{k m t}-\sum_{j=1}^{n_{m}} y_{k m t}^{j}$ (variável de estoque ignorada na resolução do PCE).

- Faça $W_{k, m, t+1}=x_{k, m, t+1}+w_{k m t}$ (disponibilidade de bobinas-mestre para o período $t+1)$.

A solução lote por lote, que resolve um PCE por período, é comumente empregada na prática.

\subsection{Solução usando heurística de antecipação de itens}

As variáveis de estoque de itens finais permitem que as demandas de vários pedidos sejam agregadas e sugerem antecipações na produção desses itens, o que pode gerar 
padrões de corte melhores, diminuindo, assim, a perda de papel e, conseqüentemente, o custo total, que mede o compromisso entre as perdas menores e o custo de estocar. Inicialmente, essas variáveis, dadas por $e_{i k t}$, são ignoradas no PCE. Isto faz com que os problemas (um para cada gramatura) sejam decompostos por período. Assim, fixandose a gramatura, resolvemos um PCE para cada período, considerando que o número de bobinas-mestre em estoque é dado pela soma da disponibilidade de bobinas para este período com o estoque de bobinas do período anterior, após o corte dos itens finais demandados (solução lote por lote, descrita na seção 4.1). Dessa forma, a solução lote por lote para o PCE escolhe quais bobinas ficarão em estoque no período $t$.

A partir da solução lote por lote, baseado nos multiplicadores simplex associados aos itens finais (isto é, variáveis duais associadas às restrições (4.2)), realizamos antecipações de itens a serem cortados em um determinado período $t$ para o período $t-1$, obedecendo as restrições de estoque, como está descrito no algoritmo a seguir.

Heurística de antecipação de itens no PCE:

Determine a solução lote por lote (seção 4.1) e sejam $\pi_{k t}^{i}$ os multiplicadores simplex associados às restrições (4.2) do modelo para o PCE.

Para $k=1$ até $K$ faça:

Para $t=1$ até $T-1$ faça:

Se $w_{k m t}>0$, para algum $m$, então realize os passos de 1 a 5 .

$\underline{\text { Passo 1: }}$ Considere o conjunto de itens favoráveis ao corte no período $t$ dado por:

$$
I F_{t}=\left\{i \text { tal que } \pi_{k t}^{i}<0 \quad \text { e } d_{k, t+1}^{i}>0\right\}
$$

isto é, itens que têm os multiplicadores simplex associados às restrições (4.2) negativos e têm demanda positiva no período $t+1$. O multiplicador negativo fornece a taxa de variação decrescente da função perda por unidade de item $i$, ou seja, com mais itens do tipo $i$, a perda pode ser reduzida.

Passo 2: Para $m=1$ até $M$ faça: 
Se $w_{k m t}>0$ então realize os passos 2.1 e 2.2. (por decisão anterior, para algum $\left.m, w_{k m t}>0\right)$

2.1: Resolva:

$$
\begin{array}{ll}
\text { minimizar } & \sum_{i \in I F_{t}} \pi_{k t}^{i} \alpha_{k m t}^{i} \\
\text { sujeito a: } & \left\{\begin{array}{l}
\sum_{i \in I F_{t}} l_{i} \alpha_{k m t}^{i} \leq L_{m} \\
0 \leq \alpha_{k m t}^{i} \leq d_{k, t+1}^{i} \quad \text { e inteiros }
\end{array}\right.
\end{array}
$$

sendo $\alpha_{k m t}^{i}$ o padrão de corte para a bobina de largura $L_{m}$.

2.2: Faça $\alpha_{k m t}=w_{k m t} \alpha_{k m t}$.

Passo 3: Determine:

$$
D A_{k t}^{i}=\min \left\{d_{k, t+1}^{i}, \sum_{m=1}^{M} \alpha_{k m t}^{i}\right\}
$$

em que $D A_{k t}^{i}$ é a demanda do item $i$ a ser antecipada do período $t+1$ para o período $t$, de gramatura $k$.

Passo 4: Atualize as demandas dos períodos $t$ e $t+1$ :

$$
d_{k t}^{i} \leftarrow d_{k t}^{i}+D A_{k t}^{i} \quad \text { e } \quad d_{k, t+1}^{i} \leftarrow d_{k, t+1}^{i}-D A_{k t}^{i}
$$

\section{Passo 5:}

5.1: Resolva o PCE (4.1)-(4.4) para o período t, com a demanda atualizada. Determine $w_{k m t}=W_{k m t}-\sum_{j=1}^{N_{m}} y_{k m t}^{j}$.

5.2: Resolva o PCE (4.1)-(4.4) para o período $t+1$ com a demanda de itens obtida no passo 4 e a disponibilidade de bobinas-mestre atualizada: $W_{k, m, t+1}=$ $x_{k, m, t+1}+w_{k m t}$.

5.3: Atualize o estoque de bobinas-mestre no período $t+1$ :

$$
w_{k, m, t+1}=W_{k, m, t+1}-\sum_{j=1}^{N_{m}} y_{k, m, t+1}^{j}
$$


A heurística proposta para a antecipação de itens no PCE procura recuperar a relevância do vetor de variáveis $\mathbf{e}_{k t}$, que havia sido ignorada. Com isso, buscamos melhorar o aproveitamento das bobinas em estoque, combinando melhor os itens finais, objetivando um custo inferior com a perda de papel durante o processo de corte.

Naturalmente, o problema de corte de estoque sobre um horizonte de planejamento (que chamamos como "o problema de corte de estoque multiperíodo") pode ser resolvido considerando-se as variáveis de estoque dos itens todas juntas. Entretanto, isto acarretaria num excessivo esforço computacional para ser usado como um procedimento embutido em outro algoritmo, tal como o algoritmo lote/corte, que é do tipo lagrangiano (apresentado no capítulo 5). A heurística simples de antecipação de itens descrita anteriormente é suficiente para diminuir a perda no processo de corte e mostrar a importância de resolver ambos os problemas juntos.

\subsection{Experimentos computacionais}

Nesta seção, apresentamos os resultados obtidos a partir da implementação da heurística de solução lote por lote (geralmente utilizada na prática) e da heurística de antecipação de itens, propostas para resolver o problema de corte de estoque multiperíodo. As implementações foram desenvolvidas utilizando o ambiente integrado de desenvolvimento de programação Delphi.

\subsubsection{Conjunto de dados}

As heurísticas propostas foram testadas em uma série de exemplos gerados aleatoriamente, classificados de acordo com o número de itens demandados $(N f=5,10)$ e o número de gramaturas $(K=2,4,6)$. Com isso, foram obtidas 6 classes, com 10 exemplos em cada classe. Para cada classe, consideramos um horizonte de planejamento de 8 períodos e bobinas-mestre em estoque de duas diferentes larguras $\left(L_{1}=540 \mathrm{~cm}\right.$ e $L_{2}=460 \mathrm{~cm}$ ). O peso específico da bobina-mestre foi fixado de gramatura $k$ foi fixado em $\rho=2 \mathrm{~kg} / \mathrm{cm}$. Alguns parâmetros foram gerados, simulando situações encontradas na indústria de papel, como descrito a seguir. 
- Custo de estoque da bobina-mestre: $h_{k t} \in\left[\begin{array}{ll}0.0000075 & 0.0000125\end{array}\right], k=1, \cdots, K, t=$ $1, \cdots, T$

- custo de estoque do item $i$ no final do período $t: \sigma_{i t}=0.5 \cdot h_{k t}, i \in S(k), k=$ $1, \cdots, K, t=1, \cdots, T$

- larguras dos itens (bobinas) finais: $l_{i} \in\left[\begin{array}{ll}0.1 & 0.3\end{array}\right] \cdot \frac{\sum_{m=1}^{M} L_{m}}{M}, i=1, \cdots, N f$;

- demanda de itens finais: $d_{i k t} \in\left[\begin{array}{ll}0 & 300\end{array}\right], \quad i=1, \cdots, N f, k=1, \cdots, K, t=$ $1, \cdots, T$. Se $d_{i k t} \leq 50$ então faça $d_{i k t}=0$.

Para cada exemplo, foi resolvido inicialmente o problema de dimensionamento de lotes, considerando-se a demanda total de itens, produzindo, assim, o estoque de bobinasmestre de cada gramatura e cada largura, disponível em cada período (dado de entrada para o problema de corte multiperíodo). Em alguns casos, o problema de dimensionamento de lotes é infactível (capacidade de produção de bobinas-mestre foi insuficiente) e o exemplo foi desconsiderado.

\subsubsection{Apresentação e análise dos resultados obtidos}

As tabelas 4.1 e 4.2 resumem os resultados obtidos para os exemplos gerados. As colunas "Perda" em "Solução lote por lote" e "Heur. Antecipação" apresentam a quantidade de papel desperdiçado durante o processo de corte ao longo do horizonte de planejamento, utilizando-se, respectivamente, as heurísticas lote por lote e de antecipação de itens. Da mesma forma, as colunas "Custo total" representam a soma dos custos associados às perdas, dos custos de estoque das bobinas e de estoque de itens finais. Finalmente, as duas últimas colunas representam a diminuição em percentual da perda e do custo associado, obtidos pela heurística de antecipação de itens, quando comparamos aos da solução lote por lote. Esses GAP's são calculados por:

$$
\left(\frac{\text { Perda(lote por lote) }- \text { Perda(antecipação) }}{\text { Perda(lote por lote) }} \times 100\right) \text { e }\left(\frac{\text { Custo(lote por lote) }- \text { Custo(antecipação) }}{\text { Custo(lote por lote) }} \times 100\right) \text {, }
$$

respectivamente. A última linha da tabela representa a média dos valores obtidos nos 10 exemplos testados. 
Tabela 4.1: Exemplos gerados considerando-se $N f=5$ e $T=8$.

\begin{tabular}{|c|c|c|c|c|c|c|c|}
\hline \multirow{2}{*}{$\begin{array}{c}\text { No. } \\
\text { Gramaturas }\end{array}$} & \multirow[b]{2}{*}{ Exemplo } & \multicolumn{2}{|c|}{ Solução lote por lote } & \multicolumn{2}{|c|}{ Heur. Antecipação } & \multicolumn{2}{|c|}{ Gap (\%) } \\
\hline & & $\begin{array}{c}\text { Perda } \\
(\mathrm{kg})\end{array}$ & $\begin{array}{c}\text { Custo total } \\
(\$)\end{array}$ & $\begin{array}{c}\text { Perda } \\
(\mathrm{kg})\end{array}$ & $\begin{array}{c}\text { Custo total } \\
\qquad(\$)\end{array}$ & Perda & Custo total \\
\hline \multirow{10}{*}{$K=2$} & 1 & 2897 & 580 & 2524 & 427 & 12.9 & 12.1 \\
\hline & 2 & 1632 & 353 & 1803 & 390 & -10.4 & -10.4 \\
\hline & 3 & 1783 & 365 & 1171 & 242 & 34.4 & 33.9 \\
\hline & 4 & 632 & 127 & 542 & 109 & 14,3 & 14.3 \\
\hline & 5 & 1610 & 284 & 1270 & 224 & 21.1 & 21.0 \\
\hline & 6 & - & - & - & - & - & - \\
\hline & 7 & 3794 & 691 & 3577 & 651 & 5.7 & 5.7 \\
\hline & 8 & - & - & - & - & - & - \\
\hline & 9 & 1441 & 309 & 1187 & 256 & 17.6 & 17.2 \\
\hline & 10 & 6644 & 1356 & 6676 & 1364 & -0.5 & -0.6 \\
\hline \multirow{10}{*}{$\mathrm{K}=4$} & 11 & 8004 & 1474 & 6448 & 1192 & 19.4 & 19.1 \\
\hline & 12 & 13126 & 2745 & 9642 & 2018 & 26.5 & 26.5 \\
\hline & 13 & 6005 & 1262 & 5794 & 1223 & 3.5 & 3.0 \\
\hline & 14 & 4227 & 844 & 3859 & 773 & 8.7 & 8.4 \\
\hline & 15 & - & - & - & - & - & - \\
\hline & 16 & 14497 & 2872 & 10890 & 2158 & 24.9 & 24.9 \\
\hline & 17 & 4321 & 1012 & 5019 & 1177 & -16.1 & -16.3 \\
\hline & 18 & 10075 & 1956 & 8366 & 1625 & 17.0 & 16.9 \\
\hline & 19 & 4981 & 1067 & 5398 & 1156 & -8.4 & -8.4 \\
\hline & 20 & 5765 & 929 & 5515 & 888 & 4.3 & 4.4 \\
\hline \multirow{10}{*}{$\mathrm{K}=6$} & 21 & 27487 & 5197 & 29336 & 5557 & -6.7 & -6.9 \\
\hline & 22 & 21121 & 4419 & 19478 & 4080 & 7.8 & 7.7 \\
\hline & 23 & - & - & - & - & - & - \\
\hline & 24 & - & - & - & - & - & - \\
\hline & 25 & 7887 & 1390 & 7848 & 1383 & 0.5 & 0.5 \\
\hline & 26 & - & - & - & - & - & - \\
\hline & 27 & - & - & - & - & - & - \\
\hline & 28 & 24159 & 4954 & 19529 & 4008 & 19.2 & 19.1 \\
\hline & 29 & 9830 & 1731 & 8430 & 1491 & 14.2 & 13.9 \\
\hline & 30 & 7990 & 1257 & 7619 & 1203 & 4.6 & 4.3 \\
\hline \multicolumn{2}{|c|}{ Média } & 8952 & 1746 & 4023 & 1590 & 9.1 & 8.9 \\
\hline
\end{tabular}


Tabela 4.2: Exemplos gerados considerando-se $N f=10$ e $T=8$.

\begin{tabular}{|c|c|c|c|c|c|c|c|}
\hline \multirow{2}{*}{$\begin{array}{c}\text { No. } \\
\text { Gramaturas }\end{array}$} & \multirow[b]{2}{*}{ Exemplo } & \multicolumn{2}{|c|}{ Solução lote por lote } & \multicolumn{2}{|c|}{ Heur. Antecipação } & \multicolumn{2}{|c|}{ Gap (\%) } \\
\hline & & $\begin{array}{r}\text { Perda } \\
(\mathrm{kg})\end{array}$ & $\begin{array}{c}\text { Custo total } \\
(\$)\end{array}$ & $\begin{array}{r}\text { Perda } \\
(\mathrm{kg})\end{array}$ & $\begin{array}{c}\text { Custo total } \\
\qquad(\$)\end{array}$ & Perda & Custo total \\
\hline \multirow{10}{*}{$\mathrm{K}=2$} & 1 & 2420 & 363 & 2836 & 426 & -17.2 & -17.4 \\
\hline & 2 & 3645 & 817 & 1723 & 386 & 52.7 & 52.7 \\
\hline & 3 & 3694 & 721 & 3253 & 635 & 12.0 & 11.9 \\
\hline & 4 & 34 & 8 & 38 & 9 & -13.3 & -22.0 \\
\hline & 5 & 174 & 29 & 141 & 24 & 18.9 & 18.0 \\
\hline & 6 & 466 & 82 & 389 & 71 & 16.5 & 13.6 \\
\hline & 7 & 644 & 128 & 435 & 87 & 32.5 & 31.8 \\
\hline & 8 & 1238 & 251 & 893 & 183 & 27.8 & 26.9 \\
\hline & 9 & 118 & 27 & 18 & 6 & 84.5 & 77.8 \\
\hline & 10 & 1257 & 254 & 990 & 201 & 21,3 & 20.9 \\
\hline \multirow{9}{*}{$\mathrm{K}=4$} & 11 & 1700 & 374 & 1349 & 300 & 20.6 & 19.8 \\
\hline & 12 & 4277 & 705 & 4202 & 696 & 1.7 & 1.2 \\
\hline & 13 & 4816 & 902 & 6730 & 1259 & -39.8 & -39.7 \\
\hline & 14 & 843 & 173 & 596 & 123 & 29.3 & 29.0 \\
\hline & 15 & 2227 & 495 & 1200 & 444 & 10.2 & 10.2 \\
\hline & 16 & 1150 & 243 & 657 & 139 & 42.9 & 42.9 \\
\hline & 17 & - & - & - & - & - & - \\
\hline & 18 & 7911 & 1743 & 10709 & 2358 & -35.4 & -35.3 \\
\hline & 19 & 1017 & 180 & 790 & 140 & 22.3 & 22.3 \\
\hline \multirow{11}{*}{$\mathrm{K}=6$} & 20 & 517 & 116 & 410 & 93 & 20.7 & 20.1 \\
\hline & 21 & 2429 & 509 & 1781 & 377 & 26.7 & 26.0 \\
\hline & 22 & 2865 & 674 & 2534 & 596 & 11.5 & 11.5 \\
\hline & 23 & 2355 & 406 & 1355 & 235 & 42.5 & 42.2 \\
\hline & 24 & 2728 & 478 & 2174 & 381 & 20.3 & 20.2 \\
\hline & 25 & 3823 & 647 & 3226 & 548 & 15.6 & 15.3 \\
\hline & 26 & 4243 & 752 & 3922 & 704 & 7.5 & 6.4 \\
\hline & 27 & 6802 & 1457 & 8333 & 1784 & -22.5 & -22.5 \\
\hline & 28 & 1264 & 259 & 952 & 195 & 24.7 & 24.4 \\
\hline & 29 & - & - & - & - & - & - \\
\hline & 30 & 2308 & 483 & 1354 & 284 & 41.3 & 41.2 \\
\hline \multicolumn{2}{|c|}{ Média } & 2429 & 482 & 2293 & 462 & 16.7 & 15.8 \\
\hline
\end{tabular}


Analisando-se as colunas em "GAP", tanto na tabela 4.1 quanto na 4.2, pode-se observar que a porcentagem de diminuição do custo total está bem próxima da porcentagem de diminuição da perda. Isto ocorre por causa do custo associado à perda sem bem maior que os custos de estoque de bobinas e de itens finais. Dessa forma, torna-se necessário uma análise mais cuidadosa dos parâmetros, procurando ajustá-los de forma a obter soluções mais significativas. No entanto, é importante ressaltar a melhoria obtida com o uso da heurística de antecipação, que permite uma melhor combinação dos itens em cada período, diminuindo significativamente a perda de papel. A diminuição média da perda obtida com a heurística de antecipação, considerando-se 5 tipos de itens demandados (Tabela 4.1) foi de $9.1 \%$ e, considerando-se 10 tipos de itens (Tabela 4.2), foi de 16.7\%. Ou seja, para os exemplos com um número maior de tipos de itens, a heurística de antecipação mostrou um desempenho ainda melhor.

O percentual de perda com sinal negativo diz que a heurística de antecipação de itens forneceu um resultado pior que a solução lote por lote. Entretanto, observou-se que em $72 \%$ dos exemplos testados, a perda nos dois primeiros períodos foi menor quando utilizouse a heurística de antecipação de itens, apresentando um desempenho pior nos últimos períodos, como é mostrado na tabela 4.3, considerando-se um exemplo específico. Isto se deve ao fato de que nos últimos períodos podem sobrar itens de difícil combinação ou podem ser cortados poucos itens de uma bobina, sendo que o restante é considerado como perda. Este fato levanta a possibilidade de, em trabalhos futuros, utilizar-se a estratégia de horizonte rolante, muito usada na prática para resolver problemas dinâmicos. 
Tabela 4.3: Resultados obtidos por período para o exemplo 27 da tabela 4.2.

\begin{tabular}{|c||c|c||c|c||c|c|}
\hline \multicolumn{1}{|c||}{} & \multicolumn{2}{|c||}{ Solução lote por lote } & \multicolumn{2}{c||}{ Heur. Antecipação } & \multicolumn{2}{c|}{ Gap (\%) } \\
\hline Período & Perda (kg) & Custo total $(\$)$ & Perda (kg) & Custo total & Perda & Custo total \\
\hline \hline 1 & 6157 & 5524 & 1318 & 1182 & 10.3 & 10.3 \\
2 & 6151 & 4561 & 1317 & 976 & 25.9 & 25.9 \\
3 & 5649 & 5204 & 1210 & 1114 & 7.9 & 7.9 \\
4 & 5032 & 3158 & 1078 & 676 & 37.2 & 37.3 \\
5 & 3518 & 2001 & 754 & 428 & 43.1 & 43.2 \\
6 & 5130 & 6428 & 1100 & 1376 & -25.3 & -25.1 \\
7 & 5700 & 6704 & 1222 & 1436 & -17.6 & -17.5 \\
8 & 17078 & 33087 & 3657 & 7084 & -93.7 & -93.7 \\
\hline Média & 6802 & 1457 & 8333 & 1784 & -22.5 & -22.5 \\
\hline
\end{tabular}

Os resultados obtidos com os testes confirmam o bom desempenho da heurística de antecipação de itens e justificam o desenvolvimento de métodos para o PCE multiperíodo, considerando as variáveis de estoque que agregam os períodos do horizonte do planejamento. A heurística de antecipação proposta é do tipo gulosa e permite ou não a antecipação do corte de itens demandados no período $t+1$ somente para o período anterior $t$, avaliando-se os valores das variáveis duais associadas aos itens. Diante disso, apostamos na adaptação do algoritmo simplex com geração de colunas para resolver o PCE multiperíodo relaxado de forma exata. A solução exata do problema de corte multiperíodo fornece valores mais adequados para as variáveis duais associadas à restrições (3.12) do modelo (3.11)-(3.15), que indicam quais itens devem ser antecipados. Além disso, a solução exata fornece valores mais adequados para as variáveis duais associadas às restrições (3.13), as quais são responsáveis pela perturbação na função objetivo do problema de dimensionamento de lotes, nas heurísticas de decomposição propostas, como veremos no capítulo 5 . 


\section{Capítulo 5}

\section{Métodos de solução para o problema}

\section{integrado}

Como o modelo (3.1)-(3.10) integra dois problemas bastante estudados: o problema de dimensionamento de lotes e o problema de corte de estoque, apresentamos duas heurísticas de decomposição que abordam ambos os problemas separadamente e iterativamente podendo, assim, fazer uso de ferramentas bem conhecidas.

A primeira heurística resolve inicialmente o problema de dimensionamento de lotes e determina como deve ser a produção de jumbos (que são escritos como múltiplos das bobinas-mestre) e, então, o problema de corte é resolvido considerando-se os jumbos produzidos. Apenas um ciclo desse procedimento, isto é, resolver o problema de dimensionamento e então resolver o problema de corte, tende a dar uma solução muito boa em termos da produção de jumbos, entretanto não em relação à perda de papel no processo de corte. A segunda heurística resolve primeiramente o problema de corte, supondo estoque ilimitado de jumbos, qualquer que seja o tipo de máquina que eles foram produzidos (lembre-se que as máquinas produzem diferentes larguras). A solução do problema dá a necessidade de jumbos (ton) por tipo de papel e período. Então, o problema de dimensionamento de lotes é resolvido, obtendo-se um plano de produção. Neste caso, apenas um ciclo da do procedimento tende a uma solução muito boa em termos da perda de papel, mas pode gerar tempos de preparação (setup's) altos. Além disso, em ambas as heurísticas nós iteragimos com o intuito de obter soluções melhores. 


\subsection{Relaxação lagrangiana}

Como as heurísticas de decomposição propostas nesta tese utilizam a técnica de relaxação lagrangiana, fazemos aqui uma breve revisão. A relaxação lagrangiana, que pode ser aplicada a problemas de programação inteira, tem demonstrado eficiência em várias experiências práticas. Consiste em relaxar restrições 'complicadas', ou seja, retirar as restrições que, sem as quais o problema apresenta uma estrutura especial (por exemplo, uma estrutura particular para a qual conhecemos um bom método de solução), colocando tais restrições como uma penalização na função objetivo.

Seja o problema de programação linear inteiro:

$$
\begin{array}{ll}
Z(P)=\min \mathbf{c x} & \\
\text { sujeito a } & \mathbf{A} \mathbf{x} \geq \mathbf{b} \\
& \mathbf{B} \mathbf{x} \geq \mathbf{d} \\
& \mathbf{x} \geq \mathbf{0} \text { e inteiro }
\end{array}
$$

em que $\mathbf{c}^{t} \in R^{n}, \mathbf{x} \in R^{n}, \mathbf{A} \in R^{m \times n}, \mathbf{b} \in R^{m}, \mathbf{B} \in R^{p \times n}, \mathbf{d} \in R^{p}$. Seja $F(P)$ o conjunto de soluções factíveis de (P).

Suponhamos que o conjunto $\mathbf{B x} \geq \mathbf{d}$ apresente uma estrutura especial. Desta forma, definimos a Relaxação Lagrangiana de $(\mathrm{P})$ relativa ao conjunto de restrições $\mathbf{A x} \geq \mathbf{b}$ e um vetor $\mathbf{u} \geq \mathbf{0}, \mathbf{u}^{t} \in R^{m}$, como:

$$
\begin{array}{lll}
Z\left(R P_{u}\right)= & \min L(\mathbf{x}, \mathbf{u}) & \\
& \text { sujeito a } & \mathbf{B} \mathbf{x} \geq \mathbf{d} \quad(R P) \\
& & \mathbf{x} \geq \mathbf{0} \text { e inteiro }
\end{array}
$$

em que $L(\mathbf{x}, \mathbf{u})=\mathbf{c x}+\mathbf{u}(\mathbf{b}-\mathbf{A x})$ é denominada função lagrangiana.

Dizemos que as restrições $\mathbf{A x} \geq \mathbf{b}$ do problema $(\mathrm{P})$ foram dualizadas e o problema resultante é chamado Problema Lagrangiano, para cada escolha de $\mathbf{u}$.

Para todo $\mathbf{x} \in F(P)$, temos $\mathbf{A} \mathbf{x} \geq \mathbf{b}$ e, com $\mathbf{u} \geq \mathbf{0}$, então:

$$
L(\mathbf{x}, \mathbf{u}) \leq \mathbf{c x}
$$


A importância de qualquer relaxação de $(\mathrm{P})$ é determinada pela proximidade do valor da função objetivo desta e o valor da função objetivo de (P). Diante disso, torna-se necessário determinar um critério pelo qual podemos medir a qualidade de uma escolha de $u$, que seria feita no caso ideal com $u$ como solução ótima do problema:

$$
\begin{aligned}
Z(D)= & \max Z\left(R P_{\mathbf{u}}\right) \\
& \text { sujeito a } \mathbf{u} \geq \mathbf{0}
\end{aligned}
$$

Este problema é denominado problema dual lagrangiano e sua solução fornece a mais apropriada escolha de $u$. Por isso sua resolução é de grande importância e o método do subgradiente é bastante utilizado, embora possa apresentar dificuldade na convergência e heurísticas lagrangianas têm sido desenvolvidas.

O método do subgradiente é uma adaptação do método do gradiente, em que os gradientes são substituídos pelos subgradientes. Dado um valor inicial $\mathbf{u}^{0}$, a sequência $\left\{\mathbf{u}^{k}\right\}$ é gerada por:

$$
\mathbf{u}^{k+1}=\mathbf{u}^{k}+t_{k}\left(\mathbf{b}-\mathbf{A} \mathbf{x}^{k}\right)
$$

em que $\mathbf{x}^{k}$ é uma solução ótima para $\left(R P_{\mathbf{u}_{k}}\right)$ e $t_{k}$ é o tamanho do passo e positivo. Pelo fato do método do subgradiente ser fácil de programar e ter mostrado um bom desempenho em problemas práticos [19], ele se tornou um método popular para se obter uma solução para (D). Existem, também, outros artigos que sugerem modificações no método do subgradiente básico, tal como Camerini (1975).

O desempenho computacional e as propriedades de convergência do método do subgradiente são discutidas em Held et al (1974). O resultado teórico fundamental é que $Z\left(D_{\mathbf{u}^{k}}\right) \longrightarrow Z(D)$, se $t_{k} \longrightarrow 0$ e $\sum_{i=0}^{k} t_{i} \longrightarrow \infty$ quando $k \longrightarrow \infty$. O tamanho do passo mais usado na prática é:

$$
t_{k}=\frac{\lambda_{k}\left(Z(P)^{*}-Z\left(D_{\mathbf{u}^{k}}\right)\right)}{\left\|\mathbf{b}-\mathbf{A} \mathbf{x}^{k}\right\|^{2}}
$$

em que $\lambda_{k}$ é um escalar satisfazendo $0 \leq \lambda_{k} \leq 2$ e $Z(P)^{*}$ é um limitante superior de $\mathrm{Z}(\mathrm{D})$, frequentemente obtido aplicando-se uma heurística a $(\mathrm{P})$, para obter uma solução factível 
de boa qualidade.

Apresentamos a seguir as heurísticas propostas para a resolução do problema integrado.

\subsection{A heurística lote-corte}

A primeira abordagem de solução para o problema integrado, que chamamos de heurística lote-corte, é baseada numa relaxação lagrangiana das restrições de integração (3.6) que são adicionadas à função objetivo (3.1), ponderadas pelas variáveis duais $\gamma_{k m t}$, $k=1, \cdots, K ; m=1, \cdots, M ; t=1, \cdots, T$. Então, a função lagrangiana é dada por:

$$
\begin{aligned}
& \sum_{t=1}^{T} \sum_{m=1}^{M} \sum_{k=1}^{K}\left(c_{k m} x_{k m t}+h_{k t} b_{k m} w_{k m t}+s_{k m t} z_{k m t}\right)+\sum_{t=1}^{T} \sum_{k=1}^{K} c p_{k t} \sum_{m=1}^{M} \sum_{j=1}^{N_{m}} p_{j m} y_{k m t}^{j}+ \\
& +\sum_{t=1}^{T} \sum_{k=1}^{K} \sum_{i \in S(k)} \sigma_{i t} \eta_{i k} e_{i k t}-\sum_{t=1}^{T} \sum_{m=1}^{M} \sum_{k=1}^{K} \gamma_{k m t}\left(\sum_{j=1}^{N m} y_{k m t}^{j}-x_{k m t}-w_{k, m, t-1}+w_{k m t}\right) \\
& =\sum_{t=1}^{T} \sum_{m=1}^{M} \sum_{k=1}^{K}\left(c_{k m}+\gamma_{k m t}\right) x_{k m t}+\sum_{t=1}^{T} \sum_{m=1}^{M} \sum_{k=1}^{K}\left[\left(h_{k t} b_{k m}-\gamma_{k m t}\right) w_{k m t}+\gamma_{k m t} w_{k, m, t-1}\right]+ \\
& +\sum_{t=1}^{T} \sum_{m=1}^{M} \sum_{k=1}^{K} s_{k m t} z_{k m t}+\sum_{t=1}^{T} \sum_{m=1}^{M} \sum_{k=1}^{K}\left(c p_{k t} \sum_{j=1}^{N_{m}} p_{j m}-\gamma_{k m t}\right) \sum_{j=1}^{N m} y_{k m t}^{j}+ \\
& \sum_{t=1}^{T} \sum_{k=1}^{K} \sum_{i \in S(k)} \sigma_{i t} \eta_{i k} e_{i k t} .
\end{aligned}
$$

Já que as restrições de integração (3.6) foram relaxadas, o problema (3.1)-(3.10) pode ser decomposto em dois subproblemas. Um é o problema de dimensionamento de lotes PDL e o outro é o problema de corte de estoque PCE. Inicialmente, a heurística lote-corte resolve o PDL, cuja função objetivo é minimizar os custos de produção e estoque e os custos de setup, que podem ser obtidos de (3.11) considerando-se apenas os termos que envolvem as decisões de produção e estoque das bobinas-mestre, sujeito às restrições (3.2)-(3.4) e (3.7)-(3.9).

A solução obtida pelo PDL fornece o estoque de bobinas-mestre para o PCE, que é resolvido com o objetivo de minimizar os custos com a perda de papel e de estoque de 
itens finais sujeito à (3.5)-(3.6) e (3.10).

A heurística lote-corte realiza um número máximo de iterações $p$ definido previamente. Na primeira iteração, fazemos $\gamma_{k m t}=0$, e nas demais iterações $\gamma_{k m t}$ é dada pela variável dual associada a (3.6) obtida pelo PCE na iteração anterior.

Note que a produção de jumbos no problema de dimensionamento de lotes deve fornecer a quantidade de papel do tipo $k$ no período $t$ suficiente para atender a demanda de itens finais no estágio de corte, incluindo uma porcentagem adicional de jumbos produzidos para cobrir eventuais perdas. Como a perda de papel é desconhecida, adicionamos uma tolerância para o total de papel produzido do tipo $k$ no período $t$, isto é, consider$\operatorname{amos} D_{k t}=(1+\theta) \sum_{i \in S(k)} \eta_{i k} d_{i k t}, k=1, \ldots, K, t=1, \ldots, T$, sendo $\theta$ uma estimativa da perda no processo de corte.

É claro que, se uma estimativa para cobrir a perda não for incorporada na produção de jumbos, o problema de corte não será capaz de atender a demanda de itens, isto é, será infactível. Isto também poderá ocorrer se a estimativa para a perda não for suficiente para cobrir a perda real de papel no processo de corte.

O PDL é resolvido heuristicamente e sua solução é arredondada para cima (lembre que o número de bobinas-mestre é inteiro e se seus pesos específicos definidos previamente são pequenos, este processo de arredondamento se torna irrelevante). Entretanto, este arredondamento é útil para cobrir a perda no processo de corte. O PDL é declarado infactível se o método de solução empregado não for capaz de encontrar uma solução factível.

O algoritmo inicia com $\theta=0$ e cresce passo a passo até um limitante superior (por exemplo, 10\%). Se o PDL é infactível para um valor de $\theta$, então será infactível para valores maiores. Portanto, sendo o PDL infactível, o algoritmo é interrrompido e a melhor solução até o momento é adotada. A melhor solução é adotada. A seguir, a heurística lote-corte é descrita. Seja $p$ o número de iterações em que o par PDL-PCE é resolvido.

\section{Algoritmo lote-corte:}

Passo 1: Faça $\gamma_{k m t}=0$ e $\theta=0$ (porcentagem de folga da demanda).

Passo 2: Para $i=1$ até $p$ faça: 
2.1: Resolva o PDL usando o método da seção 5.2.1, e $D_{k t}=(1+\theta) \sum_{i \in S(k)} \eta_{i k} d_{i k t}, k=$ $1, \ldots, K, t=1, \ldots, T$. Se o PDL for infactível, PARE.

2.2: Resolva o PCE mulitperíodo (usando um dos métodos do capítulo 4), com a disponibilidade de estoque encontrada no passo 2.1 .

Se o PCE for infactível (isto é, o método empregado não foi capaz de encontrar uma solução factível), vá para o passo 3.

2.3: Atualize os multiplicadores lagrangianos $\gamma_{k m t}$, como sendo os multiplicadores simplex associados às restrições (3.6).

$\underline{\text { Passo 3: }}$ Aumente $\theta$ (por exemplo, $\theta=\theta+0.01$ ). Se $\theta \leq$ limite (usamos limite $=0.1$ ) então volte ao Passo 2.

Passo 4: Escolha a melhor solução factível obtida no passo 2. Se nenhuma solução factível foi obtida, o problema é declarado infactível (a heurística lote/corte não foi capaz de encontrar uma solução factível).

\subsubsection{Um método de solução para o problema de dimensiona- mento de lotes}

Para resolver o PDL definido anteriormente pelas restrições (3.2)-(3.4), (3.7) e (3.8), que é um problema de dimensionamento de lotes em máquinas paralelas, usamos uma heurística desenvolvida por Toledo (1998). A autora propõe uma heurística baseada na relaxação lagrangiana das restrições de capacidade e o método do subgradiente. O problema lagrangiano resultante é decomposto em $K$ problemas de dimensionamento de lotes independentese sem restrições de capacidade, um para cada item. A cada passo do método do subgradiente os $K$ problemas de lote são resolvidos. A solução obtida para o PDL pode ser infactível e, neste caso, são aplicadas heurísticas de factibilização e finalmente de melhoria da solução. Esses procedimentos são baseados em trocas de quantidades de produção entre os períodos e máquinas para tentar construir uma solução factível e melhor e são similares aos procedimentos de suavização e melhoria propostos por Trigeiro et al. (1989). 
O seguinte algoritmo resume a heurística.

$\underline{\text { Algoritmo para o PDL: }}$

Passo 1: Faça os multiplicadores lagrangianos iguais a zero (restrições de capacidade são dualizadas).

Passo 2: Resolva os $K$ subproblemas de lote em máquinas paralelas.

Passo 3: Se a solução obtida no passo 2 for factível vá para o Passo 6.

Passo 4: Aplique o procedimento de factibilização.

Passo 5: Se foi obtida uma solução factível, aplique o procedimento de melhoria.

Passo 6: Atualize a solução incumbente (melhor solução obtida até o momento).

Passo 7: Atualize os multiplicadores lagrangianos de acordo com o método do subgradiente.

Passo 8: Se o número máximo de iterações (por exemplo, 100) não foi excedido ou a solução ótima não foi obtida, vá para o Passo 2.

A solução obtida por essa heurística supre o PCE com os jumbos a serem cortados (veja passos 2.1 e 2.2 da heurística lote/corte). O estoque de bobinas-mestre no PDL é agregado por gramatura em cadas período, e uma nova variável é definida como: $w_{k t}=$ $\sum_{m=1}^{M} b_{k m} w_{k m t}$. Então, $w_{k t}$ significa a quantidade (ton) de papel do tipo $k$ em estoque no final do período $t$. O valor de $w_{k m t}$ é recuperado quando o PCE é resolvido segundo um dos métodos do capítulo 4 (veja solução lote por lote ou heurística de antecipação).

\subsection{A heurística corte-lote}

Em vez de produzir jumbos baseado diretamente na demanda de itens finais e então aumentar a demanda de papel para cobrir a perda como feito na heurística lote-corte, a heurística corte-lote resolve primeiramente o problema de corte baseado na demanda de itens, mas com um número livre de jumbos supostamente disponíveis. Portanto, a 
solução do problema de corte produz o número necessário de bobinas-mestre para atender a demanda de qualquer tipo de papel. Então, o problema de dimensionamento de lotes, que considera custos de setups, capacidades de máquina, custos de produção e setup, etc., é resolvido, produzindo uma nova programação da produção, que será entrada para o próximo problema de corte de estoque, e assim por diante.

A heurística é descrita a seguir.

Algoritmo corte-lote:

Passo 0: Faça Iteração $=1$.

Passo 1: Resolva o PCE sobre o horizonte de planejamento (usando uma das heurísticas do capítulo 4). Se Iteração = 1, então as restrições (3.6) são omitidas.

A solução obtida neste passo produz: $\sum_{j} y_{k m t}^{j}$ que é o número necessário de bobinasmestre do tipo $k$ e largura $L_{m}$ (isto é, produzidas na máquina $m$ ) e no período $t$ para atender a demanda. Portanto, a demanda de papel do tipo $k$ no período $t$ é dada por:

$$
D_{k t}=\sum_{m} b_{k m} \sum_{j} y_{k m t}^{j}
$$

(Note que o número de bobinas-mestre de papel tipo $k$ e largura $L_{m}$ no período $t$ dado pelo problema de corte de estoque é a melhor solução em termos do processo de corte, entretanto não é a melhor solução quando consideramos a produção de jumbos. Dessa forma, a demanda agregada de jumbos por gramatura em cada período dá à produção de jumbos a oportunidade de alocar melhor os tipos de papel nas máquinas de produção.)

$\underline{\text { Passo 2: }}$ Para $k=1$ até $K$, faça:

Resolva o PDL com a demanda do tipo de papel $k$ no período $t, D_{k t}$, dado no Passo 1, basicamente formado por (3.2)-(4.4) e (3.8)-(3.9), e os termos da função objetivo relacionados ao processo de produção do jumbo. A solução do PDL fornece $x_{k m t}$, o número de bobinas-mestre do tipo $k$ produzidas na máquina $m$ (isto é, de largura $\left.L_{m}\right)$, para $t=1$ até $T$. 
Iteração $=$ Iteração +1.

Analogamente à heurística lote-corte, se o PCE é infactível então $D_{k t}$ é incrementado por uma tolerância $\theta$, e o PCE é resolvido novamente até encontrar uma solução factível, ou até $\theta$ atingir o limite superior.

Passo 3: Repita o Passo 1 e o Passo 2 um número limitado de vezes, ou pare se nenhuma melhoria for obtida de uma iteração para outra.

\subsection{Experimentos computacionais}

Nesta seção avaliamos os resultados obtidos pelas heurísticas apresentadas nas seções 5.2 e 5.3, propostas para resolver o problema integrado (3.1)-(3.10).

\subsubsection{Conjunto de dados}

Para avaliar o comportamento das heurísticas propostas, foram gerados exemplos aleatoriamente, classificados de acordo com as seguintes características:

- número de tipos de itens demandados: $N f=5,10,20$;

- número de tipos de papel (gramaturas): $K=2,4,6$;

- número de períodos: $T=8,10,12$.

Com a variação dessas características foram obtidas 27 classes, com 10 exemplos em cada classe. Consideramos $M=2$ (isto é, duas máquinas), sendo que a máquina 1 produz jumbos de largura $L_{1}=540 \mathrm{~cm}$, e a máquina 2 jumbos de largura $L_{2}=460 \mathrm{~cm}$. Adotamos como peso específico da bobina-mestre de tipo $k: \rho=2 \mathrm{~kg} / \mathrm{cm}$.

Para cada conjunto de dados, tentando simular observações com dados reais, os parâmetros foram gerados como descrito a seguir.

- Custo de produção da bobina-mestre: $c_{k m t} \in\left[\begin{array}{ll}0.015 & 0.025\end{array}\right] \cdot b_{k m}$, sendo $b_{k m}=L_{m} \rho$ (peso da bobina-mestre de gramatura $k$ produzida na máquina $m$ );

- custo de preparação de máquina: $s_{k m t} \in\left[\begin{array}{ll}0.03 & 0.05\end{array}\right] \cdot c_{k m t}$; 
- custo de estoque de bobinas-mestre: $h_{k t} \in\left[\begin{array}{ll}0.0000075 & 0.0000125\end{array}\right]$;

- perda de papel devido ao processo de produção: $f_{k m} \in\left[\begin{array}{ll}0.01 & 0.05\end{array}\right] \cdot b_{k m}$;

- custo associado à perda ocorrida no processo de corte: $c p_{k t}=\frac{\sum_{m=1}^{M} c_{k m t}}{M} \cdot 10$;

- custo de estoque do item $i$ no final do período $t: \sigma_{i k t}=0.5 \cdot h_{k t}, \quad i \in S(k)$;

- larguras dos itens finais: $l_{i} \in\left[\begin{array}{ll}0.1 & 0.3\end{array}\right] \cdot \frac{\sum_{m=1}^{M} L_{m}}{M}$;

- demanda de itens finais: $d_{i k t} \in\left[\begin{array}{ll}0 & 300\end{array}\right]$. Se $d_{i k t} \leq 50$ então faça $d_{i k t}=0$.

As capacidades das máquinas de produção foram geradas como segue.

$$
\begin{gathered}
C a p=\phi \frac{\sum_{t=1}^{T} \sum_{m=1}^{M} \sum_{k=1}^{K}\left(\frac{D_{k t}}{M}+f_{k m}\right)}{M T} \\
C_{m t}=\frac{b_{k m}}{\sum_{m=1}^{M} b_{k m}} \cdot C a p
\end{gathered}
$$

A constante $\phi$ tem a função de manter a utilização da capacidade das máquinas em torno de um percentual desejado. Em Toledo e Armentano (2005), considerou-se $\phi=1.04$, procurando manter a utilização da capacidade em torno de $80 \%$. Para os nossos testes, consideramos $\phi=1.24$. Essa alteração foi necessária, pois testes iniciais mostraram que a capacidade, utilizando-se $\phi=1.04$, ficou apertada.

\subsubsection{Apresentação e análise dos resultados obtidos}

As tabelas 5.1 e 5.2 trazem um resumo dos resultados obtidos pelas heurísticas LoteCorte e Corte-Lote para os 270 exemplos agrupados em 27 classes. Nos testes apresentados na tabela 5.1, o PCE multiperíodo foi resolvido utilizando-se a heurística lote por lote. Já nos testes da tabela 5.2, foi aplicada a heurística de antecipação de itens. A coluna 'VFO', para cada heurística, contém a média dos valores da função objetivo dos exemplos que foram bem resolvidos. Esses valores representam a soma dos custos de produção e preparação com os custos associados às perdas ocorridas durante o processo de corte, 
custos de estoque de bobinas e de estoque de itens finais, assim como descrito na função objetivo (3.1), do modelo (3.1)-(3.10). O número de exemplos bem resolvidos (10 exemplos para cada classe) é mostrado na coluna 'Resolvidos'. A coluna 'Vitoriosos' dá o número de exemplos em que uma determinada heurística teve um desempenho melhor que a outra. Se houve empate no desempenho, então não contamos vitória para nenhuma das heurísticas. Se um exemplo é resolvido por uma heurística e não pela outra, uma vitória é contada para a heurística que obteve vitória. Entretanto, este exemplo não é considerado no cálculo da média. Como os algoritmos são iterativos, também apresentamos o número de iterações, na média, em que a melhor solução foi obtida, na coluna 'Iteração' (o máximo é 30). A coluna 'GAP' mostra a diferença em percentual entre o valor obtido pela heurística Lote-Corte e o obtido pela heurística Corte-Lote $\left(\frac{V F O(L C)-V F O(C L)}{V F O(L C)} \times 100\right)$, sendo que os valores positivos dão a porcentagem de quanto melhor foi a heurística Corte-Lote. 
Tabela 5.1: Resultados computacionais das heurísticas Lote-Corte e Corte-Lote, usando a solução lote por lote para o PCE multiperíodo.

\begin{tabular}{|c|c|c|c|c|c|c|c|c|c|c|}
\hline \multirow[b]{2}{*}{ Classe } & \multirow[b]{2}{*}{$N f, T, K$} & \multicolumn{4}{|c|}{ Corte-Lote (CL) } & \multicolumn{4}{|c|}{ Lote-Corte (L/C) } & \multirow{2}{*}{\begin{tabular}{|c} 
Gap \\
$\frac{L C-C L}{C L}$ \\
$\%$ \\
\end{tabular}} \\
\hline & & $\mathrm{OFV}$ & Vitórias & Resolvidos & Iteração & $\mathrm{OFV}$ & Vitórias & Resolvidos & Iteração & \\
\hline 1 & $5,8,2$ & 62256 & 7 & 8 & 1.8 & 64848 & 2 & 10 & 3.7 & 4.0 \\
\hline 2 & $10,8,2$ & 85829 & 8 & 10 & 1.8 & 86866 & 2 & 10 & 2.7 & 1.2 \\
\hline 3 & $20,8,2$ & 175596 & 4 & 10 & 1.3 & 176741 & 0 & 10 & 3.1 & 0.6 \\
\hline 4 & $5,10,2$ & 60455 & 5 & 8 & 2.0 & 60860 & 3 & 9 & 3.6 & 0.7 \\
\hline 5 & $10,10,2$ & 109741 & 8 & 10 & 2.1 & 110528 & 2 & 10 & 1.7 & 0.7 \\
\hline 6 & $20,10,2$ & 222816 & 1 & 10 & 1.1 & 222874 & 1 & 10 & 2.3 & 0.0 \\
\hline 7 & $5,12,2$ & 83828 & 4 & 6 & 2.5 & 82422 & 2 & 6 & 8.3 & -1.7 \\
\hline 8 & $10,12,2$ & 128425 & 9 & 9 & 2.1 & 131339 & 0 & 9 & 1.0 & 2.2 \\
\hline 9 & $20,12,2$ & 267435 & 1 & 10 & 1.2 & 267344 & 2 & 10 & 1.9 & 0.0 \\
\hline 10 & $5,8,4$ & 102251 & 10 & 10 & 2.1 & 105364 & 0 & 10 & 6.0 & 3.0 \\
\hline 11 & $10,8,4$ & 190181 & 9 & 9 & 2.0 & 193986 & 0 & 9 & 2.3 & 2.0 \\
\hline 12 & $20,8,4$ & 327226 & 3 & 10 & 1.4 & 328218 & 1 & 10 & 1.3 & 0.3 \\
\hline 13 & $5,10,4$ & 127388 & 6 & 8 & 1.5 & 130450 & 2 & 8 & 4.5 & 2.3 \\
\hline 14 & $10,10,4$ & 235800 & 7 & 10 & 2.0 & 241009 & 1 & 9 & 3.8 & 2.2 \\
\hline 15 & $20,10,4$ & 420768 & 1 & 10 & 1.1 & 421249 & 1 & 10 & 1.0 & 0.1 \\
\hline 16 & $5,12,4$ & 158357 & 6 & 9 & 1.6 & 158753 & 2 & 9 & 3.9 & 0.2 \\
\hline 17 & $10,12,4$ & 283428 & 8 & 9 & 1.8 & 286423 & 1 & 9 & 1.0 & 1.0 \\
\hline 18 & $20,12,4$ & 504548 & 1 & 10 & 1.1 & 504714 & 2 & 10 & 1.1 & 0.0 \\
\hline 19 & $5,8,6$ & 154196 & 7 & 7 & 2.0 & 162500 & 0 & 7 & 4.0 & 5.1 \\
\hline 20 & $10,8,6$ & 272086 & 10 & 10 & 2.2 & 278005 & 0 & 10 & 1.0 & 2.1 \\
\hline 21 & $20,8,6$ & 455619 & 3 & 10 & 1.3 & 457566 & 1 & 10 & 1.0 & 0.4 \\
\hline 22 & $5,10,6$ & 179063 & 5 & 6 & 1.5 & 182602 & 1 & 6 & 3.5 & 1.9 \\
\hline 23 & $10,10,6$ & 323868 & 10 & 10 & 2.2 & 328492 & 0 & 10 & 1.0 & 1.4 \\
\hline 24 & $20,10,6$ & 636062 & 4 & 10 & 1.4 & 639104 & 0 & 10 & 1.0 & 0.5 \\
\hline 25 & $5,12,6$ & 250838 & 4 & 7 & 1.6 & 253934 & 3 & 7 & 1.0 & 1.2 \\
\hline 26 & $10,12,6$ & 386629 & 10 & 10 & 2.3 & 395894 & 0 & 10 & 1.0 & 2.3 \\
\hline 27 & $20,12,6$ & 761624 & 3 & 10 & 1.3 & 762182 & 1 & 10 & 1.0 & 0.1 \\
\hline
\end{tabular}


Tabela 5.2: Resultados computacionais das heurísticas Lote-Corte e Corte-Lote, com a heurística de antecipação de itens para o PCE multiperíodo.

\begin{tabular}{|c|c|c|c|c|c|c|c|c|c|c|}
\hline \multirow[b]{2}{*}{ Classe } & \multirow[b]{2}{*}{$N f, T, K$} & \multicolumn{4}{|c|}{ Corte-Lote (CL) } & \multicolumn{4}{|c|}{ Lote-Corte (L/C) } & \multirow{2}{*}{\begin{tabular}{|c} 
Gap \\
$\frac{L C-C L}{C L}$ \\
$\%$
\end{tabular}} \\
\hline & & $\mathrm{OFV}$ & Vitórias & Resolvidos & Iteração & $\mathrm{OFV}$ & Vitórias & Resolvidos & Iteração & \\
\hline 1 & $5,8,2$ & 68904 & 3 & 6 & 1.2 & 69411 & 5 & 8 & 2.6 & 4.0 \\
\hline 2 & $10,8,2$ & 86336 & 5 & 10 & 1.5 & 87045 & 4 & 10 & 1.0 & 0.8 \\
\hline 3 & $20,8,2$ & 176142 & 1 & 10 & 1.0 & 176581 & 0 & 10 & 1.0 & 0.3 \\
\hline 4 & $5,10,2$ & 60086 & 2 & 7 & 1.0 & 59686 & 8 & 10 & 2.0 & -0.7 \\
\hline 5 & $10,10,2$ & 109637 & 3 & 10 & 1.1 & 110294 & 6 & 10 & 1.0 & 0.6 \\
\hline 6 & $20,10,2$ & 224081 & 0 & 10 & 1.0 & 224080 & 0 & 10 & 1.0 & 0.0 \\
\hline 7 & $5,12,2$ & 84409 & 3 & 6 & 1.0 & 80860 & 3 & 6 & 2.3 & -4.2 \\
\hline 8 & $10,12,2$ & 129711 & 3 & 9 & 1.1 & 131828 & 4 & 9 & 1.0 & 1.6 \\
\hline 9 & $20,12,2$ & 267516 & 0 & 10 & 1.0 & 267517 & 0 & 10 & 1.0 & 0.0 \\
\hline 10 & $5,8,4$ & 101235 & 7 & 10 & 1.0 & 102060 & 3 & 9 & 1.0 & 0.8 \\
\hline 11 & $10,8,4$ & 192401 & 4 & 9 & 1.0 & 193634 & 5 & 9 & 1.0 & 0.6 \\
\hline 12 & $20,8,4$ & 328768 & 0 & 10 & 1.0 & 328771 & 0 & 10 & 1.0 & 0.0 \\
\hline 13 & $5,10,4$ & 129376 & 4 & 6 & 1.0 & 129286 & 2 & 5 & 1.2 & -0.1 \\
\hline 14 & $10,10,4$ & 238303 & 5 & 9 & 1.0 & 239151 & 3 & 9 & 1.0 & 0.4 \\
\hline 15 & $20,10,4$ & 422208 & 0 & 10 & 1.0 & 422213 & 0 & 10 & 1.0 & 0.0 \\
\hline 16 & $5,12,4$ & 171829 & 3 & 6 & 1.0 & 171858 & 3 & 6 & 1.7 & 0.0 \\
\hline 17 & $10,12,4$ & 283281 & 1 & 8 & 1.0 & 282606 & 7 & 8 & 1.0 & -0.2 \\
\hline 18 & $20,12,4$ & 504947 & 0 & 10 & 1.0 & 504951 & 0 & 10 & 1.0 & 0.0 \\
\hline 19 & $5,8,6$ & 168210 & 5 & 6 & 1.0 & 170293 & 1 & 6 & 1.0 & 1.2 \\
\hline 20 & $10,8,6$ & 274342 & 2 & 9 & 1.0 & 274153 & 7 & 9 & 1.0 & -0.1 \\
\hline 21 & $20,8,6$ & 510271 & 0 & 10 & 1.0 & 510272 & 0 & 10 & 1.0 & 0.0 \\
\hline 22 & $5,10,6$ & 198930 & 3 & 5 & 1.0 & 199707 & 2 & 4 & 1.0 & 0.4 \\
\hline 23 & $10,10,6$ & 327349 & 2 & 10 & 1.0 & 327495 & 7 & 10 & 1.0 & 0.0 \\
\hline 24 & $20,10,6$ & 638258 & 1 & 10 & 1.0 & 638223 & 1 & 10 & 1.0 & 0.0 \\
\hline 25 & $5,12,6$ & 256449 & 2 & 6 & 1.0 & 256989 & 4 & 6 & 1.0 & 0.2 \\
\hline 26 & $10,12,6$ & 382522 & 2 & 9 & 1.0 & 384204 & 7 & 10 & 1.0 & 0.4 \\
\hline 27 & $20,12,6$ & 763574 & 0 & 10 & 1.0 & 763223 & 1 & 10 & 1.0 & 0.0 \\
\hline
\end{tabular}


Note que, na tabela 5.1, a heurística Corte-Lote teve um desempenho melhor que a heurística Lote-Corte, exceto para a classe $7(N f=5, K=2, T=12)$. Entretanto, para esta classe, a heurística Corte-Lote ganha em termos do número de vitórias. O número total de vitórias obtido pela heurística Corte-Lote foi 155 dos 270 exemplos (isto é, 57\%), e as heurísticas obtiveram o mesmo valor para a função objetivo em $33 \%$ dos exemplos. Ambas as heurísticas resolveram 90\% dos exemplos. A heurística Corte-Lote, em geral, obteve a melhor solução mais rapidamente que a heurística Lote-Corte, em média, 1.7 e 2.5 iterações respectivamente. É importante notar que a heurística Corte-Lote pára com a melhor solução obtida em, na média, 1.7 iterações. Entretanto, a heurística Lote-Corte roda $p$ iterações (usamos $p=30$ ) e as melhores soluções são obtidas, na média, em 2.5 iterações.

Na tabela 5.2, observa-se pela coluna "GAP" que os valores das funções objetivos obtidos pelas duas heurísticas, realizando-se antecipação de itens no PCE multiperíodo, estão bem próximos, em média 0.1\% Ambas as heurísticas resolveram em torno de $85 \%$ dos exemplos e obtiveram o mesmo valor para a função objetivo em $34 \%$ dos exemplos. A heurística Lote-Corte obteve a melhor solução, em média, na iteração 1.2 e com a heurística Corte-Lote, a melhor solução foi obtida, em média, na iteração 1. A obtenção da melhor solução, na maioria dos exemplos, na primeira iteração, mostra a necessidade de considerar custos associados às perdas e custos de estoque mais representativos, quando comparados aos custos operacionais (de produção e de preparação). Ou seja, com os parâmetros considerados nos testes, um pequeno acréscimo na demanda para o problema de dimensionamento de lotes aumenta muito os custos de produção e de preparação, e os custos associados às perdas e aos estoques tornam-se insignificantes, como pode ser visto na tabela 5.3, que apresenta um exemplo específico. 
Tabela 5.3: Custos obtidos pela heurística Lote-Corte, usando antecipação de itens no PCE multiperíodo (Exemplo 8 - Classe 26).

\begin{tabular}{|c|c|c|c|c|}
\hline Iteração & CPP & CE & CP & CT \\
\hline \hline 1 & 416505 & 183 & 4526 & 421214 \\
2 & 442595 & 176 & 2868 & 445639 \\
3 & 422906 & 237 & 3355 & 426498 \\
4 & 591890 & 331 & 0 & 592221 \\
5 & 591890 & 331 & 0 & 592221 \\
6 & 591890 & 331 & 0 & 592221 \\
7 & 591890 & 331 & 0 & 592221 \\
8 & 591890 & 331 & 0 & 592221 \\
9 & 591890 & 331 & 0 & 592221 \\
10 & 591890 & 331 & 0 & 592221 \\
11 & 591890 & 331 & 0 & 592221 \\
12 & 591890 & 331 & 0 & 592221 \\
13 & 591890 & 331 & 0 & 592221 \\
14 & 591890 & 331 & 0 & 592221 \\
15 & 591890 & 331 & 0 & 592221 \\
16 & 591890 & 331 & 0 & 592221 \\
17 & 591890 & 331 & 0 & 592221 \\
18 & 591890 & 331 & 0 & 592221 \\
19 & 591890 & 331 & 0 & 592221 \\
20 & 591890 & 331 & 0 & 592221 \\
21 & 591890 & 331 & 0 & 592221 \\
22 & 591890 & 331 & 0 & 592221 \\
23 & 591890 & 331 & 0 & 592221 \\
24 & 591890 & 331 & 0 & 592221 \\
25 & 591890 & 331 & 0 & 592221 \\
26 & 591890 & 331 & 0 & 592221 \\
27 & 591890 & 331 & 0 & 592221 \\
28 & 591890 & 331 & 0 & 592221 \\
29 & 591890 & 331 & 0 & 592221 \\
30 & 591890 & 331 & 0 & 592221 \\
\hline
\end{tabular}


Na tabela 5.3, a coluna 'CPP' representa os custos operacionais (custo de produção e de preparação), a coluna 'CE' representa os custos de estoque (de bobinas-mestre e de itens finais), a coluna 'CP' fornece o custo associado às perdas e a coluna 'CT' representa a soma destes custos. Observe que as perdas diminuem significativamente com as informações que a solução do problema de corte fornece para o problema de dimensionamento de lotes, mas os custos operacionais aumentam muito. Por exemplo, da primeira para a segunda iteração, o custo da perda diminuiu $36.6 \%$, enquanto os custos operacionais aumentaram somente $6.2 \%$. No entanto, pelo fato de os custos operacionais considerados serem muito altos quando comparados com os custos associados às perdas, o custo total obtido é definido exclusivamente pelos custos da coluna 'CPP'. O mesmo ocorre da terceira para a quarta iteração, sendo o percentual de diminuição da perda de $100 \%$ e o aumento dos custo operacionais, de 39.9\%. A partir da quarta iteração os valores obtidos se repetem. Por esse motivo, mesmo que a antecipação de itens consiga diminuir significativamente a perda de papel, não fica evidenciado o seu impacto nos custos totais. Dessa forma, o menor valor para a função objetivo é, geralmente, o da primeira iteração. 


\section{Capítulo 6}

\section{Conclusões e perspectivas}

Seguindo a tendência atual de tratar problemas de planejamento e programação da produção de forma integrada, este trabalho abordou a integração dos problemas de dimensionamento de lotes e corte de estoque, motivado por aplicações práticas em indústrias de papel. O processo de produção consiste em produzir jumbos (bobinas grandes) de diferentes larguras que, posteriormente, são cortadas para atender a demanda de itens (bobinas menores), dentro de um horizonte de planejamento dividido em períodos. Os jumbos são produzidos em máquinas paralelas, que têm capacidades limitadas e desempenhos próprios. Os pedidos de itens finais são bem definidos por: largura, gramatura, demanda e data de entrega. Tratar esses dois problemas de forma separada pode elevar os custos globais, principalmente se o problema de corte for economicamente relevante no processo.

Inicialmente, propomos um modelo matemático inteiro misto que integra as decisões de produção e corte dos jumbos, com o objetivo de minimizar a soma dos custos de produção, preparação, estoque de jumbos e itens finais e dos custos associados às perdas de papel durante o processo de corte.

O modelo integrado apresenta várias dificuldades. O problema de dimensionamento de lotes é capacitado, em um ambiente com máquinas paralelas distintas e considera perdas na preparação das máquinas. O problema de encontrar uma solução factível nessas condições é NP-completo e, por isso, a maioria dos métodos encontrados na literatura são heurísticos. Por outro lado, as restrições de corte possuem dois fatores que tornam essa formulação muito difícil: o número grande de variáveis associadas e as condições de 
integralidade sobre essas variáveis. Para contornar esta dificuldade, pode-se relaxar as restrições de integralidade, utilizar o método simplex com geração de colunas e, posteriormente, usar uma heurística de arredondamento da solução. Além disso, nas restrições (3.5) do modelo integrado, podemos notar que existe uma interdependência entre as decisões de corte nos diferentes períodos por causa das variáveis de estoque de itens finais. A esse problema chamamos "problema de corte de estoque multiperíodo", definido na seção 3.3.

O problema do corte multiperíodo raramente aparece na literatura, apesar de frequentemente aparecer no processo de planejamento da produção em indústrias (podemos destacar o trabalho de Hendry, 1996). Diante disso, implementamos dois métodos heurísticos de solução. A primeira implementação considera a solução lote por lote, como é feito na prática, ou seja, fixando-se a gramatura, resolve-se um problema de corte (PCE) para cada período, respeitando a disponibilidade de bobinas-mestre em estoque. Os PCE's são relaxados e resolvidos usando o método simplex com geração de colunas.

O segundo método, chamado Heurística de Antecipação de Itens, considera as variáveis de estoque de itens $e_{i k t}$, que aparecem nas restrições (3.5) do modelo integrado e que foram ignoradas na solução lote por lote. Com essa heurística, pretendemos ressaltar a importância dessas variáveis e os resultados obtidos durante os experimentos confirmam o seu bom desempenho, que apresentou o custos totais (custos de perda e estoques) bastante inferiores, quando comparados com a solução lote por lote. Em média, a diminuição da perda foi de $9.1 \%$ para 5 diferentes tipos de itens e $16.7 \%$ para 10 diferentes tipos de itens. Esses resultados nos levam a apostar, futuramente, no desenvolvimento de um método exato, a partir da adaptação do método simplex com geração de colunas para o problema de corte multiperíodo.

Para contornar as dificuldades apresentadas pelo modelo integrado, propomos duas heurísticas baseadas na decomposição do problema: heurísticas Lote-Corte e Corte-Lote.

A heurística Lote-Corte baseia-se na relaxação lagrangiana das restrições de integração (3.6), que são adicionadas à função objetivo (3.1), ponderadas pelas variáveis duais associadas. Assim, o problema integrado decompõe-se em dois subproblemas: problema de dimensionamento de lotes e problema de corte de estoque. O problema de dimensionamento de lotes determina primeiramente como deve ser a produção de jumbos (escritos como múltiplos das bobinas-mestre) e, então, o problema de corte é resolvido, 
considerando-se os jumbos produzidos. Essa heurística realiza um número máximo de iterações definidas previamente.

A heurística Corte-Lote constitui-se num processo iterativo. Inicialmente, resolve-se o problema de corte, supondo estoque ilimitado de bobinas-mestre. A solução fornece a necessidade de bobinas-mestre por gramatura e período. Então, o problema de dimensionamento de lotes é resolvido, obtendo-se um plano de produção que será entrada para o próximo problema de corte, e assim por diante.

As heurísticas Lote-Corte e Corte-Lote foram implementadas, utilizando as heurísticas de solução lote por lote e de antecipação de itens, propostas no capítulo 4, para resolver o problema de corte multiperíodo relaxado. O problema de dimensionamento de lotes foi resolvido utilizando uma adaptação da heurística proposta por Toledo (1998). Foram gerados aleatoriamente 270 exemplos, divididos em 27 classes, variando-se o número de tipos de itens, de gramaturas e de períodos.

Os resultados obtidos pelas duas heurísticas foram comparados entre si e mostraramse bastante satisfatórios. As heurísticas resolveram em torno de $90 \%$ dos exemplos gerados. Quando o problema de corte foi resolvido pela solução lote por lote (tabela 5.1), a heurística Corte-Lote apresentou um desempenho melhor que a heurística Lote-Corte, em média 1.3\%. Já com a utilização da heurística de antecipação de itens para o problema de corte multiperíodo, as duas heurísticas obtiveram valores bem próximos para a função objetivo, em média $0.1 \%$, ressaltando que o mesmo valor foi obtido em $34 \%$ dos exemplos testados.

Podemos considerar esses resultados como preliminares, pois há ainda a necessidade de uma revisão mais criteriosa dos parâmetros da função objetivo do modelo integrado, provavelmente equilibrando a importância dos custos associados às perdas, quando comparados com os custos operacionais (produção e preparação). A função tem natureza multi-objetivo, e talvez a análise da teoria multi-objetivo possa ser de grande valia para conclusões mais definivas. Além disso, como a convergência das heurísticas Lote-Corte e Corte-Lote é bastante rápida, acreditamos que é vantajoso investir na melhoria das heurísticas propostas para resolver os problemas de dimensionamento de lotes e corte de estoque multiperíodo.

A continuação deste trabalho envolve um investimento maior na teoria da relaxação 
lagrangiana para ser usada nas heurísticas Lote-Corte e Corte-Lote, e no método do subgradiente para resolver o dual lagrangiano. Além disso, no problema de corte de estoque, as restrições de integralidade não foram exploradas neste trabalho, o que tem particularidades próprias e merece um tema de investigação futura. Sugerimos também, a aplicação da estratégia de horizonte rolante, bastante utilizada na prática para resolver problemas dinâmicos. o modelo (3.1)-(3.10) pode ser empregado nos somente nos primeiros períodos, por ser bastante detalhado, e nos períodos seguintes, resolve-se apenas o problema de dimensionamento de lotes com a demanda agregada.

Em resumo, a contribuição desta tese foi orientada para o desenvolvimento de abordagens que tratam os vários problemas que surgem em indústrias de forma integrada, possibilitanto a troca de informações entre eles, com o objetivo, por exemplo, de minimizar custos. Apesar dos resultados computacionais serem preliminares, eles mostram claramente que a abordagem utilizada e os métodos heurísticos de solução propostos neste trabalho são adequados para tratar o problema integrado de dimensionamento de lotes e corte de estoque em indústrias papeleiras e abrem novas possibilidades de investigação. 


\section{Bibliografia}

[1] Anthony, R. N., "Planning and Control Systems: A Framework for Analysis". Harvard University Press, Cambridge, Mass, apud em Hax e Candes (1965).

[2] AGGARWAL, A., PARK, J. K., "Improved algorithms for economic lot size problems". Operations Research, 41: 549-57 (1993).

[3] ARAujo, S. A., AREnAleS, M. N., "Problemas de dimensionamento de lotes monoestágio com restrição de capacidade: modelagem, método de resolução e resultados computacionais". Pesquisa Operacional, v.20, n.2, 287-306 (2000).

[4] AREnAleS, M. N., MORABITO, R., YANASSE, H. H., "O problema de corte e empacotamento e aplicações industriais". Livro-Texto de Minicurso, XXXVI SBPO, São João Del Rei - MG (2004).

[5] BAHL,H. C., RITZMAN, L. P., GUPTA, J. N. D., "Determining lot sizes and resource Requirements : A Review". Operations Research 35, n.3, 329-345 (1987).

[6] BILlingtON, P. J., McClAIN, J. O., THOMAS, L. J., "Mathematical programming approaches to capacity MRP systems: Review, formulation and problem reduction". Management Science 29, n.10, 1126-1141 (1983).

[7] BRAhImi, N., DAUZERE-PERES, NAJID, N. M., NORDLI, A., "Single Item Lot Sizing Problems". European Journal of Operational Research, 168: 1-16 (2006).

[8] CAMERINI, P. M., FRATTA, L., MAFFIOLI, F., "On improving relaxation methods by modified gradient techniques". Mathematical Programming Study, 3: 26-54 (1975).

[9] CHANDRA, P., FISHER, M. L., "Coordination of production and distribution planning”. European Journal of Operational Research 72: 503-517 (1994). 
[10] CORREIA, M.H., OLIVEIRA, J. F., FERREIRA, J.S., "Reel and sheet cutting at a paper mill'. Computers \& Operations Research 31: 1223-1243 (2004).

[11] CARvalho, J. M. V., RODRIGUES, A. J. G., "An LP-based approach to a twostage cutting stock problem". European Journal of Operational Research, 84(3): 580589 (1995).

[12] DOWSLAND, K., DOWSLAND, W., "Packing problems". European Journal of Operational Research 56: 2-14 (1992).

[13] DREXL, A., KIMMS, A., "Lot sizing and scheduling - survey and extensions". European Journal of Operational Research, 99: 221-235 (1997).

[14] DYCKHOFF, H., KRUSE, H. J., ABEL, D., GAL, T., "Trim loss and related problems". Omega 13: 59-72 (1985).

[15] EVANS, J. R., "An efficient implementation of the Wagner-Whitin algorithm for dynamic lot-sizing". Journal of Operations Mangament 5, n. 2, 229-235 (1985).

[16] FARLEY, A. A., "Mathematical Programming Models for Cutting-Stock Problems in the Clothing Industry". Operational Research Society, 1: 41-53 (1988).

[17] FEDERGRUEN, A., TZUR, M., "A simple forward algorithm to solve general dynamic lot sizing models with $n$ periods in $O(n \log n)$ or $O(n)$ time". Management Science, 37: 909-925(1991).

[18] FERREIRA, J. S., NEVES, M. A., CASTRO, P. F., "A two-phase roll cutting problem". European Journal of Operational Research, 44(2): 185-196 (1990).

[19] Fisher, M.L. (1981). The lagrangian relaxation method for solving integer programming problems. Management Science, 27, 1-18.

[20] FOERSTER, H., WÄSCHER, G., "Pattern reduction in one-dimensional cuttingstock problems". International Journal of Production Research, 38: 1657-1676 (2000).

[21] GILMORE, P. C., GOMORY, R. E., "A linear programming approach to the cutting stock problem". Operations Research, 9: 848-859 (1961). 
[22] GILMORE, P. C., GOMORY, R. E., "A linear programming approach to the cutting stock problem - Part II'. Operations Research, 11: 863-888 (1963).

[23] GILMORE, P. C., GOMORY, R. E., "Multi-stage cutting stock problems of two and more dimensions". Operations Research, 13: 94-120 (1965).

[24] GRAMANI, M. C. N., "Otimização do processo de cortagem acoplado ao planejamento da produção". Tese de Doutorado, DENSIS - UNICAMP, (2001).

[25] HAESSLER, R. W., "Controlling cutting pattern changes in one-dimensional trim loss problems". Operations Research, 23: 483-493 (1975).

[26] HAESSLER, R. W., "Solving the two-estage cutting stock problem". Omega, The International Journal of Management Science 7(2): 145-151 (1979).

[27] HAESSLER, R. W., "A note on computational modifications to the Gilmore-Gomory cutting stock algorithm". Operations Research, 28: 1001-1005 (1980).

[28] HELD, M., WOLFE, P., CROWEDER, H., "Validation of subgradient Optimization". Mathematical Programming, 6: 62-68 (1974).

[29] HENDRY, L. C., FOK, K.K., SHEK, K.W. "A cutting stock and scheduling problem in the copper industry". Operational Research Society, 47: 38-47 (1996).

[30] HINXMAN A., "The trim-loss and assortment problems: A survey". European Journal of Operational Research 5: 8-18 (1980).

[31] HOTO R., ARENALES, M., MACULAN, N., "The compartmentalised one dimensional cutting stock problem: a case study". European Journal of Operational Research, a aparecer (2005).

[32] JOHNSON, L. A., MONTGOMERY, D.C, "Operations Research in Production Planning, Scheduling and Inventory Control'. New York, John Wiley \& Sons (1974).

[33] KARIMI, B., FATEMI GHOMI, S.M.T., WILSON, J.M., "The capacitated lot sizing problem: a review of models and algorithms". OMEGA, 31: 365-378 (2003). 
[34] KUIK, R., SALOMON, M., VAN WASSENHOVE, L. N., "Batching decisions: structure and models". European Journal of Operational Research, 75: 243-263 (1994).

[35] LIMEIRA, M. S., YANASSE, H. H., "Uma heurística para o problema de redução de padrões de corte". Anais da V Oficina Nacional de Problemas de Corte e Empacotamento, São José dos Campos, SP, pp. 137-145, (2001).

[36] LODI, A., MARTELlO, S., MONACI, M., "Two-dimensional packing problems: A survey". European Journal of Operational Research 141: 241-252 (2002).

[37] MAES J., McCLAIN, J. O., VAN WASSENHOVE, L. N., "Multilevel capacitated lotsizing complexity and LP based heuristic". European Journal of Operational Research 53, 131-148 (1991).

[38] MARQUES, F.P. e ARENALES, M. N., "The constrained compartmentalised Knapsack problem". Computers \& Operations Research (2005), a aparecer.

[39] MENON S., SCHRAGE, L., "Order allocation for stock cutting in the paper industry". Operations Research 50, 324-332 (2002).

[40] MORABITO R., "Uma Abordagem em Grafo-E/OU para o Problema de Empacotamento: Aplicação ao Carregamento de Páletes e Contêineres". Tese de Doutorado, USP/EESC (1992).

[41] NONAS, S. L., THORSTENSON, A., "A combined cutting-stock and lot-sizing problem". European Journal of Operational Research, 120: 327-342 (2000).

[42] PINTO, M. J., "O problema de corte de estoque inteiro". Dissertação de Mestrado, ICMC - USP, (1999).

[43] POLDI, K. C., ARENAleS, M. N. "Dealing with Small Demand in Integer Cutting Stock Problems with Limited Different Stock Lengths". Notas do ICMC - Série Computação, 85, ICMC - USP (2005).

[44] POLDI, K. C., "Algumas extensões do problema de corte de estoque”. Dissertação de Mestrado, ICMC-USP (2003). 
[45] RESPÍCIO, A., CAPTIVO, M. E., "Integrating the cutting stock problem in capacity planning". Department of Informatics and Centre of Operational Research. University of Lisbon/Portugal (2002).

[46] SCHEITHAUER, G., TERNO, J., "A branch and bound algorithm for solving onedimensional cutting stock problems exactly". Applicatione Mathematikae, 23, 2: 151167 (1995a).

[47] SCHEITHAUER, G., TERNO, J., "The Modified Integer Round-Up Property of the One-Dimensional Cutting Stock Problem". European Journal of Operational Research, 84: 562-571 (1995b).

[48] TOLEDO, F. M. B., "Dimensionamento de lotes em máquinas paralelas". Tese de Doutorado. DENSIS-UNICAMP (1998).

[49] TOledo, F. M. B., ARMEnTANO, V. A., "A lagrangian-based heuristic for the capacitated lot-sizing problem in parallel machines". European Journal of Operational Research, a aparecer (2005).

[50] THOMAS, D. J., GRIFFIN, P.M., "Coordinated supply chain management". European Journal of Operational Research, 94: 1-15 (1996)

[51] TRIGEIRO W. W., THOMAS L. G. McCLAIN J. O., "Capacitated lot sizing with setup times". Management Science 35, n. 3, 353-366 (1989).

[52] WAGELMANS, A., HOESEL, S. VAN, KOLEN, A., "Economic lot sizing: an O(n $\log n)$ algorithm that runs in linear time in the Wagner-Whitin case". Operations Research, 40: 145-156 (1992).

[53] WAGNER, H. M., WHITIN, T. M., "Dynamic version of the economic lot size model'. Management Science 5, n.1, 89-96 (1958).

[54] WÄSCHER, G., GAU, T., "Heuristics for the integer one-dimensional cutting stock problem: a computational study”. OR Spektrum, 18: 131-144 (1996).

[55] WOLSEY, L. A., "Progress with single-item lot-sizing". European Journal of Operational Research, 86: 395-401 (1995). 
[56] ZAK, E. J., "Modeling multistage cutting stock problems". European Journal of Operational Research, 141: 313-327 (2002). 